\title{
EFEITOS ESTERILIZANTES E LETAIS DAS RADIACCÕES GAMA NAS DIFERENTES FASES DO CICLO EVOLUTIVO DE Sitotroga erealella (Olivier) EM ARROZ E MILHO
}

\author{
VALTER ARTHUR
}

Orientador: Prof. Di. FREDERICO MAXIMILIANO WIENDL

Tese apresentada à Escola Superior de Agricultura "Luiz de Queiroz", da Universidade de São Paulo, para obtenção do título de Doutor em Ciências. Área de: Concentração : Entomologia.

\author{
PIRACICABA \\ Estado de São Paulo - Brasil \\ Setembro - 1985
}


. $i$.

Aos meus pais,

PALLO e ROSINA,

OFEREÇO

A minha esposa, CLEIDE

e minha filha, PAULA

DEDICO 


\section{AGRADECIMENTOS}

- Ao Dr. Frederico Maximiliano Wiendl, a amizade e orientação;

- Ao Dr. JuZio Marcos Melges Walder, as criticas e sugestões;

- Aos Professores do Curso de Pös-Graduação em Entomologia-ESALQ, USP, pelos inestimáveis ensinamentos transmitidos;

- A Diregão do Centro de Energia Nuclear na Agricultura da Uni versidade de São Paulo (CENA/USP);

- A Comissão Nacional de Energia Nuclear (CNEN);

- A Fundação de Amparo à Pesquisa do Estado de São Paulo (FAPESP);

- Ao Conselho Nacional de Desenvolvimento Cientifico e Tecnológico (CNPq);

- Aos amigos da Segão de Radioentomologia, como também todos os colegas do CENA, o incentivo e amizade;

- Ao Antonio Alfredo Lacerda, pela confecção das Figuras e ao Cleusval Bissi, pelo serviço de datilografia.

- A todos que, direta ou indiretamente, embora não citados, cola boraram para o desenvolvimento deste trabalho de pesquisa.

- A Deus, por ter-me dado forças nas horas dificeis. 
.iii.

T $D \perp C E$

Pägina

RESUMO ........................ iv

SUMMARY. ......................... vi

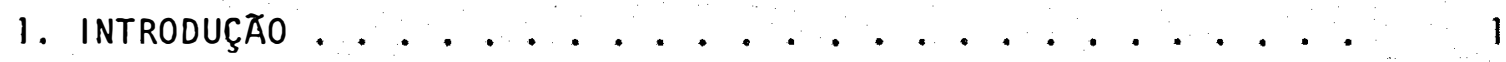

2. REVISÃO DE LITERATURA. ............................ 4

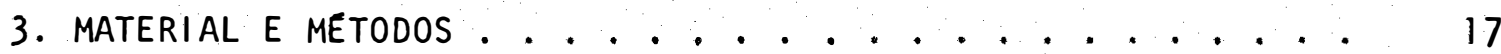

4. RESULTADOS E ANALISE DOS RESULTADOS............ 22

5. DISCUSSÃO ........................... 60

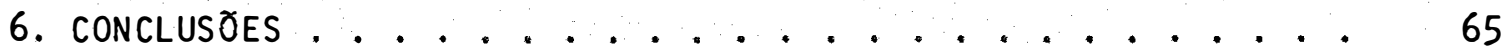

7. LITERATURA CITADA. .......................... 67 
iv.

EFEITOS ESTERILIZANTES E LETAIS DAS RADIAÇOES GAMA NAS DIFERENTES FASES DO CICLO EVOLUTIVO DE Sitotroga cerealella (01ivier) EM ARROZ E MILHO

\section{VALTER ARTHUR}

FREDERICO MAXIMILIANO WIENDL

- Orientador -

\section{RES U M O}

Esta pesquisa foi desenvolvida nos laboratōrios da Seção de Entomologia do Centro de Energia Nuclear na Agricultura (CENA), Univer sidade de São Paulo (USP), Piracicaba, São Paulo, Brasil. Teve por obje tivo verificar os efeitos das radiações gama em individuos que se encontravam em suas diferentes fases do ciclo evolutivo da traça do milho, Sitotroga cerealella (01 ivier, 1819).

Para os tratamentos com radiação gama utilizou-se uma fon te de Cobalto-60 tipo Gammabeam-650, com uma atividade de aproximadamente $3,1 \times 10^{14} \mathrm{~Bq}$. , a uma taxa de dose de 3,01 kGy por hora.

Após todas os ensaios, os insetos foram mantidos em uma câmara climatizada regulada a temperatura de $25 \pm 1^{\circ} \mathrm{C}$ e umidade rela tiva de $70 \pm 5 \%$

Verificou-se que a $\mathrm{DL}_{100}$ para ovos provenientes de adultos criados em arroz e milho foram, respectivamente, as doses de 100 Gy e 125 Gy. As doses esterilizantes nos adultos, tratados nas fases de lagar 
ta e crisālida foram as doses de 100 Gy e 200 Gy e 150 Gy e 250 Gy em ar roz e milho, respectivamente. As doses esterilizantes para fêmeas e machos, criados em milho, foram 350 Gy e $500 \mathrm{~Gy}$, respectivamente. As $\mathrm{DL}_{100}$ para adultos foram 4500 Gy e 4750 Gy para machos e fêmeas criados em arroz e de 4750 Gy para ambos os sexos, quando provenientes do milho. 
. vi.

STERILIZING AND LETHAL EFFECTS OF GAMMA RADIATION ON DIFFERENT PHASES OF LIFE CYCLE OF THE sitotroga cerealella (01ivier) IN RICE AND MAIZE

\title{
VALTER ARTHUR
}

\author{
FREDERICO MAXIMILIANO WIENDL \\ - Adviser -
}

\section{S U M M A R Y}

This research was carried out at the laboratory of the Entomology Section of the Nuclear Energy for Agriculture Center (CENA) in Piracicaba, São Paulo State, Brazil. The objective was to verify the effects of the gamma radiation on different phases of the life cycle of the moth grain Angoumois, Sitotroga cerealella (01ivier, 1819).

For 211 the treatment with gamma radiation a Cobalt -60 source type Gammabeam-650 was used and the activity was approximately $3.1 \times 10^{14} \mathrm{~Bq}$. , with dose rate of $3.01 \mathrm{kGy}$ per hour.

The experiments were conducted under controlled conditions with temperature at $25 \pm 1{ }^{\circ} \mathrm{C}$ and relative humidity of $70 \pm 5 \%$.

The $L D_{100}$ of gamma radiation for eggs of insects reared in rice and maise were respectively 100 Gy and $125 \mathrm{~Gy}$. The sterilizing doses in adults which were irradiated at immature phases (larvae and pupae) were $100 \mathrm{~Gy}$ and $200 \mathrm{~Gy}$ in rice and $150 \mathrm{~Gy}$ and 250 Gy in maise, respectively. The sterilizing doses for females and 
.vii.

males in maise were respectively $350 \mathrm{~Gy}$ and $500 \mathrm{~Gy}$.

The $L D_{100}$ for adult females were $4500 \mathrm{~Gy}$ and $4750 \mathrm{~Gy}$

for males, both in rice. The $L D_{100}$, for adult reared on maise was

4750 Gy for both sexs. 


\section{INTRODUÇÃO}

No Brasil, segundo o IBGE (1983), produziu-se uma quantia de, respectivamente, 18.743 .760 e 7.749 .513 toneladas de milho e arroz, observando-se que ambas as culturas estão disseminadas por todo o país. Calcula-se, ainda, que as perdas foram de 3.092 .721 e 1.549 .903 to neladas, respectivamente, e que,pelo menos metade dessas perdas, foram causadas por insetos. Entre as pragas, destaca-se a traça do milho Sitotroga cerealella (OLIVIER, 1819), que è capaz de atacar ambos os cereais. Infelizmente, no Brasil, são poucas as pesquisas no sentido de detectar com exatidão os prejuízos, mas ROSSETO (1966) estimou uma perda de $30 \%$ em milho na região de Campinas, destacando-se, como uma das pragas responsāveis, a traça do milho. 0 Banco Nacional de Desenvolvimento Econômico (B.N.D.E.), atravēs da Rede Nacional de Armazéns e Silos,o "Plano Renas", estimou as perdas em 20\% (PUZZI, 1973). Pesqui sas realizadas pela FAO (1975), no mundo inteiro, mostram que a quantidade de grãos destruídos por carunchos e traças, durante um ano, seria sufi ciente para abastecer $100 \mathrm{milhões} \mathrm{de} \mathrm{pessoas.}$ 
Devido ao constante crescimento da população mundial e o consequente aumento da procura de alimentos, muito se tem feito com o intuito de prolongar o máximo possível intacta a vida comercial dos produtos armazenados.

A primeira aplicação de radiações ionizantes com resultados promissores foi realizada por RUNNER (1916) utilizando raio-X para controlar Lasioderma serricorne (L.) uma praga do tabaco armazenado. Porém, somente a partir da década de 1950, se verificou grande avanço nesse tipo de pesquisa.

Quando qualquer substância é exposta às radiações gama, raio- $X$, partículas alfa, beta, elétrons ou núcleos acelerados ocorrem muitos fenômenos. Em tecidos orgânicos um dos principais è o da ionização, primária e secundária. Em meio aquoso, como é o caso de tecidos vivos, os efeitos das radiações normalmente aumentam com o seu grau de reprodução e diminuem com o seu grau de diferenciação (LAMM, 1972). Inicialmente o efeito é causado pela formação de radicais livres $\left(\mathrm{H}^{+}\right.$e $\left.\mathrm{OH}^{-}\right)$ da água constituinte dos tecidos. Em reaçōes secundārias, tais radicais interagirão com os constituintes celulares. Sendo as célúlas orgânicas ricas em átomos de hidrogênio, podem ser formadas inümeras molécu las novas pela simples combinação destes dois radicais. Torna-se claro que isto è prejudicial à célula e as consequências variam desde a inibi ção da divisão celular atē a sua prōpria morte. E devido a esses efeitos das radiações ionizantes que ocorre a esterilização ou morte dos se- 
res vivos (PIZZARELLO e WITCOFSKI, 1972).

Como a irradiação de grãos e produtos armazenados visa es terilizar os insetos sem causar danos nos alimentos, a técnica poderá re duzir os problemas da falta de alimentos. Como vantagem adicional,se pode citar a não indução de resistência genética,sem ainda acumular resíduos tóxicos ou mutagênicos, com uma eficiência comprovada de $100 \%$ de controle.

Pela necessidade de uma melhor conservação, com tecnologia moderna e avançada eficiencia, baixo custo e ausência de efeitos colaterais, a irradiação tornou-se uma solução óbvia. Na prätica,a técnica consiste em desinfestar os grãos com determinada dose de radiações, inibindo a reprodução dos insetos, e causando o declínio das populações infestantes. Segundo SINGH e LILES (1972), è um método efetivo e facilmente incorporado na prätica moderna do manuseio de grãos, sendo suas principais recomendações a absoluta inocuidade e total eficiência.

Assim,para evidenciar a validade desse método de controle, programou-se a presente pesquisa irradiando-se a traça do mi lho Sitotroga cerealella (OLIVIER, 1819), visando-se a indução de esterilidade e letalidade conseqüentemente o seu controle, em arroz e milho. 
.4.

\section{REVISAO DA LITERATURA}

2.1. Prejuĩzos e aspectos biológicos de Sitotroga cerealella (01iv.)

2.1.1. Valor econômico

CARTWRIGHT (1939) realizou um trabalho sobre infestação de campo, em espigas de milho atacadas por insetos na Carolina do Sul, USA. Verificou que a porcentagem de espigas de milho atacadas por Sitotroga cerealella (01iv.), antes da colheita, era de $31,04 \%$

LEPAGE (1939) indicou como pragas mais importantes dos ce reais armazenados: Sitophilus oryzae (L.) e Sitotroga cerealella (01iv.) sendo que o prejuízo causado no mi ho foi estimado em $15 \%$.

LEPAGE (1946) observou que o prejuízo causado por sitophilus oryzae (L.) e Sitotroga cerealella (01iv.) foi da ordem de $30 \%$ do total da colheita de milho.

MARANHÃO (1957) demonstrou teoricamente, que de uma única mariposa de Sitotroga cerealella ( $01 \mathrm{iv.}$ ) resultam na quinta geração 625.000 .000 adultos, o que equivaleria a uma perda de $191.327 \mathrm{~kg}$ de milho. 
GERBERG e GOLDHEIM (1957) determinaram como sendo de $10 \%$ a perda em peso causada pelo ataque de Sitotroga cerealella (01iv.) em milho pipoca infestado sob condições de armazēm.

GENEL e BARNES (1958) observaram que os insetos mais co muns em millho e trigo no México são: Sitophilus oryzae (L.), Sitophilus granarius (L.), Tribolium sp., Sitotroga cerealella (01iv.), Plodia sp. e Ephestia sp.

FLOYD et alii (1959) fizeram levantamento na Louisiana, USA, e verificaram os seguintes graus de infestação em grãos armazenados ocasionados por: Sitophilus oryzae (L.) e Sitotroga cerealella(01iv.); $10,6 \%$ na época da colheita, 17,1\% após colheita (maio) e 30,5\% em junho.

CORSEUIL (1960) estimou o prejuízo do milho em $15 \%$, indicando como pragas mais prejudiciais Sitophilus oryzae (L.) e Sitotroga cerealella (01iv.)

FERRAZ (1962) estimou o prejuízo em milho armazenado entre 15 e $20 \%$ pelas pragas, incluindo a traça do milho Sitotroga cerealella (0liv.) como uma das principais.

EVERLY et alii (1963) observaram os efeitos da infestação de Sitotroga cerealella (01iv.) sobre a germinação e vigor do milho. Concluiram que o milho infestado reduziu o vigor das plântulas do milho pipoca em aproximadamente $90 \%$ e no dentado em aproximadamente $56 \%$. 
ROSSETO (1966), fazendo observações sobre infestaçōes em propriedades agrícolas na região de Campinas, estimou um prejuízo de $30 \%$ em milho, sendo uma das principais pragas responsāveis pela perda Sitotroga cerealella (01iv.).

MOOKE et alii (1966) estudaram as perdas causadas pela traça do milho Sitotroga cerealella (01iv.). Verificaram que uma ünica traça consumiu em mëdia $32,9 \mathrm{mg}$ de milho durante o seu desenvolvimento.

GALLO (1966) e GALLO e FLECHTMANN (1967) citaram Sitotro ga cerealella (01iv.) como uma das mais importantes pragas de grãos arma zenados.

AMARAL Fo et alii (1969) fizeram um levantamento das espẹ cies pragas que ocorrem na região de Botucatu, em milho armazenado. Encontraram, em ordem decrescente: Sitophilus oryzae (L.), Sitotroga cerealella (01iv.) e Plodia interpunctella (Huib.).

FLOYD (1971) verificou que os grãos de milho quando armazenados com infestação de: 0 (test.), 1,$2 ; 3,5$ e $6,3 \%$ de dano, após 7 meses de armazenamento estavam respectivamente com menos de 1,0; 34,7; 43 e $63 \%$ de dano. Observou ainda que Sitotroga cerealella (01iv.) prefere - infestar o milho quando o grão jā estā atacado pelo Sitophilus sp.

AMARAL (1973) demonstrou ser o prejuizo causado pela as- 
sociação de Sitophilus zeamais (Mots.) e Sitotroga cerealella (01iv.) em paiōis abertos e de täbuas muito significativo.

\subsubsection{Aspectos biolögicos}

ELLINGTON (1930) desenvolveu um método para obtenção de ovos de Sitotroga cerealella (01iv.).

LEPAGE e GONÇALVES (1939) determinaram que a fêmea de $\mathrm{Si}$ totroga cerealella (0liv.), apōs a fecundação, oviposita, em média, 200 ovos, após uma cópula que dura entre 2 e 3 horas. 0s ovos tem, em ambien te normal, um período de incubação entre 6 e 10 dias, mas a $30^{\circ} \mathrm{C}$ è de ape nas 4 dias. A fase larval apresenta 3 -instares, com um período que varia ao redor dos 25 dias. A fase pupal vai de 7 a 10 dias à temperatü ra de $24^{\circ} \mathrm{C}$. 0 s adultos vivem, em mëdia, 10 a 15 dias.

CROMBIE (1943) determinou que a Sitotroga cerealella (0liv.), em sua fase larval passa por 4 instares.

A fase adulta de Sitotroga cerealella (01iv.) mede de 11 a $15 \mathrm{~mm}$ de envergadura. Suas asas são de coloração palha, possuindo lar gas franjas. Apōs fecundação a fêmea oviposita os ovos, de coloração creme, são depositados na superfície dos grãos dos värios cereais que infesta, dando preferência ao local onde os grãos são mais moles. Põe de 2 a 7 ovos sobre um mesmo grão. Após 6 a 10 dias eclode a lagartinha que penetra no grão. A duração da fase larval e pupal varia de 20 
a 30 e 7 a 10 dias respectivamente. Então, rompe-se o casulo, emergindo o adulto. A fêmea oviposita, em média, 200 ovos. 0 número máximo de gerações varia de 6 a 8 por ano (LEPAGE, 1943).

CARVALHO (1963), estudando a preferencia al imentar das lar vas de Sitotroga cerealella (01iv.) por cereais, verificaram pertencer o arroz sempre ao grupo dos menos preferidos.

MILLS (1965) realizou estudos sobre os efeitos da alimentação de lagartas de Sitotroga cerealella (01 iv.) em sementes de trigo. Determinou que a fase larval apresenta de 4 a 7 instares, de acordo com o alimento mais ou menos nutritivo e que preencha as necessidades deste inseto.

KHAPE e MILLS (1968) pesquisaram o desenvolvimento da lagarta de Sitotroga cerealella (0liv.) em sementes de trigo, sorgo e mi1ho. Concluiram haver diferenças significativas em relação aos locais de al imentação das lagartas nas sementes.

CHIPPENDALE (1971) descreveu um método para estudar as di ferentes fases de Sitotroga cerealella (0liv.) em dietas artificiais, de terminando que a fase larval possui 4 instares.

NANATES e CUNHA (1978) fizeram observações sobre a capaci dade de oviposição, viabilidade e período de incubação de ovos e longevidade de adultos. Concluiram que baixas temperaturas ( 10 a $14^{\circ} \mathrm{C}$ ) pre- 
judicaram sensivelmente a oviposição e o desenvolvimento embrionärio do inseto. Temperaturas entre 26 e $30^{\circ} \mathrm{C}$ reduzem o período de incubação e aumentam o número e a viabilidade dos ovos e a esperança de vida dos adultos.

GALLO et alii (1978) citam que os adultos de Sitotroga cerealella (01iv.) vivem em média entre 6 e 10 dias. Os ovos são coloca dos sobre os grãos, preferencialmente naqueles que sofreram em sua integridade física, sendo aderentes à sua superfície. 0 inseto apresenta in festação cruzada, sendo que a oviposição varia de acordo com o substrato alimentar, entre 40 e 280 ovos. Para o milho, o número médio foi de 221 ovos. Após a eclosão, as lagartas penetram nos grãos alimentando-se do seu conteúdo, onde completam o desenvolvimento em 15 dias. Seu tamanho attinge $6 \mathrm{~mm}$ de comprimento, sendo inicialmente brancas. Quan do mais desenvolvidas, ficam recurvadas e com o tórax mais largo que o abdome. Este se estreita gradualmente em direção ao äpice. Suas mandí bulas são castanho escuras. Antes da lagarta se transformar em pupa ela faz a abertura para a emergência do adulto. o ciclo evolutivo completo vai de 30 a 40 dias, com uma média de 33 dias.

\subsection{Efeitos das radiações em Lepidoptera}

NICHOLAS e WIANT (1959) irradiaram adultos de Setotroga cerealella (01iv.) com a dose única de 10.000 rad, não sendo esta sufí ciente para induzir a esterilidade total. Diminuiu porém consideravel- 
mente o número de adultos na segunda geração. A esterilidade nos adultos só foi induzida com doses de 40.000, sendo que a primeira não alte rou. a longevidade dos adultos.

No Brasil, foi GALLO (1960) o primeiro a trabalhar com ir radiação de insetos, visando a esterilização de Ceratitis capitata(Wied.) e Diatraea saccharalis (Fabr.). Devido a fonte de irradiação de baixa atividade porém, não logrou obter resultados positivos.

PENDLEBURY et alii (1962) observaram alguns efeitos da ra diação gama em Plodia interpunctella (Hüb.). Em pupas irradiadas com 36.000 rad, houve uma redução de 60 a $70 \%$ na emergência dos adultos quan do comparadas com a testemunha. A dose porém não afetou a competitivida de de ambos os sexos. Aumentando-se a dose de radiação nas pupas, houve um aumento no número de deformações, principalmente alares, nos adultos.

CARVALHO (1963) apresentou a importância do método radio gräfico para o estudo das diversas fases imaturas da Sitotroga cerealella (01iv.). Assim conseguiu enumerar detalhes sobre aspectos bio-ecológ cos da traça.

GORESLINE (1965) demonstrou a importância da utilização das radiações ionizantes como método de controle de pragas de grãos armazenados. Fez ainda considerações a respeito da fonte de radiação e do pessoal necessário para formar uma equipe piloto capaz de atuar numa unidade de irradiação. 
BAROUCHI-BONAG (1965) estudou os efeitos das radiações ionizantes em Ephestia kuehniella zeller. Observou que lagartas do ültimo instar quando submetidos a doses de 2.000 a 14.000 rad sofrem um retardamento no período pupal e uma mortalidade de $25 \%$. Nas lagartas expostas a 6.000 rad, a mortalidade foi de $72 \%$, e na dose de 14.000 rad foi de $100 \%$.

COGBURN et alii (1966) observaram que ovos, lagartas, pupas e adúltos de Plodia interpunctella (Hüb.) forem submetidos a doses de: 13,$2 ; 17,5 ; 25 ; 40$ e 100 krad há um decréscimo na eclosão de lagartas a medida que a dose aumenta. Além disso, muitas lagartas provenientes de ovos tratados com doses de 13,2 e 17,5 krad, quando comparados à testemunha, eram pouco ativas e logo morriam. As que sobreviviam atin giam o estägio adul to mas não conseguiam voar ou coordenar seus movimen tos, devido a deformação alar, morrendo logo após a emergência. Das lagartas irradiadas nenhuma atingiu a fase adulta. A longevidade dos adul tos provenientes de pupas irradiadas, comparada com a testemunha, não mos trou nenhuma diferença acentuada, exceto nos casos de deformação alar. Outros efeitos foram a esterilidade e redução em sua fecundidade.

QURESHI (1966) observou os efeitos da radiação gama em diferentes estägios de Sitotroga cerealella (01iv.) concluindo que as lagartas provenientes de ovos irradiados com as doses de 10,14 e $18 \mathrm{Kr}$ não se desenvolveram. Já com a dose de $6 \mathrm{Kr}$ o desenvolvimento foi normal. Lagartas de terceiro e quarto instar submetidas a dose de $25 \mathrm{Kr}$, fo- 
ram inibidas completamente em seus desenvolvimentos. E quando foram irradiadas pupas com $20 \mathrm{Kr}$, os adultos destas eram estéreis, sendo sua fe cundidade drasticamente afetada.

WATTERS e MAC-QUEEN (1967) concluíram ser a radiação gama capaz de controlar cinco espécies pragas de grãos armazenados, dentre elas a traça do milho,com doses variando de 6.250 rad a 150.000 rad. Observaram haver uma grande diferença na sensibilidade entre as espécies. Concluíram que o tempo de sobrevivência é função da dose, mas nenhuma dose usada causou efeitos adversos sobre o trigo que continha os insetos no ato da irradiação.

WIENDL e BERTI Fo (1968) irradiaram adultos de Sitotro ga cerealella (01iv.) com doses de: $2,5,10$ e $20 \mathrm{krad}$, de radiação gama do cobalto-60. Observaram um aumento na longevidade, quando comparados com a testemunha.

QURESHI et alii (1969) observaram os efeitos da radiação gama em prë-pupas, pupas e adultos de Sitotroga cerealella (01iv.). Fêmeas irradiadas na fase de pré-pupa com $10 \mathrm{kr}$ e colocadas em contacto com machos virgens e vice-versa normalmente não ovipositaram. Quando ovipositaram os ovos eram inférteis. A dose de $20 \mathrm{Kr}$ em pupas foi suficiente para induzir a esterilida de e deformações alares em ambos os sexos. Nos adultos a dose de $25 \mathrm{Kr}$ não foi suficiente para induzir a esterilidade. 
ARANDA (1970) irradiou adultos de Sitotroga cerealella (01iv.) com doses de: $3,6,12$ e $24 \mathrm{krad}$. Concluiu que as doses de 6 , 12 e $24 \mathrm{Krad}$, induziram maior porcentagem de mortalidade num menor tempo.

AHMED et alii (1970) realizaram cruzamento da traça Ephestia cautella (Walk.) provenientes de pais irradiados com espécies nativas. Concluíram que algumas espēcies descendentes des tes cruzamentos podem apresentar vigor híbrido ou heterose.

HOLT e NORTH (1970) observaram os efeitos causados pela radiação gama no mecanismo de transferência do esperma em Trichoplusiani (Hüb.). Concluir am haver algumas causas que con tribuíram para a redução parcial ou total da fertilidade. Observaram intumescência do bulbo, esperma eupirene sem mobilidade para chegar a espermateca e as vias que levam o esperma até a espermate ca obstruídas.

ASHRAF et azii (1971) concluiram serem os insetos mais resistentes às radiações gama se comparados aos vertebrados. Este fato está normalmente relacionado com a mais lenta divisão celular nos inse tos adultos. Mesmos nos imaturos, com exceção das cēlulas embrionārias,as atividades mitóticas são restritas a curtos períodos. As células diferenciadas dos insetos exibem al to grau de resistência em comparação às indiferenciadas em divisão. No entanto, a divisão celular pode ocorrer 
.14.

no intestino mëdio e nas gonodas dos insetos adultos, fazendo com que esses tecidos sejam particularmente sensíveis às radiações ionizantes.

COGBURN et alii (1971) combinou radiações gama com infra-vermelhas para controlar Sitotroga cerealella (01iv.) em todos os estägios de desenvolvimento. Usando quatro tipos de tratamento: radiação gama; infra-vermelho; primeiro gama e depois infra-vermelho e infra-vermelho e depois gama, obteve uma redução na emergência de adultos de: $52,2 \%, 55,3 \%, 93 \%$ e $92,8 \%$, respectivamente.

ASHRAFI et alii (1972) submeteram lagartas do quinto ins tar de Plodia interpunctella (Hüb.) a uma dose $3,5 \mathrm{krad}$ de radiação gama. Observaram uma redução de $72 \%$ no nümero de descendentes.

BROWER (1972) observou dois tipos de mutações causadas p $\underline{e}$ las radiações gama em Plodia interpunctella (Hüb.): descamação e al tera ção na melanina das asas.

WIENDL et alii (1975) observaram a influência da radiação gama em ovos e adultos de Sitotroga cerealella (01iv.). Concluíram que, com uma dose de $14 \mathrm{Krad}$ a eclosão de lagarta foi de $16,1 \%$. Doses crescentes até 70 Krad em adultos não foram suficientes para induzir a esterilidade e não influenciaram na longevidade.

RODRICUES et alii (1981) determinaram as doses letais para ovos e esterilizante para adultos de Sitotroga cerealella (01iv.). Observaram ser $10 \mathrm{Krad}$ a letal para ovos, e a dose esterilizante para 
adultos de $100 \mathrm{krad}$. A letal imediata para adultos foi de $320 \mathrm{Krad}$. Porém, todos os insetos estavam mortos após dois dias (LD, $100 / 2$ ) com a dose de 100 Krad.

ARTHUR et alii (1984a) determinaram as doses letal este rilizante para lagartas de Plodia interpunctella (Hüb.) criadas em uma dieta artificial. Observaram ser a dose de 150 Gy letal para lagartas. A dose suficiente para obter adultos da geração filial ( $F_{1}$ ) estéreis foi a de 50 Gy, quando se irradiaram estas lagartas.

ARTHUR et alii (1984b) determinaram a dose esterilizante para adultos de Plodia interpunctella (Hüb.) pelo método da perda de peso em arroz integral. Concluiram ser esta de 600 Gy.

ARTHUR et alii (1984c) procuraram obter a dose esterilizante para adultos de Plodia interpunctella (Hüb.) criados em uma dieta artificial. Observaram que as doses de 100 e 150 Gy foram esterilizantes na geração fillial $\left(F_{1}\right)$, mas só a dose de 200 Gy causou esterilidade total nos individuos da geração irradiada.

As radiações gama podem ainda causar outros efeitos em Plodia interpunctella (Hüb.) e Cadra cautella (Walk.), tanto na sua biologia como nas suas progênies, dependendo da dose e do tempo de exposição. Observa-se uma diminuição ou um aumento na duração das fases do ciclo evolutivo, na longevidade dos adultos, fecundidade e esterilidade nas geraçōes filiais como citam trabalhos de COGBURN et alii (1973); 
.16 .

BROWER (1973, 1974, 1975, 1976b e 1980); AHMED et alii(1976); AMOAKO-ATTA e MILLS (1977).

Alteraçōes no aparel ho reprodutor de Plodia interpunctella (Hüb.), alēm de induzidas por radiações ionizantes, tambēm ocorrem em insetos tratados por luz ultravioleta, microondas e determinados produtos químicos como citam: SMITH et alii (1964); OUYER et alii (1964); RAUN et alii (1967); FLINT e KRESSIN (1969); PROSHOLD e BARTELL (1970); SNOW et alii (1972); ASHRAFI e ROPPEL (1973) e BROWER (1976a). 


\section{MATERIAL E METODOS}

Esta pesquisa foi realizada na Seção de Entomologia do Centro de Energia Nuclear na Agricultura (CENA), USP, Piracicaba, São Paulo.

A fonte de radiação gama utilizada foi uma de Cobalto-60, tipo Gammabeam-650, da Atomic Energy of Canadā Ltd, Ottawa, Canadā, com uma atividade de aproximadamente de $3,1 \times 10^{14} \mathrm{~Bq}$, no início dos ensaios. A taxa de dose foi de $3,01 . \mathrm{kGy} /$ hora para todos os tratamentos.

Os insetos da espécie Sitotroga cerealella (01 iv.), traça do milho, utilizados nesta pesquisa, eram provenientes de uma criação estoque da prōpria Seção, onde são mantidos em sala climatizada com temperatura de $25 \pm 1^{\circ} \mathrm{C}$ e umidade relativa de $70 \pm 5 \%$. Estas mesmas condições climáticas foram mantidas durante o transcorrer de todos os ensaios.

Os substratos utilizados foram arroz integral Oryza sativa L., cv. Jaguari e milho Zea mays L., cv. Hibrido HMD 7974. Para que não houvesse a interferéncia de outros insetos que por acaso se encontrassem no interior dos grãos, estes foram mantidos em baixas temperaturas 
$\left(-15^{\circ} \mathrm{C}\right)$ por um período de aproximadamente 15 dias, a fim de eliminar infestação latente.

Para a criação e multiplicação dos insetos na realização de todos os ensaios, nos substratos já citados anteriormente, utilizaram-se vidros transparentes com boca de $8 \mathrm{~cm}$ de diâmetro e capacidade pa ra $3.000 \mathrm{ml}$. Na tampa foi adaptada uma tela metálica de malha 200 , reves tida com lenço de papel a fim de permitir as trocas gasosas e evitar a penetração de ácaros. A quantidade de substrato colocado em cada vidro era de no máximo um terço do total, deixando o restante do espaço para vôo e cópula dos insetos.

\section{a) Ensaios com ovos}

Após a multiplicação dos insetos a um nivel suficiente para que fosse possivel a obtenção dos ovos, utilizou-se a técnica descri ta por ELLINGTON (1930). Os ovos, foram coletados por intermédio de duas tiras de cartolina preta de aproximadamente $1,5 \mathrm{~cm}$ de largura por $15 \mathrm{~cm}$ de comprimento, grampeadas nas extremidades. Estas tiras eram coloca das no interior dos vidros de criação contendo os insetos adultos e deixadas por 24 horas, para que a oviposição fosse realizada entre as tiras. Posteriormente eram retiradas fazendo-se então a separação das massas de ovos. Devido a esta metodologia empregada não foi possivel a obtenção de um nümero uniforme de ovos para cada tratamento.

Para a irradiação as massas de ovos foram colocadas em tu bos de vidro de $2,5 \mathrm{~cm}$ de diâmetro por $8,5 \mathrm{~cm}$ de altura, tampados com 
algodão, afim de evitar a penetração de àcaros.

As doses de radiação gama utilizadas foram as seguintes: 0 (test.), $25,50,75,100,125,150,175$ e 200 Gy. Após a irradiação os ovos foram mantidos em câmara climatizada com $25 \pm 1^{\circ} \mathrm{C}$ de tempera tura e $70 \pm 5 \%$ de umidade relativa. Diariamente efetuavam-se as contagens das eclosões das lagartas, com o auxilio de uma lupa binocular.

\section{b) Ensaio com lagartas e pupas}

Para os ensaios de i rradiação de lagartas e crisálidas, co letou-se das criações de arroz e milho, uma amostra de 100 grãos, fazendo-se a sua abertura para determinar a porcentagem de infestação nas fases de lagarta e pupas. Determinou-se esta em $90 \%$, para ambos os substratos de criação.

Após este procedimento coletaram-se aproximadamente 150 grãos de milho e de arroz infestado, para cada tratamento.

Para irradiação desses substratos infestados com lagartas e crisălidas utilizaram-se vidros de $3,5 \mathrm{~cm}$ de altura por $3,5 \mathrm{~cm}$ de diâmetro, com tampas plāsticas perfuradas.

As doses de radiação gama utilizadas foram as seguintes: 0 (test.), $50,100,150,200,250,300$ e 350 Gy. Após a irradiação, es ses grãos infestados foram mantidos em câmara climatizada, jā descrita anteriormente, atē a emergència total dos adultos. Estes adultos foram transferidos para vidros maiores, de $9,0 \mathrm{~cm}$ de altura por $5,0 \mathrm{~cm}$ de diạ 
metro contendo aproximadamente 50 gramas de substrato (arroz e milho) on de se aguardou a emergência da geração filial $\left(F_{1}\right)$.

\section{c) Ensaio com adultos}

Para realização deste ensaio utilizaram-se adultos prove nientes de uma criação mantida em laboratōrio em ambos os substratos. Cada repetição constou de 50 gramas de substratos (arroz e milho) e mais 15 insetos adultos com idade variável, acondicionados em vidros de $9,0 \mathrm{~cm}$ de altura por $5,0 \mathrm{~cm}$ de diâmetro com tampa rosqueável conten do tela metálica e lenço de papel.

A irradiação gama foi feita com as seguintes doses: 0 (test.), $50,100,150,200,250,300$ e 350 Gy. Apōs a irradiação foram mantidos em câmara climatizada, efetuando-se pesagens semanais com balança de precisão de 0,01 grama, até que não houvesse mais variação no peso. A perda de peso, revela um aumento populacional dos insetos, devi do a transformação do substrato em gās carbōnico e energia dissipadas (WIENDL et alii, 1974). Para controle da variação de peso, devida a umi dade relativa, tomaram-se frascos contendo somente substratos (arroz e milho). As pesagens destes vidros foram feitas juntamente com as demais.

Para o ensaio de cruzamento de machos irradiados com fêmeas normais e vice-versa, utilizaram-se machos e fêmeas virgens com ida de máxima de 24 horas, irradiados com as seguintes doses: 0 (test.), 200, $250,300,350$ e 400 Gy. Em outro ensaio adicional somente os machos foram irradiados com doses de: 400, 450, 500 e 550 Gy, e cruzados com fê- 
meas normais. Durante a irradiação dos insetos utilizaram-se tubos de vidro de $2,5 \mathrm{~cm}$ de diâmetro por $8,5 \mathrm{~cm}$ de altura. Apös a irradiação os insetos foram colocados com o sexo oposto num total de cinco casais por tratamento, mais as tiras de cartolina preta, para que efetuassem a oviposição. Fez-se a contagem da mortalidade dos adultos, a cada três dias. As cartolinas com ovos eram removidas para vidros contendo novo substrato (milho), para posterior contagem dos ovos viāveis, inviāveis e da emergência da geração fillial $\left(F_{1}\right)$. Este ensaio foi realizado apenas com substrato de milho, devido a maior facilidade na sexagem dos insetos pelo tamanho do abdome, que nas fêmeas è bem mais. desenvolvidos que em machos. Tal fato não ocorre com os insetos criados em arroz, quan do os insetos de ambos os sexos são bastante pequenos.

d) Ensaio para determinasão da dose letal imediata de radiasão gama em adultos (DL $I_{100}$ )

Para a determinação da dose letal imediata( $\left(L D_{1_{100}}\right)$ em adul tos provenientes dos substratos arroz e milho, utilizaram-se insetos com no máximo 24 horas de idade. 0 ensaio constou de seis repetições com 15 insetos em cada tubo de vidro de $2,5 \mathrm{~cm}$ de diâmetro por $8,5 \mathrm{~cm}$ de altura. As doses de radiação gama utilizadas foram crescentes de 250 em 250 Gy, sendo que após cada dose faziam-se as contagens sendo os insetos mortos retirados. Nova dose de radiação era administrada atē que houvesse a morte de todos os insetos. 


\section{RESULTADOS E ANALISES DOS RESULTADOS}

Constam da Tabela l e Figura l, os dados de viabilidade dos ovos irradiados com diferentes doses de radiação gama, provenientes de adultos de Sitotroga cerealella (01iv.) criados em arroz e milho. Nas Tabelas $2,3,4$ e 5 , constam o nümero de adultos emergidos por repetição, o total e a média por tratamento, cujas lagartas e crisālidas foram irradiadas com diferentes doses de radiação gama em arroz e mi lho. Com os dados dessas Tabelas, construíram-se as Figuras 2 e 3 , onde constam as mèdias e variações numēricas da emergência dos adultos. Nas Figuras 4 e 5, constam o nümero total de adul tos da geração filial $\left(F_{1}\right)$, provenientes de adultos cujas lagartas e crisālidas foram irradiadas.

Constam da Tabela 6 , valores numéricos referentes à emergência de adultos com deformações alares, para cada repetição, assim como - total por tratamento quando lagartas e crisălidas provenientes de arroz e mi lho foram irradiadas com diferentes doses de radiação gama. Com os dados dessa tabela, construíram-se os histogramas das figuras 6 e 7 , 
onde observaram os valores em porcentagens de adultos com deformações alares.

Na Tabela 7 estão representados os valores numéricos da mortalidade de adultos, contados a cada três dias, quando irradiados com doses crescentes de radiação gama e cruzados com adultos normais. Também são apresentados os valores das respectivas esperanças de vida $\left(\mathrm{e}_{0}^{\mathrm{x}}\right)$, so matōrio a cada três dias e a média de $\left(e_{0}^{x}\right)$ para machos e fêmeas. Na Tabela 8 , somente para machos irradiados e cruzados com fêmeas norma is es tão os valores das mortalidades e esperanças de vida. Nas Tabelas 9 e 10 constam os nümeros de ovos viäveis, inviáveis e adultos emergidos na geração filial $\left(F_{1}\right)$ provenientes da geração paterna criada em milho, irradiada e cruzada com a normal, e somente quando machos foram irradiados, além do somatōrio total e a média. Para elucidar melhor os resultados das Tabelas 9 e 10 , construíram-se as Figuras $8,9,10$ e 11 , onde temos o número total de adultos da geração filial $\left(F_{1}\right)$ emergidos e o número mé dio de ovos viäveis e inviäveis, quando machos e fêmeas e só machos foram irradiados e cruzados com normais.

Constam na Tabela 11 as médias das esperanças de vida $\left(e_{0}^{x}\right)$ para adultos irradiados e cruzados com os normais, e sua respectiva anäl ise e diferença estatística.

Nas Tabelas 12 e 13 estão resumidas as médias das variações em porcentagem e a diferença entre as médias da perda de peso do substrato para cada tratamento de irradiação. Estas variações foram cal- 
culadas pela diferença de peso calculada entre a primeira e sucessivas pesagens. Temos ainda as diferenças de pesagens para arroz e milho devi do somente a variação de umidade relativa do ar da câmara onde se desenvolveu o experimento. Estes resultados podem ser melhor visualizados nas figuras 12 e 13 onde temos a variação porcentual da perda de peso ocorrida em arroz e milho nas diferentes doses de radiação gama, mais o controle "umidade".

Nas Tabelas 14 e 15 constam os valores de mortalidade de adultos provenientes de arroz e milho, obtidos em contagens durante a irradiação dos mesmos, com doses crescentes de radiação gama, ass im como os respectivos somatórios. A partir destas tabelas, elaboraram-se as Ta belas 16,17 e 18 onde constam a mortalidade em porcentagem, a dose letal calculada, médias calculadas e sua respectiva anālise e diferença estatistica entre as doses letais imediata. Com os dados da Tabela 16 , construiram-se as Figuras 14 e 15 onde observa-se a mortalidade em por centagem para machos e fêmeas irradiados com doses crescentes de radia çāo gama. 
Tabela 1 - Viabilidade de ovos de Sitotroga cerealcla (0liv.) irrndiados com diferentes doses de radiaçäo gana criados en arroz e mi tho (média nì).

\begin{tabular}{|c|c|c|c|c|c|c|c|c|c|}
\hline \multirow{2}{*}{$\begin{array}{c}\text { Doses } \\
(\text { Gy })\end{array}$} & \multirow{2}{*}{ Rep. } & \multicolumn{3}{|c|}{ Substrato: Arroz } & \multicolumn{5}{|c|}{ Substrato: Milho } \\
\hline & & $\begin{array}{l}\text { No } \\
\text { ovos }\end{array}$ & Viăveis & $\begin{array}{l}\text { Inviá- } \\
\text { veis }\end{array}$ & $\begin{array}{l}\% \text { ovos } \\
\text { viäve is }\end{array}$ & $\begin{array}{l}119 \\
\text { ovos }\end{array}$ & Viaveis & $\begin{array}{l}\text { Inviá- } \\
\text { veís }\end{array}$ & $\begin{array}{l}\text { \% ovos } \\
\text { viáveis }\end{array}$ \\
\hline \multirow{5}{*}{$!$} & 1 & 32 & 30 & 2 & & 30 & 29 & 1 & \\
\hline & 2 & 30 & 22 & 8 & & 32 & 29 & 3 & \\
\hline & 3 & 35 & 31 & 4 & & 31 & 30 & 2 & \\
\hline & 4 & 31 & 30 & 1 & & 30 & 28 & 2 & \\
\hline & 5 & 33 & 31 & 2 & & 32 & 31 & 1 & \\
\hline \multirow[t]{3}{*}{$\bar{m}$} & & 32,2 & 28,8 & 3,4 & 100,0 & 31,0 & 29,4 & 1,8 & 100,0 \\
\hline & 1 & 28 & 22 & 6 & & 37 & 30 & 7 & \\
\hline & 2 & 33 & 11 & 22 & & 32 & 21 & 11 & \\
\hline \multirow[t]{3}{*}{25} & 3 & 29 & 27 & 2 & & 46 & 35 & 11 & \\
\hline & 4 & 31 & 29 & 2 & & 34 & 29 & 5 & \\
\hline & 5 & 37 & 30. & 7 & & 32 & 28 & 4 & \\
\hline \multirow[t]{3}{*}{$\bar{m}$} & . & 31,6 & 23,8 & 7,8 & 82,6 & 36,2 & 28,6 & 7,6 & 97,2 \\
\hline & 1 & 44 & 14 & 30 & & 36 & 14 & 22 & \\
\hline & 2 & 31 & 5 & 26 & & 34 & 15 & 19 & \\
\hline \multirow[t]{3}{*}{50} & 3 & 39 & 5 & 34 & & 37 & 12 & 25 & \\
\hline & 4 & 30 & 10 & 20 & & 33 & 14 & 19 & \\
\hline & 5 & 30 & 13 & 17 & & 33 & 14 & 19 & \\
\hline \multirow[t]{3}{*}{$\bar{m}$} & & 34,8 & 9,4 & 25,4 & 32,6 & 34,6 & 13,8 & 20,8 & 46,3 \\
\hline & 1 & 30 & 1 & 29 & & 35 & 1 & 34 & \\
\hline & 2 & 31 & 1 & 30 & & 33 & 0 & 33 & \\
\hline \multirow[t]{3}{*}{75} & 3 & 32 & 0 & 32 & & 32 & 1 & 31 & \\
\hline & 4 & 34 & 0 & 34 & & 40 & 0 & 40 & \\
\hline & 5 & 30 & 0 & 30 & & 32 & 2 & 30 & \\
\hline \multirow[t]{3}{*}{$\bar{m}$} & & 31,2 & 0,4 & 31,0 & 1,3 & 34,4 & 0,8 & 33,6 & 2,7 \\
\hline & 1 & 30 & 0 & 30 & & 31 & 0 . & 31 & \\
\hline & 2 & 31 & 0 & 31 & & 32 & 0 & 32 & \\
\hline \multirow[t]{3}{*}{100} & 3 & 35 & 0 & 35 & & 29 & 1 & 28 & \\
\hline & 4 & 29 & 0 & 29 & & 30 & 0 & 30 & \\
\hline & 5 & 38 & 0 & 38 & & 30 & 0 & 30 & \\
\hline $\bar{m}$ & & 32,6 & 0,0 & 32,6 & 0,0 & 30,4 & 0,2 & 30,2 & 0,6 \\
\hline \multirow[t]{2}{*}{7} & 1 & 33 & 0 & 33 & & 30 & 0 & 30 & \\
\hline & 2 & 31 & 0 & 31 & & 31 & 0 & 31 & \\
\hline \multirow[t]{3}{*}{125} & 3 & 30 & 0 & 30 & & 34 & 0 & 34 & \\
\hline & 4 & 29 & 0 & 29 & & 30 & 0 & 30 & \\
\hline & 5 & 36 & 0 & 36 & & 33 & 0 & 33 & \\
\hline $\bar{n}$ & & 31,8 & 0,0 & 31,8 & 0,0 & 32,0 & 0,0 & 32,0 & 0,0 \\
\hline
\end{tabular}


Tabela 2 - Nünero de adultos de Sitotroga cercaleler (0liv.) provenientes de lagartas irradiadas e sua geração filial $\left(F_{1}\right)$. (Substrato de criação: arroz). (Total $=\Sigma ;$ mëdia $=$ mi).

\begin{tabular}{|c|c|c|c|}
\hline $\begin{array}{c}\text { Doses } \\
(G y)\end{array}$ & $\begin{array}{l}\text { Repeti- } \\
\text { f̧öes }\end{array}$ & $\begin{array}{l}\text { No de } \\
\text { adultos }\end{array}$ & $F_{1}$ \\
\hline \multirow{5}{*}{0} & 1 & 20 & 130 \\
\hline & 2 & 19 & 121 \\
\hline & 3 & 25 & 175 \\
\hline & 4 & 17 & 50 \\
\hline & 5 & 27 & 215 \\
\hline \multirow[t]{3}{*}{$\Sigma(\bar{m})$} & & $108(21,6)$ & $691(138,2)$ \\
\hline & 1 & 15 & 19 \\
\hline & 2 & 22 & 17 \\
\hline \multirow[t]{3}{*}{50} & 3 & 16 & 35 \\
\hline & 4 & 20 & 67 \\
\hline & 5 & 15 & 12 \\
\hline \multirow[t]{3}{*}{$\Sigma(\bar{m})$} & & $88(17,6)$ & $150 \quad(30,0)$ \\
\hline & 1 & 13 & 0 \\
\hline & 2 & 8 & 0 \\
\hline \multirow[t]{3}{*}{100} & 3 & 5 & 0 \\
\hline & 4 & 7 & 0 \\
\hline & 5 & 4 & 0 \\
\hline \multirow[t]{3}{*}{$\Sigma(\bar{m})$} & & $37(7,4)$ & 0,0 \\
\hline & 1 & 0 & 0 \\
\hline & 2 & 0 & 0 \\
\hline \multirow[t]{3}{*}{150} & 3 & 4 & 0 \\
\hline & 4 & 0 & 0 \\
\hline & 5 & 0 & 0 \\
\hline \multirow[t]{3}{*}{$\Sigma(\bar{m})$} & & $4(0,8)$ & 0,0 \\
\hline & 1 & 0 & 0 \\
\hline & 2 & 0 & 0 \\
\hline \multirow[t]{3}{*}{200} & 3 & 0 & 0 \\
\hline & 4 & 0 & 0 \\
\hline & 5 & 0 & 0 \\
\hline$\sum(\bar{m})$ & & 0,0 & 0,0 \\
\hline
\end{tabular}




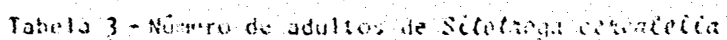
(oliv.) proventeares de crisalldas irradia

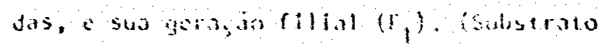

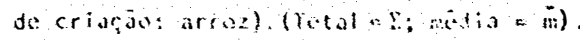

\begin{tabular}{|c|c|c|c|}
\hline $\begin{array}{l}\text { Woss } \\
\left(C_{y}\right)\end{array}$ & $\begin{array}{l}\text { foneti- } \\
\text { fors }\end{array}$ & $\begin{array}{l}\text { No de } \\
\text { adultos }\end{array}$ & $E_{1}$ \\
\hline 0 & $\begin{array}{l}1 \\
2 \\
3 \\
4 \\
5 \\
\end{array}$ & $\begin{array}{l}10 \\
19 \\
25 \\
27 \\
26\end{array}$ & $\begin{array}{l}141 \\
132 \\
165 \\
151 \\
120\end{array}$ \\
\hline$\because(3)$ & & $107(21,4)$ & $702(140,4)$ \\
\hline 50 & $\begin{array}{l}1 \\
2 \\
3 \\
4 \\
5\end{array}$ & $\begin{array}{l}15 \\
14 \\
13 \\
14 \\
12\end{array}$ & $\begin{array}{l}61 \\
56 \\
41 \\
40 \\
47\end{array}$ \\
\hline$\Sigma(\overline{i i})$ & & $68(13,6)$ & $245(49,0)$ \\
\hline 100 & $\begin{array}{l}1 \\
2 \\
3 \\
4 \\
5\end{array}$ & $\begin{array}{r}9 \\
8 \\
10 \\
13 \\
15\end{array}$ & $\begin{array}{l}18 \\
11 \\
17 \\
21 \\
19\end{array}$ \\
\hline$\therefore(\overline{i i n})$ & & $55(11,0)$ & $86(17,2)$ \\
\hline 150 & $\begin{array}{l}1 \\
2 \\
3 \\
5\end{array}$ & $\begin{array}{l}10 \\
15 \\
13 \\
9 \\
7\end{array}$ & $\begin{array}{l}5 \\
8 \\
6 \\
2 \\
1\end{array}$ \\
\hline$\Sigma(n i)$ & & $54(10,8)$ & $22 \quad(4,4)$ \\
\hline 200 & $\begin{array}{l}1 \\
2 \\
3 \\
4 \\
5\end{array}$ & $\begin{array}{r}7 \\
10 \\
12 \\
9 \\
8\end{array}$ & $\begin{array}{l}0 \\
0 \\
0 \\
0 \\
0\end{array}$ \\
\hline$\Sigma(\bar{m})$ & & $46 \quad(9,2)$ & 0,0 \\
\hline 250 & $\begin{array}{l}1 \\
2 \\
3 \\
4 \\
5\end{array}$ & $\begin{array}{r}8 \\
9 \\
8 \\
10 \\
7 \\
\end{array}$ & $\begin{array}{l}0 \\
0 \\
0 \\
0 \\
0\end{array}$ \\
\hline$\pi(i i)$ & & $1,2(8,4)$ & 0,0 \\
\hline $30 n$ & $\begin{array}{l}1 \\
2 \\
3 \\
4 \\
5\end{array}$ & $\begin{array}{l}5 \\
8 \\
6 \\
9 \\
7 \\
\end{array}$ & $\begin{array}{l}0 \\
0 \\
0 \\
0 \\
0\end{array}$ \\
\hline$\ddot{2}(\overline{i i})$ & & $35 \quad(7,0)$ & 0,0 \\
\hline 350 & $\begin{array}{l}1 \\
2 \\
3 \\
4 \\
5 \\
\end{array}$ & $\begin{array}{l}7 \\
7 \\
5 \\
4 \\
9\end{array}$ & $\begin{array}{l}0 \\
0 \\
0 \\
0 \\
0\end{array}$ \\
\hline$x(\vec{n})$ & & $32 \quad(6,4)$ & 0,0 \\
\hline
\end{tabular}


Tabela 4 - Número de adultos de Sitotroga cerenlelea (oliv.) provenientes de lagarlas irradiadas e sua geração filial $\left(F_{1}\right)$. (Substrato de criação: milho). (Total $=\Sigma$; média $=\bar{m}$ ).

\begin{tabular}{|c|c|c|c|}
\hline $\begin{array}{c}\text { Doses } \\
\text { (Gy) }\end{array}$ & $\begin{array}{l}\text { Repeti- } \\
\text { ções }\end{array}$ & $\begin{array}{l}\text { No de } \\
\text { adultos }\end{array}$ & $F_{1}$ \\
\hline \multirow{5}{*}{0} & 1 & 19 & 164 \\
\hline & 2 & 24 & 150 \\
\hline & 3 & 23 & 168 \\
\hline & 4 & 17 & 166 \\
\hline & 5 & 16 & 129 \\
\hline$\Sigma(\bar{m})$ & & $99(19,8)$ & $777(155,4)$ \\
\hline \multirow{5}{*}{50} & 1 & 20 & 135 \\
\hline & 2 & 14 & 111 \\
\hline & 3 & 15 & 134 \\
\hline & 4 & 16 & 117 \\
\hline & 5 & 14 & 119 \\
\hline$\Sigma(\bar{m})$ & & $79(15,8)$ & $616(123,2)$ \\
\hline \multirow{5}{*}{100} & 1 & 15 & 0 \\
\hline & 2 & 13 & 1 \\
\hline & 3 & 14 & 1 \\
\hline & 4 & 12 & 0 \\
\hline & 5 & 10 & 1 \\
\hline$\sum(\bar{m})$ & & $64(12,8)$ & $3(0,6)$ \\
\hline \multirow{5}{*}{150} & 1 & 1 & 0 \\
\hline & 2 & 1 & 0 \\
\hline & 3 & 1 & 0 \\
\hline & 4 & 4 & 0 \\
\hline & 5 & 0 & 0 \\
\hline \multirow[t]{3}{*}{$\Sigma(\bar{m})$} & & $7(1,4)$ & 0,0 \\
\hline & 1 & 0 & 0 \\
\hline & 2 & 0 & 0 \\
\hline \multirow[t]{3}{*}{200} & 3. & 0 & 0 \\
\hline & 4 & 0 & 0 \\
\hline & 5 & 0 & 0 . \\
\hline$\Sigma(\bar{m})$ & & 0,0 & 0,0 \\
\hline
\end{tabular}




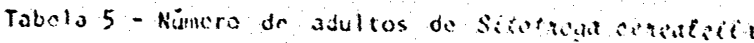
(oliv.) prosmiences de crisillidas irradiados, e sua gerą̧a filliul $\left(f_{1}\right)$ (sotstrato

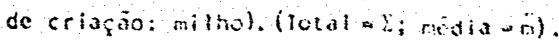

\begin{tabular}{|c|c|c|c|}
\hline $\begin{array}{l}\text { Duses } \\
\text { (Gy) }\end{array}$ & $\begin{array}{l}\text { Repeli- } \\
\text { f̧ös }\end{array}$ & $\begin{array}{l}\text { No de } \\
\text { adul tos }\end{array}$ & $F_{1}$ \\
\hline 0 & $\begin{array}{l}1 \\
2 \\
3 \\
4 \\
5\end{array}$ & $\begin{array}{l}19 \\
20 \\
16 \\
17 \\
26\end{array}$ & $\begin{array}{l}151 \\
164 \\
155 \\
159 \\
162\end{array}$ \\
\hline$\sum[\bar{n})$ & & $98(19,6)$ & $791(158,2)$ \\
\hline 50 & $\begin{array}{l}1 \\
2 \\
3 \\
4 \\
5\end{array}$ & $\begin{array}{l}25 \\
16 \\
15 \\
20 \\
12\end{array}$ & $\begin{array}{l}71 \\
78 \\
45 \\
60 \\
51\end{array}$ \\
\hline$\Sigma(\bar{m})$ & & $88(17,6)$ & $305(61,0)$ \\
\hline 100 & $\begin{array}{l}1 \\
2 \\
3 \\
4 \\
5\end{array}$ & $\begin{array}{l}10 \\
18 \\
17 \\
14 \\
17\end{array}$ & $\begin{array}{l}27 \\
36 \\
43 \\
23 \\
29\end{array}$ \\
\hline$\Sigma(\overline{n i})$ & & $76(15,2)$ & $158(31,6)$ \\
\hline 150 & $\begin{array}{l}1 \\
2 \\
3 \\
4 \\
5\end{array}$ & $\begin{array}{l}15 \\
16 \\
12 \\
14 \\
13\end{array}$ & $\begin{array}{r}6 \\
9 \\
4 \\
17 \\
19\end{array}$ \\
\hline$\Sigma(\bar{m})$ & & $70(14,0)$ & $55(10,4)$ \\
\hline 200 & $\begin{array}{l}1 \\
2 \\
3 \\
4 \\
5\end{array}$ & $\begin{array}{l}12 \\
11 \\
16 \\
10 \\
15\end{array}$ & $\begin{array}{l}1 \\
0 \\
2 \\
2 \\
3\end{array}$ \\
\hline$\sum(\bar{m})$ & & $64(12,8)$ & $8 \quad(1,6)$ \\
\hline 250 & $\begin{array}{l}1 \\
2 \\
3 \\
4 \\
5\end{array}$ & $\begin{array}{r}15 \\
14 \\
9 \\
7 \\
13\end{array}$ & $\begin{array}{l}0 \\
0 \\
0 \\
0 \\
0\end{array}$ \\
\hline$\Sigma\left(n_{n}^{-}\right)$ & & $58(11,6)$ & 0.0 \\
\hline 300 & $\begin{array}{l}1 \\
2 \\
3 \\
4 \\
5\end{array}$ & $\begin{array}{l}5 \\
8 \\
9 \\
6 \\
5\end{array}$ & $\begin{array}{l}0 \\
0 \\
0 \\
0 \\
0\end{array}$ \\
\hline$\Sigma(\bar{m})$ & & $33(6,6)$ & 0,0 \\
\hline 350 & $\begin{array}{l}1 \\
2 \\
3 \\
4 \\
5\end{array}$ & $\begin{array}{l}4 \\
6 \\
8 \\
7 \\
4\end{array}$ & $\begin{array}{l}0 \\
0 \\
0 \\
0 \\
0\end{array}$ \\
\hline$\because(n)$ & . & $23 \quad(5,8)$ & 0.0 \\
\hline
\end{tabular}




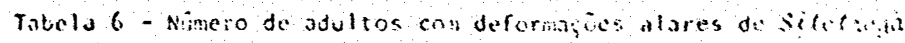

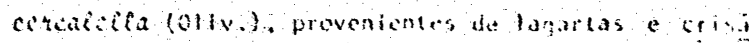

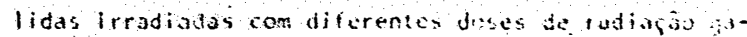
mo, cin diferences sithstratos. (Total = I).

\begin{tabular}{|c|c|c|c|c|c|}
\hline \multirow{2}{*}{$\begin{array}{c}\text { Doses } \\
(G y)\end{array}$} & \multicolumn{3}{|c|}{ Substroto: Artoz } & \multicolumn{2}{|c|}{ Substrites Milino } \\
\hline & $\begin{array}{l}\text { Repet i } \\
\text { coes }\end{array}$ & $\begin{array}{c}\text { Lagar } \\
\text { las }\end{array}$ & $\begin{array}{l}\text { Crisa } \\
\text { lidas }\end{array}$ & $\begin{array}{l}\text { lagar } \\
\text { tas }\end{array}$ & $\begin{array}{l}\text { Crisi } \\
\text { litiss }\end{array}$ \\
\hline 0 & $\begin{array}{l}1 \\
2 \\
3 \\
4 \\
5\end{array}$ & $\begin{array}{l}0 \\
0 \\
0 \\
0 \\
0\end{array}$ & $\begin{array}{l}0 \\
0 \\
0 \\
0 \\
0\end{array}$ & $\begin{array}{l}0 \\
0 \\
0 \\
0 \\
0\end{array}$ & $\begin{array}{l}0 \\
0 \\
0 \\
0 \\
0\end{array}$ \\
\hline$\Sigma$ & & 0 & 0 & 0 & 0 \\
\hline 50 & $\begin{array}{l}1 \\
2 \\
3 \\
4 \\
5\end{array}$ & $\begin{array}{l}1 \\
3 \\
0 \\
1 \\
1\end{array}$ & $\begin{array}{l}0 \\
0 \\
0 \\
0 \\
0\end{array}$ & $\begin{array}{l}0 \\
0 \\
0 \\
0 \\
0\end{array}$ & $\begin{array}{l}0 \\
0 \\
0 \\
0 \\
0\end{array}$ \\
\hline$\Sigma$ & & 6 & 0 & 0 & 0 \\
\hline 100 & $\begin{array}{l}1 \\
2 \\
3 \\
4 \\
5\end{array}$ & $\begin{array}{l}4 \\
3 \\
2 \\
3 \\
2\end{array}$ & $\begin{array}{l}0 \\
1 \\
2 \\
1 \\
2\end{array}$ & $\begin{array}{l}3 \\
2 \\
3 \\
1 \\
1\end{array}$ & $\begin{array}{l}0 \\
0 \\
0 \\
0 \\
0\end{array}$ \\
\hline$\Sigma$ & & 14 & 6 & 10 & 0 \\
\hline 150 & $\begin{array}{r}1 \\
2 \\
3 \\
4 \\
5\end{array}$ & $\begin{array}{l}0 \\
0 \\
3 \\
0 \\
0\end{array}$ & $\begin{array}{l}1 \\
2 \\
3 \\
1 \\
1\end{array}$ & $\begin{array}{l}1 \\
1 \\
1 \\
1 \\
0\end{array}$ & $\begin{array}{l}2 \\
0 \\
0 \\
0 \\
2\end{array}$ \\
\hline$\Sigma$ & $\therefore$ & 3 & 8 & 4 & 4 \\
\hline 200 & $\begin{array}{r}1 \\
2 \\
3 \\
4 \\
5\end{array}$ & $\begin{array}{l}0 \\
0 \\
0 \\
0 \\
0\end{array}$ & $\begin{array}{l}3 \\
5 \\
3 \\
1 \\
1\end{array}$ & $\begin{array}{l}0 \\
0 \\
0 \\
0 \\
0\end{array}$ & $\begin{array}{l}2 \\
1 \\
2 \\
1 \\
3\end{array}$ \\
\hline $\boldsymbol{\Sigma}$ & & 0 & 13 & 0 & 9 \\
\hline 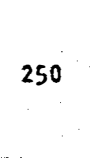 & $\begin{array}{l}1 \\
2 \\
3 \\
4 \\
5\end{array}$ & $\begin{array}{l}0 \\
0 \\
0 \\
0 \\
0\end{array}$ & $\begin{array}{l}4 \\
1 \\
2 \\
4 \\
2\end{array}$ & $\begin{array}{l}0 \\
0 \\
0 \\
0 \\
0\end{array}$ & $\begin{array}{l}2 \\
1 \\
2 \\
1 \\
3\end{array}$ \\
\hline$i$ & & 0 & 13 & 0 & 10 \\
\hline 300 & $\begin{array}{l}1 \\
2 \\
3 \\
4 \\
5\end{array}$ & $\begin{array}{l}0 \\
0 \\
0 \\
0 \\
0\end{array}$ & $\begin{array}{l}1 \\
3 \\
4 \\
3 \\
2\end{array}$ & $\begin{array}{l}0 \\
0 \\
0 \\
0 \\
0\end{array}$ & $\begin{array}{r}2 \\
3 \\
3 \\
2 \\
2\end{array}$ \\
\hline$\Sigma$ & & 0 & 13 & $0 \quad$ & 12 \\
\hline 350 & $\begin{array}{l}1 \\
2 \\
3 \\
4 \\
5\end{array}$ & $\begin{array}{l}0 \\
0 \\
0 \\
0 \\
0\end{array}$ & $\begin{array}{l}5 \\
2 \\
2 \\
2 \\
3\end{array}$ & $\begin{array}{l}0 \\
0 \\
0 \\
0 \\
0\end{array}$ & $\begin{array}{l}2 \\
2 \\
4 \\
4 \\
1\end{array}$ \\
\hline$r$ & & 0 & 14 & 0 & 13 \\
\hline
\end{tabular}


Tabela 7 - Mortalidade de adultos de Sitotroga cercalclla (01iv.) irradiudos e cruzados com normais, e suas respectivas esperanças de vida. (Periodo de conta gens: 3 dias; substrato de criação: milho). (Total $=\Sigma$, mèdias $=\bar{n})$.

\begin{tabular}{|c|c|c|c|c|c|c|c|c|c|c|c|c|c|c|c|c|}
\hline \multirow{3}{*}{$\begin{array}{c}\text { Doses } \\
\text { (Gy) } \\
e \\
\text { Cruzamen } \\
\text { tos }\end{array}$} & \multirow{3}{*}{ Rep. } & \multicolumn{12}{|c|}{$0 \quad 1 \quad a \quad s$} & \multirow{2}{*}{\multicolumn{3}{|c|}{$e_{0}^{x}$}} \\
\hline & & \multicolumn{2}{|c|}{3} & \multicolumn{2}{|c|}{6} & \multicolumn{2}{|c|}{9} & \multicolumn{2}{|c|}{12} & \multicolumn{2}{|c|}{15} & \multicolumn{2}{|c|}{18} & & & \\
\hline & & $M$ & $F$ & M & $F$ & M & $F$ & $M$ & $\mathrm{~F}$ & M & $F$ & $M$ & $F$ & & $M$ & $F$ \\
\hline$\left(F_{N} \times M_{N}\right)$ & $\begin{array}{l}1 \\
2 \\
3 \\
4 \\
5\end{array}$ & $\begin{array}{l}0 \\
0 \\
0 \\
0 \\
0\end{array}$ & $\begin{array}{l}0 \\
0 \\
0 \\
0 \\
0\end{array}$ & $\begin{array}{l}0 \\
0 \\
0 \\
0 \\
0\end{array}$ & $\begin{array}{l}1 \\
0 \\
0 \\
1 \\
0\end{array}$ & $\begin{array}{l}0 \\
0 \\
0 \\
0 \\
0\end{array}$ & $\begin{array}{l}0 \\
1 \\
0 \\
0 \\
1\end{array}$ & $\begin{array}{l}1 \\
1 \\
1 \\
1\end{array}$ & 1 & & & & & & $\begin{array}{l}13,5 \\
13,5 \\
13,5 \\
13,5 \\
13,5\end{array}$ & $\begin{array}{r}7,5 \\
10,5 \\
13,5 \\
7,5 \\
10,5\end{array}$ \\
\hline$\Sigma$ & & 0 & 0 & 0 & 0 & 1 & 1 & 5 & 1 & & & & & $\bar{m}$ & 13,5 & 9,9 \\
\hline$\left(F_{N} \times M_{1}\right)$ & $\begin{array}{l}1 \\
2 \\
3 \\
4 \\
5\end{array}$ & $\begin{array}{l}0 \\
0 \\
0 \\
0 \\
0\end{array}$ & $\begin{array}{l}0 \\
0 \\
0 \\
0 \\
0\end{array}$ & $\begin{array}{l}0 \\
0 \\
0 \\
0 \\
0\end{array}$ & $\begin{array}{l}0 \\
0 \\
0 \\
0 \\
0\end{array}$ & $\begin{array}{l}1 \\
0 \\
0 \\
0 \\
1\end{array}$ & $\begin{array}{l}1 \\
1 \\
0 \\
1 \\
1\end{array}$ & $\begin{array}{l}1 \\
1 \\
0\end{array}$ & $\begin{array}{l}0 \\
0\end{array}$ & $\begin{array}{l}0 \\
1\end{array}$ & 1 & & & & $\begin{array}{l}10,5 \\
13,5 \\
13,5 \\
16,5 \\
10,5\end{array}$ & $\begin{array}{l}10,5 \\
10,5 \\
16,5 \\
10,5 \\
10,5\end{array}$ \\
\hline$\Sigma$ & & 0 & 0 & 0 & 0 & 2 & 4 & 2 & 0 . & 1 & 1 & & & $\bar{n}$ & 12,9 & 11,9 \\
\hline$\left(F_{1} \times M_{N}\right)$ & $\begin{array}{l}1 \\
2 \\
3 \\
4 \\
5\end{array}$ & $\begin{array}{l}0 \\
0 \\
0 \\
0 \\
0\end{array}$ & $\begin{array}{l}0 \\
0 \\
1 \\
0 \\
0\end{array}$ & $\begin{array}{l}0 \\
0 \\
0 \\
1 \\
0\end{array}$ & $\begin{array}{l}0 \\
0 \\
0 \\
1 \\
0\end{array}$ & $\begin{array}{l}1 \\
1 \\
0 \\
0\end{array}$ & $\begin{array}{l}0 \\
0 \\
0 \\
0\end{array}$ & $\begin{array}{l}0 \\
0 \\
0\end{array}$ & $\begin{array}{l}1 \\
0 \\
0\end{array}$ & $\begin{array}{l}0 \\
1\end{array}$ & 1 & & & & $\begin{array}{l}10,5 \\
10,5 \\
16,5 \\
7,5 \\
16,5\end{array}$ & $\begin{array}{r}13,5 \\
16,5 \\
4,5 \\
7,5 \\
16,5\end{array}$ \\
\hline$\Sigma$ & & 0 & 1 & 1 & 1 & 2 & 0 & 0 & 1 & 2 & 2 & & & $\bar{m}$ & 12,3 & 11,7 \\
\hline$\frac{250}{\left(F_{N} \times M_{1}\right)}$ & $\begin{array}{l}1 \\
2 \\
3 \\
4 \\
5\end{array}$ & $\begin{array}{l}0 \\
0 \\
0 \\
0 \\
0\end{array}$ & $\begin{array}{l}0 \\
0 \\
0 \\
0 \\
0\end{array}$ & $\begin{array}{l}1 \\
0 \\
0 \\
0 \\
1\end{array}$ & $\begin{array}{l}0 \\
0 \\
0 \\
1 \\
0\end{array}$ & $\begin{array}{l}0 \\
0 \\
0 \\
0 \\
0\end{array}$ & $\begin{array}{l}0 \\
0 \\
1 \\
0 \\
0\end{array}$ & $\begin{array}{l}0 \\
1 \\
0 \\
1 \\
0\end{array}$ & $\begin{array}{l}1 \\
1 \\
0\end{array}$ & 0 & 1 & & & & $\begin{array}{r}7,5 \\
13,5 \\
16,5 \\
13,5 \\
7,5\end{array}$ & $\begin{array}{r}13,5 \\
13,5 \\
10,5 \\
7,5 \\
16,5\end{array}$ \\
\hline$\Sigma$ & & 0 & 0 & 2 & 1 & 0 & 1. & 2 & 2 & 1 & 1 & & & $\bar{m}$ & 11,7 & 12,3 \\
\hline$\left(F_{1} \times M_{N}\right)$ & $\begin{array}{l}1 \\
2 \\
3 \\
4 \\
5\end{array}$ & $\begin{array}{l}0 \\
0 \\
0 \\
0 \\
0\end{array}$ & $\begin{array}{l}0 \\
0 \\
0 \\
0 \\
0\end{array}$ & $\begin{array}{l}0 \\
0 \\
0 \\
0 \\
0\end{array}$ & $\begin{array}{l}1 \\
0 \\
0 \\
0 \\
0\end{array}$ & $\begin{array}{l}0 \\
0 \\
1 \\
0 \\
0\end{array}$ & $\begin{array}{l}0 \\
0 \\
0 \\
0 \\
0\end{array}$ & $\begin{array}{l}1 \\
1 \\
0 \\
1 \\
0\end{array}$ & $\begin{array}{l}0 \\
1 \\
1 \\
0\end{array}$ & 0 & 1 & 0 & 1 & & $\begin{array}{l}13,7 \\
13,5 \\
10,5 \\
13,5 \\
16,5\end{array}$ & $\begin{array}{l}7,5 \\
16,5 \\
13,5 \\
13,5 \\
19,5\end{array}$ \\
\hline$\Sigma$ & & 0 & 0 & 0 & 1 & 1 & 0 & 3 & 2 & 1 & 1 & 0 & 1 & $\bar{m}$ & 13,5 & 14,1 \\
\hline $\begin{array}{c}300 \\
\left(F_{N} \times M_{1}\right)\end{array}$ & $\begin{array}{l}1 \\
2 \\
3 \\
4 \\
5\end{array}$ & $\begin{array}{l}0 \\
0 \\
0 \\
0 \\
0\end{array}$ & $\begin{array}{l}0 \\
0 \\
0 \\
0 \\
0\end{array}$ & $\begin{array}{l}0 \\
0 \\
0 \\
1 \\
0\end{array}$ & $\begin{array}{l}0 \\
1 \\
0 \\
0 \\
0\end{array}$ & $\begin{array}{l}0 \\
0 \\
0 \\
0 \\
0\end{array}$ & $\begin{array}{l}0 \\
0 \\
1 \\
1 \\
1\end{array}$ & $\begin{array}{l}1 \\
1 \\
1 \\
1\end{array}$ & 0 & 0 & 1 & & & & $\begin{array}{r}13,5 \\
13,5 \\
13,5 \\
7,5 \\
13,5\end{array}$ & $\begin{array}{r}16,5 \\
7,5 \\
10,5 \\
10,5 \\
10,5\end{array}$ \\
\hline$\Sigma$ & & 0 & 0 & 1 & $1:$ & 0 & 3 & 4 & 0 & 0 & 1 & & & $\bar{m}$ & 12,3 & 11,1 \\
\hline
\end{tabular}


Tabela 7 - Continuação.

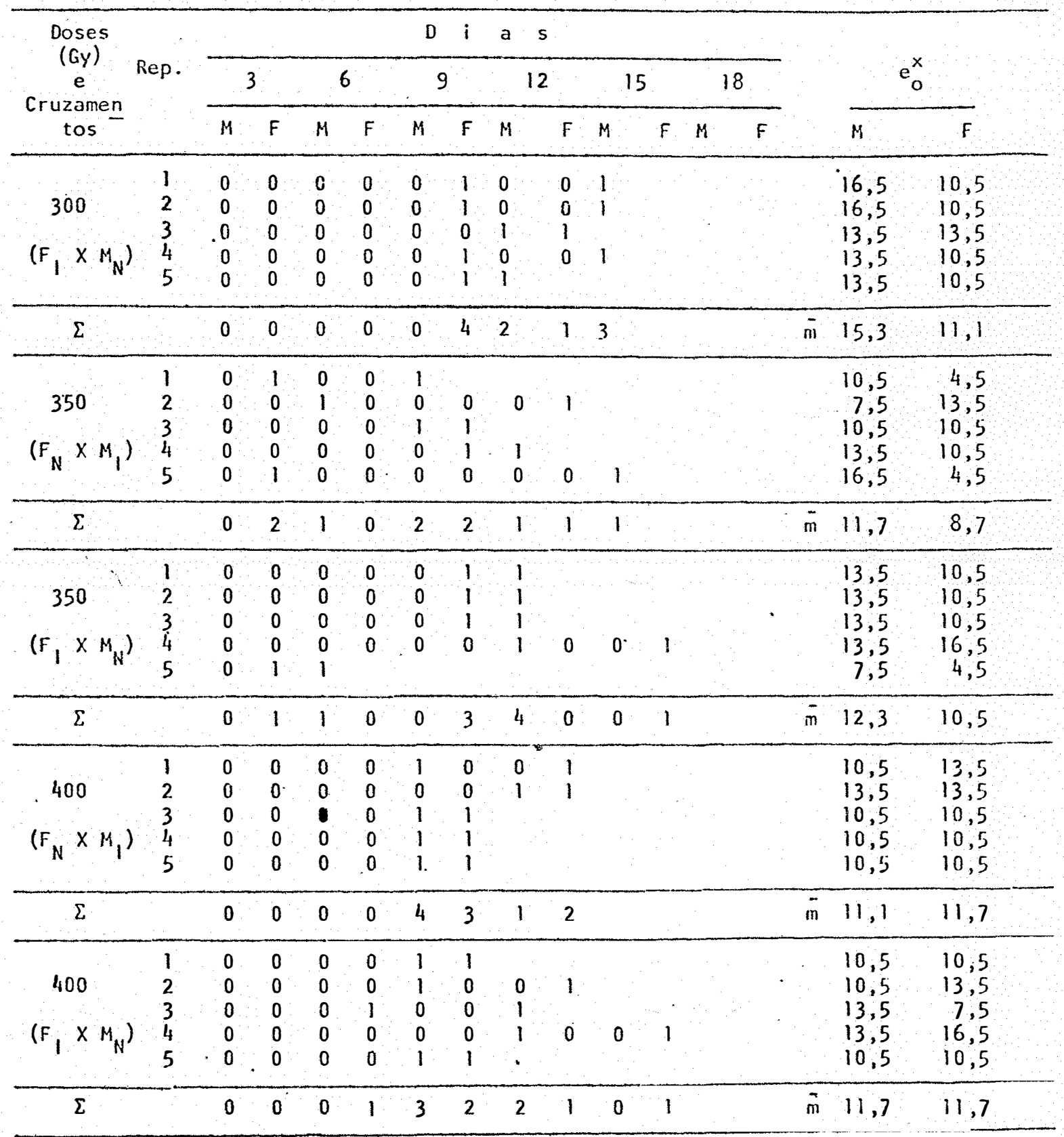

$M=$ Macho; $F=$ Fêmea $; \quad I=1 \mathrm{rradiado} ; N=N$ õo $\mathrm{irradiado.}$ 
Tabela 8 - Mortalidade de adultos (machos) de siceticga cehealella (oliv.) irradisdos e cruzados com fencas normais, e suas respectivas esperancas de vida. (Periodo de contagens: 3 dias; substrato de criação: milho). (Total = $\Sigma$, medias $=\bar{m})$.

\begin{tabular}{|c|c|c|c|c|c|c|c|c|c|c|c|c|c|c|c|c|}
\hline \multirow{3}{*}{$\begin{array}{c}\text { Doses } \\
\text { (Gy) } \\
e \\
\text { Cruzamen } \\
\text { tos }\end{array}$} & \multirow{3}{*}{ Rep. } & \multicolumn{12}{|c|}{$0 \quad i \quad a$} & & \multirow{2}{*}{\multicolumn{2}{|c|}{$e_{0}^{x}$}} \\
\hline & & \multicolumn{2}{|c|}{3} & \multicolumn{2}{|c|}{6} & \multicolumn{2}{|c|}{9} & \multicolumn{2}{|c|}{12} & \multicolumn{2}{|c|}{15} & \multicolumn{2}{|c|}{18} & & & \\
\hline & & $M$ & $\mathrm{~F}$ & $M$ & $F$ & $M$ & $F$ & $M$ & $\mathrm{~F}$ & $M$ & $F$ & $M$ & $F$ & & $M$ & $F$ \\
\hline \multirow{5}{*}{$\left(\begin{array}{c}400 \\
\left(F_{N} \times M_{1}\right)\end{array}\right.$} & 1 & 0 & 0 & 0 & 0 & 0 & 1 & 0 & 0 & 1 & & & & & 16,5 & 10,3 \\
\hline & 2 & 0 & 1 & 0 & 0 & 1 & & & & & & & & & 10,5 & 4,5 \\
\hline & 3 & 0 & 0 & 0 & 0 & 0 & 1 & 1 & & & & & & & 13,5 & 10,5 \\
\hline & 4 & 0 & 0 & 0 & 1 & 1 & & $\because$ & & & & . & & & 10,5 & 7,5 \\
\hline & 5 & 0 & 1 & 0 & 0 & 0 & 0 & 1 & & & & & & & 13,5 & 4,5 \\
\hline \multirow[t]{2}{*}{$\Sigma$} & & 0 & 2 & 0 & 1 & 2 & 2 & 2 & 0 & 1 & & & & $\bar{m}$ & 12,9 & 7,5 \\
\hline & 1 & 0 & 0 & 1 & 1 & & & & & & & & & & 7,5 & 7,5 \\
\hline \multirow{4}{*}{$\left(F_{N} \times M_{1}\right.$} & 2 & 0 & 0 & 0 & 0 & 1 & 1 & & & & & & & & 10,5 & 10,5 \\
\hline & 3 & 0 & 0 & 0 & 0 & 1 & 1 & & & & & & & & 10,5 & 10,5 \\
\hline & 4 & 0 & 1 & 0 & 0 & 0 & 0 & 1 & & & & & & : & 13,5 & 4,5 \\
\hline & 5 & 0 & 1 & 0 & ? & 0 & 0 & 1 & & & & & & & 13,5 & 4,5 \\
\hline \multirow[t]{2}{*}{$\Sigma$} & & 0 & 2 & 1 & 1 & 2 & 2 & 2 & & & & & & $\overline{\mathrm{m}}$ & 11,1 & 7,5 \\
\hline & 1 & 0 & 0 & 0 & 0 & 1 & 0 & 0 & 1 & & & & & & 10,5 & 13,5 \\
\hline \multirow{4}{*}{$\left(F_{N} \times M_{1}\right.$} & 2 & 0 & 0 & 0 & 0 & 0 & 0 & 1 & 1 & & & & & & 13,5 & 13,5 \\
\hline & 3 & 0 & 0 & 0 & 0 & 1 & 1 & & & & & & & & 10,5 & 10,5 \\
\hline & 4 & 1 & 0 & 0 & 0 & 0 & 0 & 0 & 1 & & & & & & 4,5 & 13,5 \\
\hline & 5 & 1 & 0 & 0 & 0 & 0 & 0 & 0 & 1 & & & & & & 4,5 & 13,5 \\
\hline \multirow[t]{2}{*}{$\Sigma$} & & 2 & 0 & 0 & 0 & 2 & 1 & 1 & 4 & & & & & ni & 8,7 & 10,8 \\
\hline & 1 & 0 & 0 & 1 & 1 & & & & & & & & & & 7,5 & 7,5 \\
\hline \multirow{4}{*}{$\begin{array}{c}550 \\
\left(F_{N} \times M_{1}\right.\end{array}$} & 2 & 1 & 1 & & & & & & & & & & & & 4,5 & 4,5 \\
\hline & 3 & 0 & 0 & 0 & 0 & 1 & 1 & & & & & & & & 10,5 & 10,5 \\
\hline & 4 & 0 & 0 & 0 & 0 & 1 & 1 & & & & & & & & 10,5 & 10,5 \\
\hline & 5 & 0 & 1 & 1 & & & & & & & & & & & $7,5^{\pi}$ & 4,5 \\
\hline$\Sigma$ & & 1 & 2 & 2 & 1 & 2 & 2 & & & & & & & $\overline{\mathrm{m}}$. & 8.1 & 7,5 \\
\hline
\end{tabular}


Tabela 9 - Numero de ovos viáveis, inviäveis e adultos da geração $\left(F_{1}\right)$, provenientes de adultos de Sitothoga cerealefla (0liv.) irra diados e cruzados com os normais. (Substrato de criação: mi1ho). (Total $=\Sigma$, médias $=\bar{m}$ ).

\begin{tabular}{|c|c|c|c|c|}
\hline $\begin{array}{l}\text { Doses (Gy) } \\
\text { (Cruzamento) }\end{array}$ & $\begin{array}{l}\text { Repeti- } \\
\text { çöes }\end{array}$ & $\begin{array}{c}\text { Ovos } \\
\text { viāveis }\end{array}$ & $\begin{array}{c}\text { Ovos } \\
\text { inviäveis }\end{array}$ & $F_{1}$ \\
\hline$\left(\begin{array}{c}0 \\
\left(F_{N} \times M_{N}\right)\end{array}\right.$ & $\begin{array}{l}1 \\
2 \\
3 \\
4 \\
5\end{array}$ & $\begin{array}{r}126 \\
172 \\
198 \\
0 \\
121\end{array}$ & $\begin{array}{r}6 \\
39 \\
9 \\
0 \\
40\end{array}$ & $\begin{array}{r}115 \\
151 \\
167 \\
0 \\
109\end{array}$ \\
\hline$\Sigma(\bar{m})$ & & $617(123,4)$ & $94(18,8)$ & 542 \\
\hline$\left(F_{N}^{200} \times M_{1}\right)$ & $\begin{array}{l}1 \\
2 \\
3 \\
4 \\
5\end{array}$ & $\begin{array}{r}126 \\
100 \\
45 \\
127 \\
60\end{array}$ & $\begin{array}{l}44 \\
59 \\
60 \\
35 \\
25\end{array}$ & $\begin{array}{r}26 \\
11 \\
1 \\
22 \\
2\end{array}$ \\
\hline$\Sigma(\overline{i n})$ & & $458(91,6)$ & $223(44,6)$ & 62 \\
\hline$\frac{200}{\left(F_{1} \times M_{N}\right)}$ & $\begin{array}{l}1 \\
2 \\
3 \\
4 \\
5\end{array}$ & $\begin{array}{l}23 \\
3 \\
0 \\
0 \\
0\end{array}$ & $\begin{array}{r}146 \\
0 \\
0 \\
0 \\
0\end{array}$ & $\begin{array}{l}0 \\
0 \\
0 \\
0 \\
0\end{array}$ \\
\hline$\Sigma(\bar{m})$ & . & $26 \quad(5,2)$ & $146(29,2)$ & 0 \\
\hline $\begin{array}{c}250 \\
\left(F_{N} \times M_{i}\right)\end{array}$ & $\begin{array}{l}1 \\
2 \\
3 \\
4 \\
5\end{array}$ & $\begin{array}{r}39 \\
0 \\
87 \\
98 \\
0\end{array}$ & $\begin{array}{r}39 \\
0 \\
84 \\
45 \\
0\end{array}$ & $\begin{array}{r}8 \\
0 \\
9 \\
12 \\
0\end{array}$ \\
\hline$\Sigma(\bar{m})$ & & $224(44,8)$ & $168(33,6)$ & 29 \\
\hline $\begin{array}{c}250 \\
\left(F_{1} \times M_{N}\right)\end{array}$ & $\begin{array}{l}1 \\
2 \\
3 \\
4 \\
5\end{array}$ & $\begin{array}{r}0 \\
8 \\
0 \\
47 \\
0\end{array}$ & $\begin{array}{r}27 \\
175 \\
108 \\
112 \\
0\end{array}$ & $\begin{array}{l}0 \\
0 \\
0 \\
2 \\
0\end{array}$ \\
\hline$\Sigma(\bar{m})$ & & $55(11,0)$ & $422(84,4)$ & 2 \\
\hline $\begin{array}{c}300 \\
\left(F_{N} \times M_{1}\right)\end{array}$ & $\begin{array}{l}1 \\
2 \\
3 \\
4 \\
5\end{array}$ & $\begin{array}{l}53 \\
39 \\
45 \\
58 \\
60\end{array}$ & $\begin{array}{l}86 \\
45 \\
50 \\
68 \\
74\end{array}$ & $\begin{array}{l}1 \\
0 \\
0 \\
0 \\
0\end{array}$ \\
\hline$\Sigma(\bar{m})$ & & $255(45,0)$ & $323(64,6)$ & 1 \\
\hline
\end{tabular}


Tabela 9 - Cont inuação.

\begin{tabular}{|c|c|c|c|c|}
\hline $\begin{array}{l}\text { Doses (Gy) } \\
\text { (Cruzamento) }\end{array}$ & $\begin{array}{l}\text { Repet i- } \\
\text { çöes }\end{array}$ & $\begin{array}{l}\text { Ovos } \\
\text { viáveis }\end{array}$ & $\begin{array}{l}\text { Ovos } \\
\text { inviăveis }\end{array}$ & $F_{1}$ \\
\hline $\begin{array}{c}300 \\
\left(F_{1} \times M_{N}\right)\end{array}$ & $\begin{array}{l}1 \\
2 \\
3 \\
4 \\
5\end{array}$ & $\begin{array}{r}31 \\
6 \\
45 \\
2 \\
0\end{array}$ & $\begin{array}{r}93 \\
127 \\
128 \\
244 \\
59\end{array}$ & $\begin{array}{l}7 \\
0 \\
2 \\
0 \\
0\end{array}$ \\
\hline$\Sigma(\bar{m})$ & & $84(16,8)$ & $651(130,2)$ & 9 \\
\hline $\begin{array}{c}350 \\
\left(F_{N} \times M_{1}\right)\end{array}$ & $\begin{array}{l}1 \\
2 \\
3 \\
4 \\
5\end{array}$ & $\begin{array}{r}0 \\
0 \\
18 \\
49 \\
70\end{array}$ & $\begin{array}{r}0 \\
10 \\
80 \\
98 \\
7\end{array}$ & $\begin{array}{l}0 \\
0 \\
0 \\
1 \\
20\end{array}$ \\
\hline$\Sigma(\bar{m})$ & & $137 \quad(27,4)$ & $195(39,0)$ & 21 \\
\hline $\begin{array}{c}350 \\
\left(F_{1} \times M_{N}\right)\end{array}$ & $\begin{array}{l}1 \\
2 \\
3 \\
4 \\
5\end{array}$ & $\begin{array}{l}0 \\
1 \\
0 \\
0 \\
0\end{array}$ & $\begin{array}{r}181 \\
156 \\
91 \\
144 \\
4\end{array}$ & $\begin{array}{l}0 \\
0 \\
0 \\
0 \\
0\end{array}$ \\
\hline$\Sigma(\bar{m})$ & & $1(0,2)$ & $612(122,4)$ & 0 \\
\hline $\begin{array}{c}400 \\
\left(F_{N} \times M_{1}\right)\end{array}$ & $\begin{array}{l}1 \\
2 \\
3 \\
4 \\
5\end{array}$ & $\begin{array}{r}25 \\
68 \\
111 \\
26 \\
6\end{array}$ & $\begin{array}{r}163 \\
9 \\
56 \\
173 \\
56\end{array}$ & $\begin{array}{l}0 \\
3 \\
1 \\
0 \\
0\end{array}$ \\
\hline$\Sigma(\bar{m})$ & & $236(47,2)$ & $457(91,4)$ & 4 \\
\hline $\begin{array}{c}400 \\
\left(F_{1} \times M_{N}\right)\end{array}$ & $\begin{array}{l}1 \\
2 \\
3 \\
4 \\
5\end{array}$ & $\begin{array}{l}3 \\
0 \\
0 \\
0 \\
0\end{array}$ & $\begin{array}{r}188 \\
15 \\
80 \\
0 \\
0\end{array}$ & $\begin{array}{l}0 \\
0 \\
0 \\
0 \\
0\end{array}$ \\
\hline$\sum(\overline{m i})$ & & $3(0,6)$ & $283(56,6)$ & 0 \\
\hline
\end{tabular}


Tabela 10 - Número de ovos vióveis, inviáveis e adultos da geração $\left(F_{1}\right)$, provenientes de adultos (machos) de Sitothoga ccreafelfa (oliv.) irradiados e cruzados con fêneas normais. (Substrato de criaçäo: milho). (Total $=\Sigma$, meedia $=\bar{n})$.

\begin{tabular}{|c|c|c|c|c|}
\hline $\begin{array}{l}\text { Doses (Gy) } \\
\text { (Cruzamento) }\end{array}$ & $\begin{array}{l}\text { Repeti- } \\
\text { çöes }\end{array}$ & $\begin{array}{l}\text { Ovas } \\
\text { viäveis }\end{array}$ & $\begin{array}{l}\text { Ovos } \\
\text { inviaveis }\end{array}$ & $F_{1}$ \\
\hline$\left(F_{N} \times M_{1}\right)$ & $\begin{array}{l}1 \\
2 \\
3 \\
4 \\
5\end{array}$ & $\begin{array}{r}0 \\
28 \\
0 \\
43 \\
7\end{array}$ & $\begin{array}{l}0 \\
93 \\
0 \\
90 \\
15\end{array}$ & $\begin{array}{l}0 \\
0 \\
0 \\
0\end{array}$ \\
\hline$\Sigma(\bar{m})$ & & $78(15,6)$ & $188(37,6)$ & 0 \\
\hline$\left(F_{N} \times M_{1}\right)$ & $\begin{array}{l}1 \\
2 \\
3 \\
4 \\
5\end{array}$ & $\begin{array}{r}43 \\
1 \\
0 \\
12 \\
4\end{array}$ & $\begin{array}{r}144 \\
26 \\
0 \\
110 \\
19\end{array}$ & $\begin{array}{l}1 \\
0 \\
0 \\
0 \\
0\end{array}$ \\
\hline$\Sigma(\bar{m})$ & & $60(12,0)$ & $269(53,8)$ & 1 \\
\hline$\left(F_{N} \times M_{1}\right)$ & $\begin{array}{l}1 \\
2 \\
3 \\
4 \\
5\end{array}$ & $\begin{array}{l}0 \\
0 \\
9 \\
0 \\
2\end{array}$ & $\begin{array}{r}0 \\
132 \\
72 \\
0 \\
24\end{array}$ & $\begin{array}{l}0 \\
0 \\
0 \\
0 \\
0\end{array}$ \\
\hline$\Gamma(\bar{m})$ & & $11 \quad(2,2)$ & $228(45,6)$ & 0 \\
\hline$\left(F_{N} \times M_{1}\right)$ & $\begin{array}{l}1 \\
2 \\
3 \\
4 \\
5\end{array}$ & $\begin{array}{l}0 \\
0 \\
0 \\
9 \\
0\end{array}$ & $\begin{array}{r}32 \\
0 \\
0 \\
142 \\
0\end{array}$ & $\begin{array}{l}0 \\
0 \\
0 \\
0 \\
0\end{array}$ \\
\hline$\Sigma(\bar{m})$ & & $9(1,8)$ & $174(34,8)$ & 0 \\
\hline
\end{tabular}


Tabela 11 - Medios das esperangas oc vida (e ${ }_{0}^{x}$ ) para aunltos de Sitotroga cchenfelfa (0liv) irradiados e cruzados conforme indicaşa e suas respectivas onälises c diferenças estatísticas.

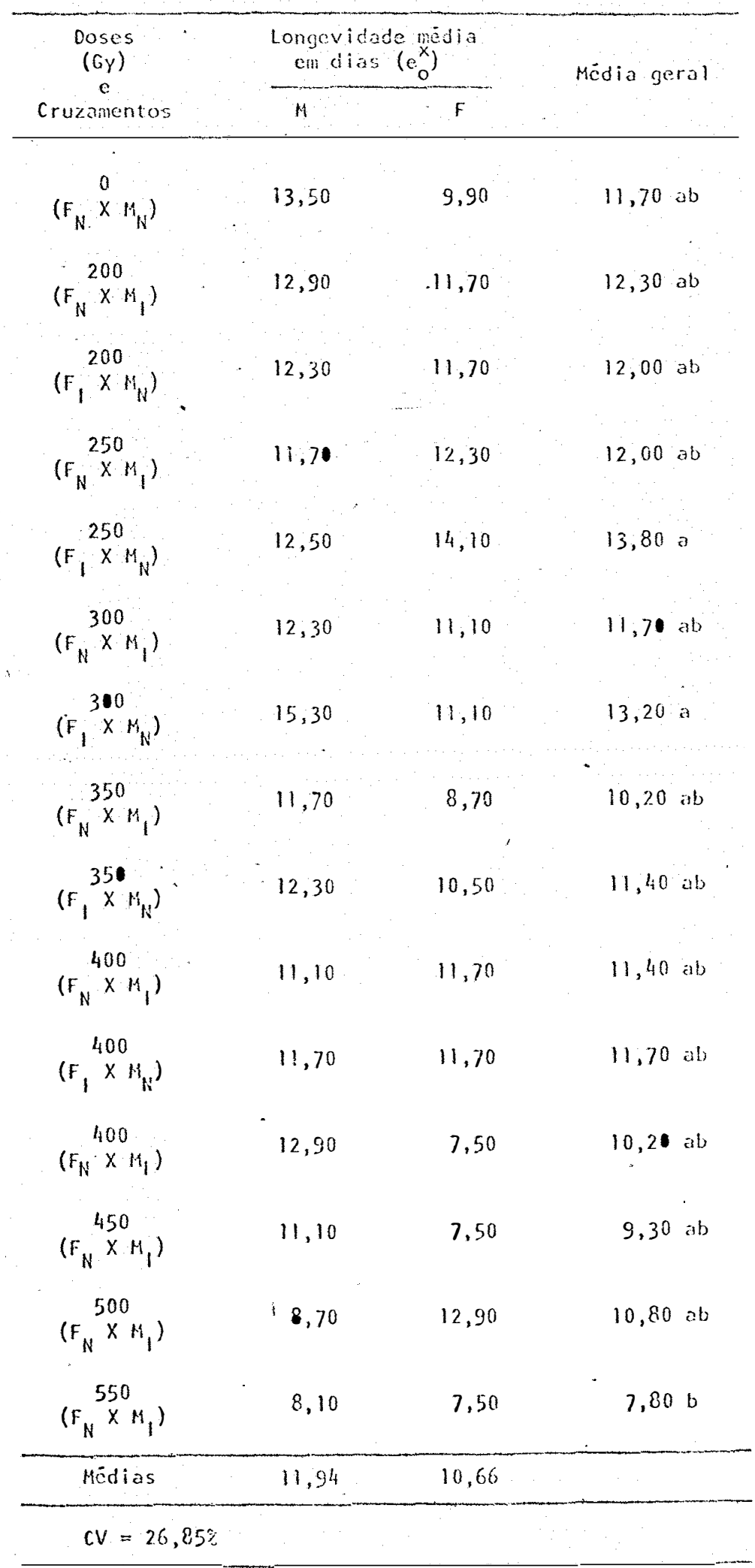

Os tratamentos de mesma letra nä́o diferen entre si. (Tukey 5\%). 


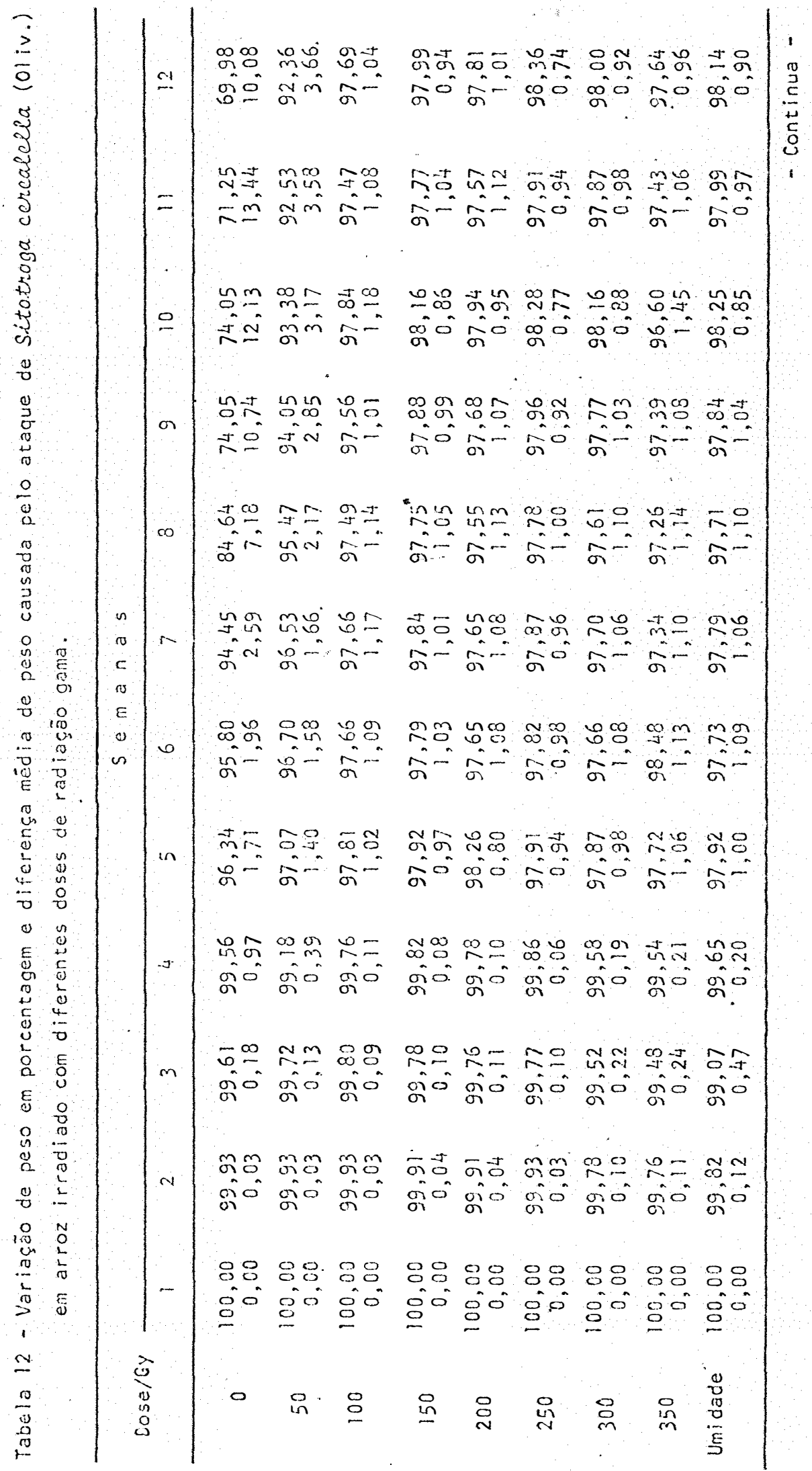




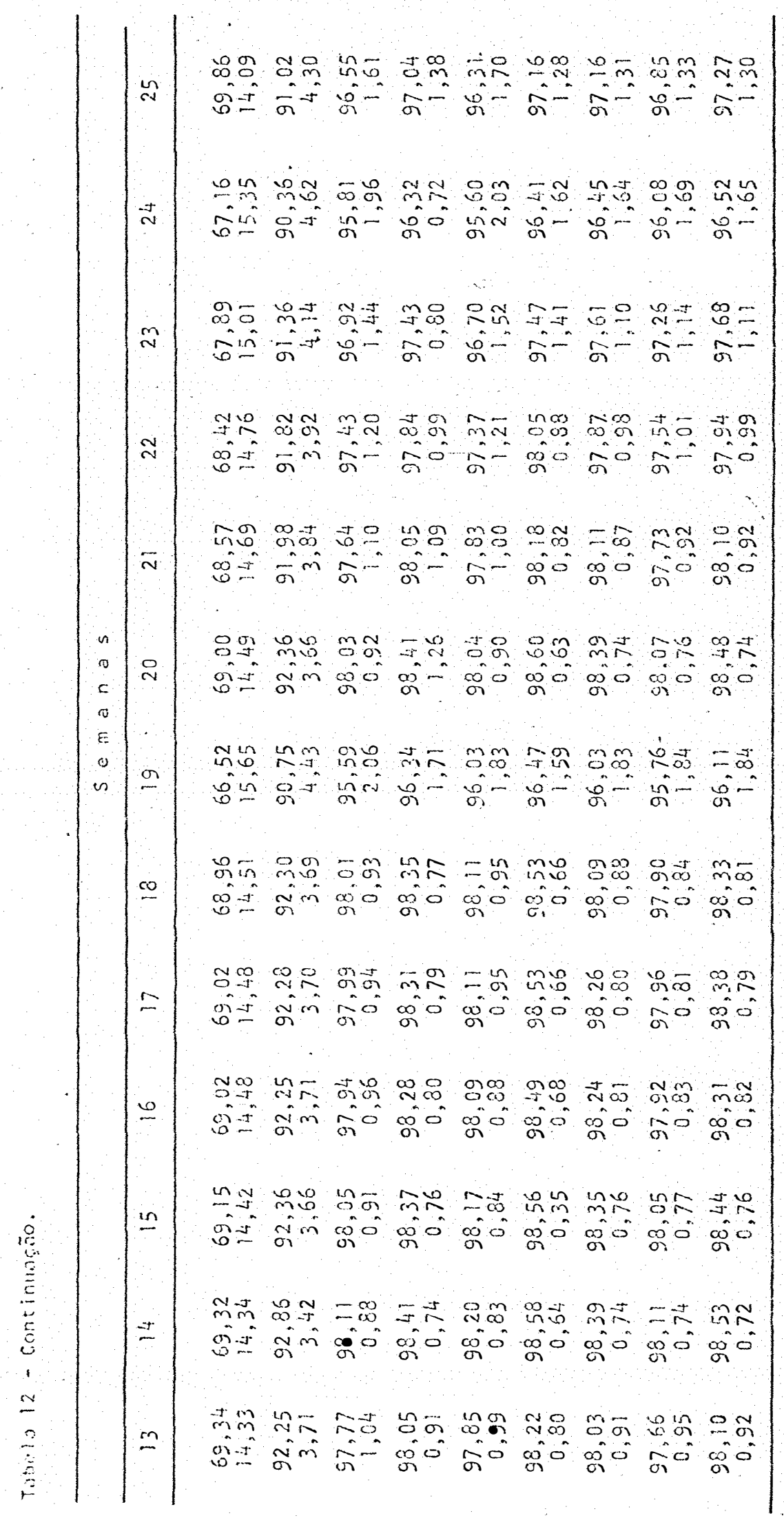




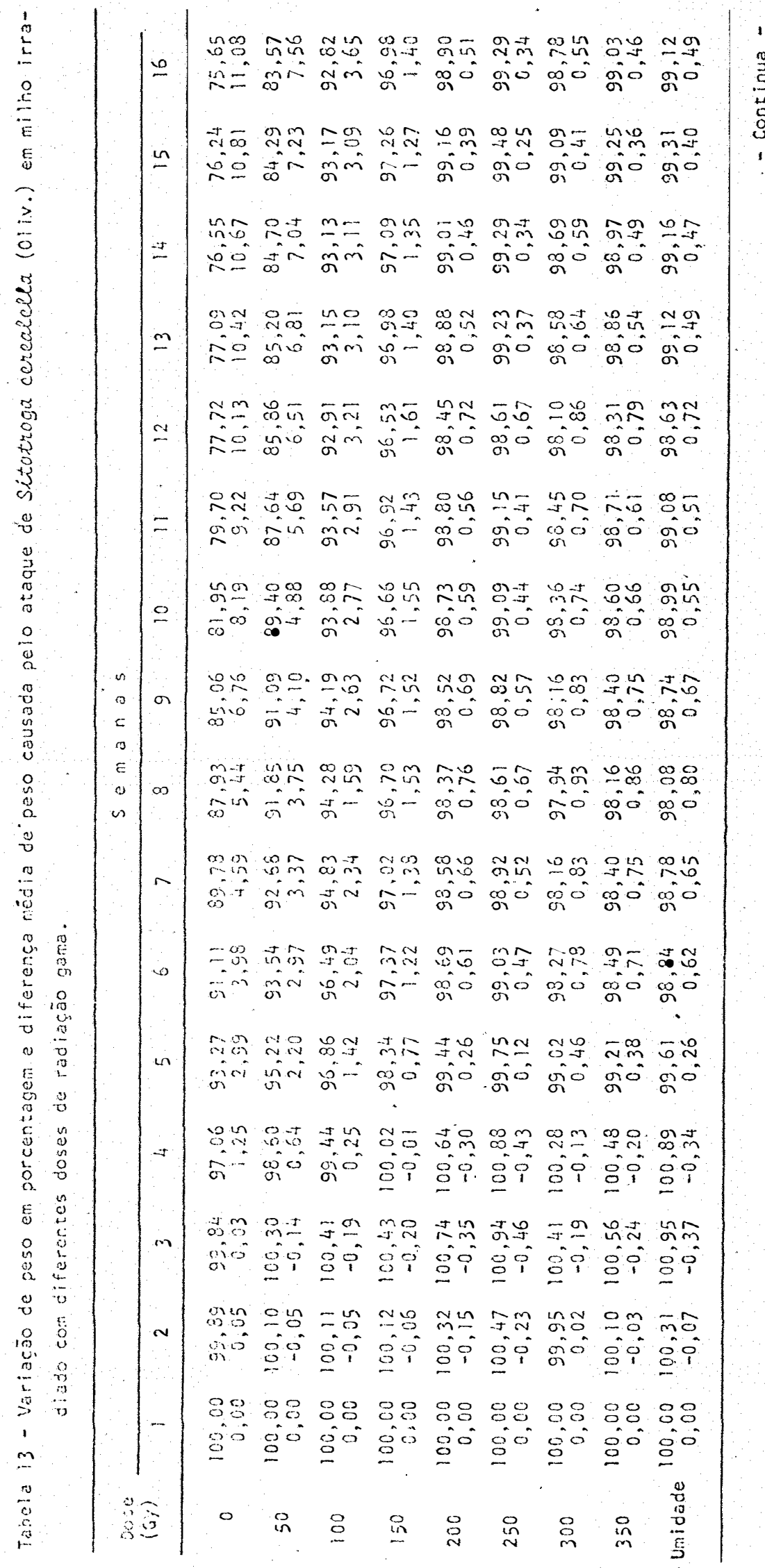

.40 


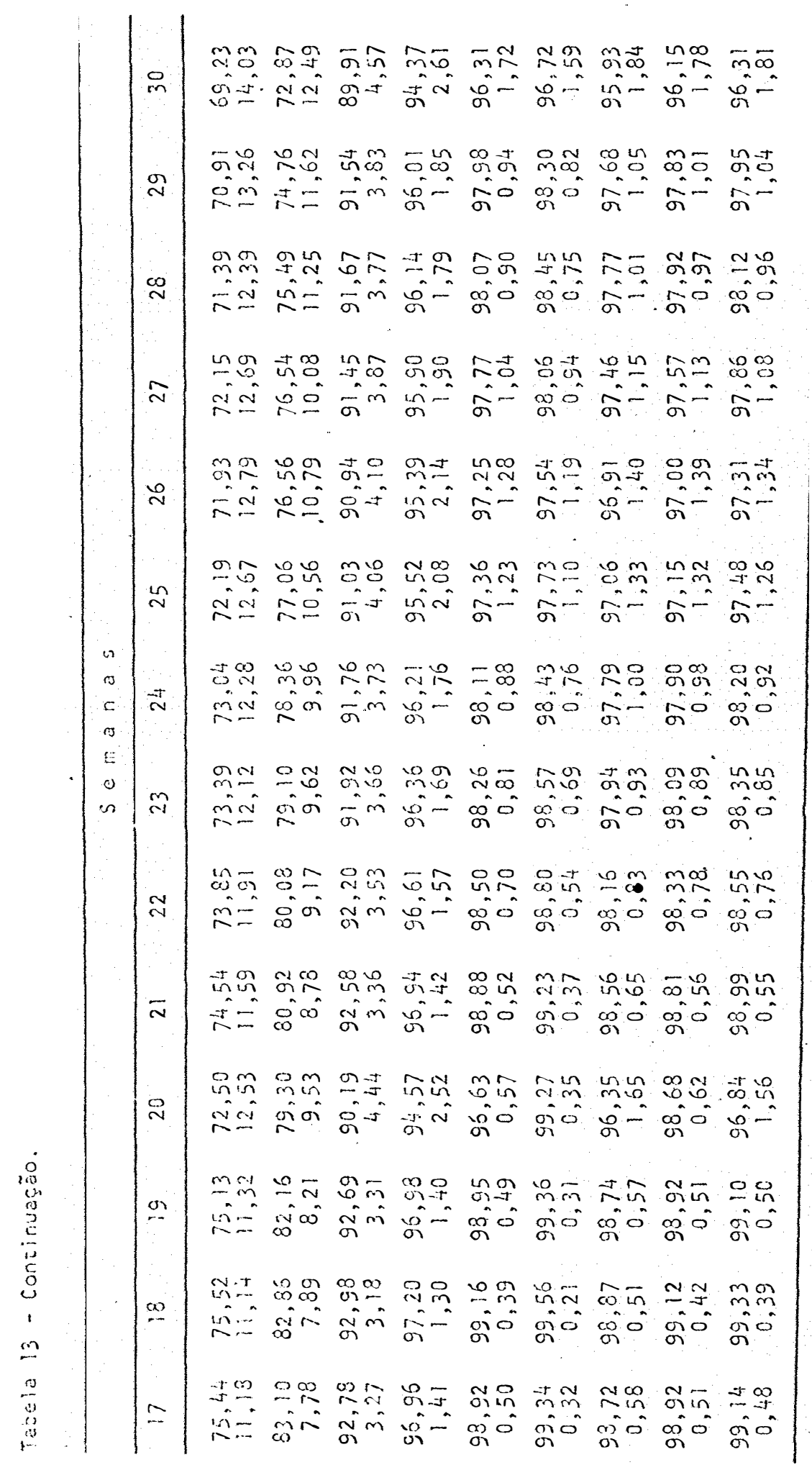


.42 .

Tabela 14 - Mortalidade de adultos de Sitotroga cerealella (01iv.) irra diados com doses crescentes de radiação gama. $($ Total $=\Sigma)$, provenientes do substrato de arroz.

\begin{tabular}{|c|c|c|c|c|c|c|c|c|c|c|c|c|}
\hline \multirow{3}{*}{$\begin{array}{c}\text { Doses } \\
(G y)\end{array}$} & \multicolumn{12}{|c|}{$R \in p e t i c$ o e s } \\
\hline & \multicolumn{2}{|c|}{1} & \multicolumn{2}{|c|}{2} & \multicolumn{2}{|c|}{3} & \multicolumn{2}{|c|}{4} & \multicolumn{2}{|c|}{5} & \multicolumn{2}{|c|}{6} \\
\hline & $M$ & $F$ & $M$ & $F$ & $M$ & $F$ & $M$ & $F$ & $M$ & $F$ & $M$ & $F$ \\
\hline
\end{tabular}

$\begin{array}{lllllllllllll}2.000 & 0 & 0 & 0 & 0 & 0 & 0 & 0 & 0 & 0 & 0 & 0 & 0\end{array}$

$\begin{array}{lllllllllllll}2.250 & 0 & 0 & 0 & 0 & 0 & 0 & 0 & 0 & 0 & 0 & 0 & 0\end{array}$

$\begin{array}{lllllllllllll}2.500 & 0 & 0 & 0 & 0 & 0 & 0 & 0 & 0 & 0 & 0 & 0 & 0\end{array}$

$\begin{array}{lllllllllllll}2.750 & 0 & 0 & 0 & 1 & 0 & 0 & 0 & 0 & 0 & 2 & 0 & 0 .\end{array}$

$\begin{array}{lllllllllllll}3.000 & 0 & 1 & 1 & 1 & 0 & 0 & 0 & 1 & 0 & 1 & 0 & 2\end{array}$

$\begin{array}{lllllllllllll}3.250 & 1 & 0 & 0 & 0 & 0 & 1 & 0 & 1 & 0 & 1 & 0 & 2\end{array}$

$\begin{array}{lllllllllllll}3.500 & 0 & 0 & 0 & 2 & 0 & 1 & 2 & 0 & 1 & 1 & 0 & 2\end{array}$

$\begin{array}{lllllllllllll}3.750 & 0 & 0 & 4 & 0 & 2 & 0 & 2 & 2 & 2 & 1 & 3 & 2\end{array}$

$\begin{array}{lllllllllllll}4.000 & 6 & 1 & 3 & 0 & 2 & 4 & 1 & 0 & 4 & 2 & 0 & 2\end{array}$

$\begin{array}{lllllllllllll}4.250 & 1 & 2 & 1 & 1 & 0 & 2 & 1 & 1 & 0 & 0 & 0 & 2\end{array}$

$\begin{array}{lllllllllllll}4.500 & 0 & 3 & 1 & 0 & 0 & 2 & 1 & 1 & 0 & 1 & 0 & 2\end{array}$

$\begin{array}{lllllllllllll}4.750 & 0 & 0 & 0 & 0 & 0 & 1 & 0 & 2 & 0 & 0 & 0 & 0\end{array}$

$\begin{array}{llllllllllllll}\Sigma & 8 & 7 & 10 & 5 & 4 & 11 & 7 & 8 & 6 & 9 & 3 & 14\end{array}$ 
Tabela 15 - Mortalidade de adultos de Sitotroga cerealella (01iv.) irra diados com doses crescentes de radiação gama. $($ Tota $)=\Sigma)$, provenientes do substrato de milho.

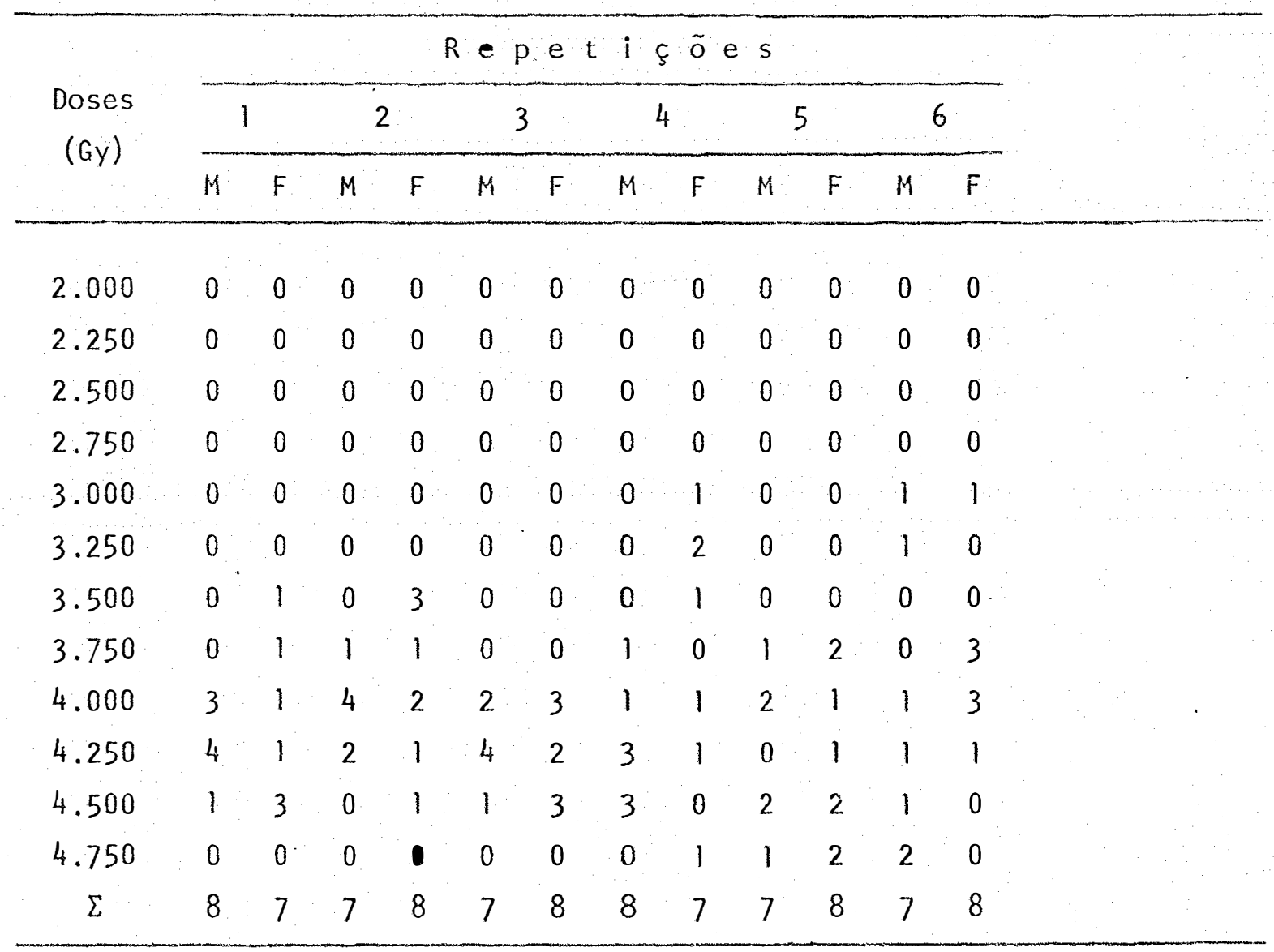


Tabela 16 - Dados de nortalidacic em porcentagem de Sitotroga cerealelka (01iv.) provenicntes dos substrates arroz e milho, quando irradiados con di ferentes doses de radiação gama.

\begin{tabular}{|c|c|c|c|c|c|c|c|c|}
\hline \multirow{3}{*}{$\begin{array}{l}\text { Dose } \\
\text { (Gy) }\end{array}$} & \multicolumn{4}{|c|}{ Substrato: Arroz } & \multicolumn{4}{|c|}{ Substrato: Milho } \\
\hline & \multicolumn{2}{|r|}{$M$} & \multicolumn{2}{|r|}{$F$} & \multicolumn{2}{|c|}{$M$} & \multicolumn{2}{|c|}{$F$} \\
\hline & vivos & $\frac{\%}{\text { mortos }}$ & vivos & mortos & vivos & mortos & vivos & mortos \\
\hline 2000 & $100,00^{\circ}$ & 0,00 & 100,00 & 0,00 & 100,00 & $\bullet, 00$ & 100,00 & 0,00 \\
\hline 2250 & 100,00 & 0,00 & 100,0 & 0,00 & 100,00 & 0,0 & 100,00 & 0,00 \\
\hline 2500 & 100,00 & 0,00 & 100,00 & 0,00 & 100,00 & 0,00 & 100,00 & 0,00 \\
\hline 2750 & 100,00 & 0,00 & 94,54 & 5,45 & 100,00 & 0,00 & 100,00 & 0,00 \\
\hline 300 & 97,36 & 2,63 & 83,63 & 16,36 & 97,73 & 2,27 . & 95,40 & $4,44_{4}$ \\
\hline 3250 & 94,73 & 5,26 & 72,72 & 27,27 & 35,46 & 4,54 & 91,11 & 8,88 \\
\hline 3500 & 89,47 & 10,52 & 61,81 & 38,18 & 93,19 & 6,81 & 82,22 & 17,77 \\
\hline 3750 & 55,26 & 44,73 & 52,72 & 47,27 & 86,34 & 13,63 & 66,67 & 33,33 \\
\hline 400 & 13,15 & 86,84 & 36,36 & 63,63 & 56,82 & 43,18 & 42,22 & $5 \%, 77$ \\
\hline 4250 & 5,26 & 94,73 & 21,81 & 78,18 & 25,00 & 75,00 & 26,66 & 73,33 \\
\hline 4500 & 0,00 & 100,00 & 5,45 & 34,54 & 6,82 & 93,18 & 6,66 & 33,33 \\
\hline 4750 & & & 0,00 & 100,00 & 0,00 & 100,00 & 0,00 & 100,00 \\
\hline
\end{tabular}


Tabela 17 - Dose letal calculada a partir dos dados das Tabelas 14 e 15 para adultos de Sitotroga cerealella (01iv.) quando submeti dos a doses crescentes de radiação gama.

\begin{tabular}{|c|c|c|c|c|}
\hline \multirow{3}{*}{ Rep. } & \multicolumn{4}{|c|}{ Dose letal calculada (Gy) } \\
\hline & \multicolumn{2}{|c|}{ Substrato: Arroz } & \multicolumn{2}{|c|}{ Substrato: Milho } \\
\hline & $M$ & $\mathrm{~F}$ & $M$ & $\mathrm{~F}$ \\
\hline 1 & 4062,50 & 4267,90 & 4312,50 & 4267,90 \\
\hline 2 & 4000,00 & 3525,00 & 4160,70 & 4000,00 \\
\hline 3 & 4000,00 & 4215,90 & 4339,30 & 4375,00 \\
\hline 4 & 4017,90 & 4125,00 & 4375,00 & 3839,30 \\
\hline 5 & 4041,70 & 3625,00 & 4267,90 & 4406,20 \\
\hline 6 & 3875,00 & 3875,00 & 4196,40 & 3937,50 \\
\hline$\overline{\mathrm{m}}$ & 3999,50 & 3939,00 & 4275,30 & 4137,70 \\
\hline
\end{tabular}


Tabela 18 - Médias calculadas das doses letais de radiação gama em (Gy) para Sitotroga cerealella (01iv.) e suas respectivas anälises e diferenças estatísticas.

\begin{tabular}{|c|c|c|c|c|}
\hline \multirow{3}{*}{$\begin{array}{l}\text { Repeti- } \\
\text { çôes }\end{array}$} & \multicolumn{4}{|c|}{ Substratos } \\
\hline & Arroz/Milho & Arroz/Milho & Arroz & Milho \\
\hline & $M$ & $F$ & $M e F$ & $M e F$ \\
\hline 1 & 4187,50 & 4267,90 & 4165,20 & 4298,20 \\
\hline 2 & 4083,00 & 3762,50 & 3762,50 & 4080,30 \\
\hline 3 & 4169,60 & 4295,40 & 4107,90 & 4357,10 \\
\hline 4 & 4196,40 & 3982,10 & 4071,40 & 4107,10 \\
\hline 5 & 4154,80 & 4015,60 & 3833,30 & 4337,00 \\
\hline 6 & 4035,70 & 3906,20 & 3875,00 & 4066,90 \\
\hline Arroz & $3999,50 \mathrm{~b}$ & 3938,90 a & $3939,00 \mathrm{a}$ & $4137,60 a$ \\
\hline Milho & $4275,30 a$ & $4137,60 a$ & 3999,50 a & $4275,30 a$ \\
\hline CV & $1,82 \%$ & $6,95 \%$ & $3,61 \%$ & $4,31 \%$ \\
\hline
\end{tabular}

Os tratamentos de mesma letra não diferem entre si (Tukey $5 \%$ ). 
.47.
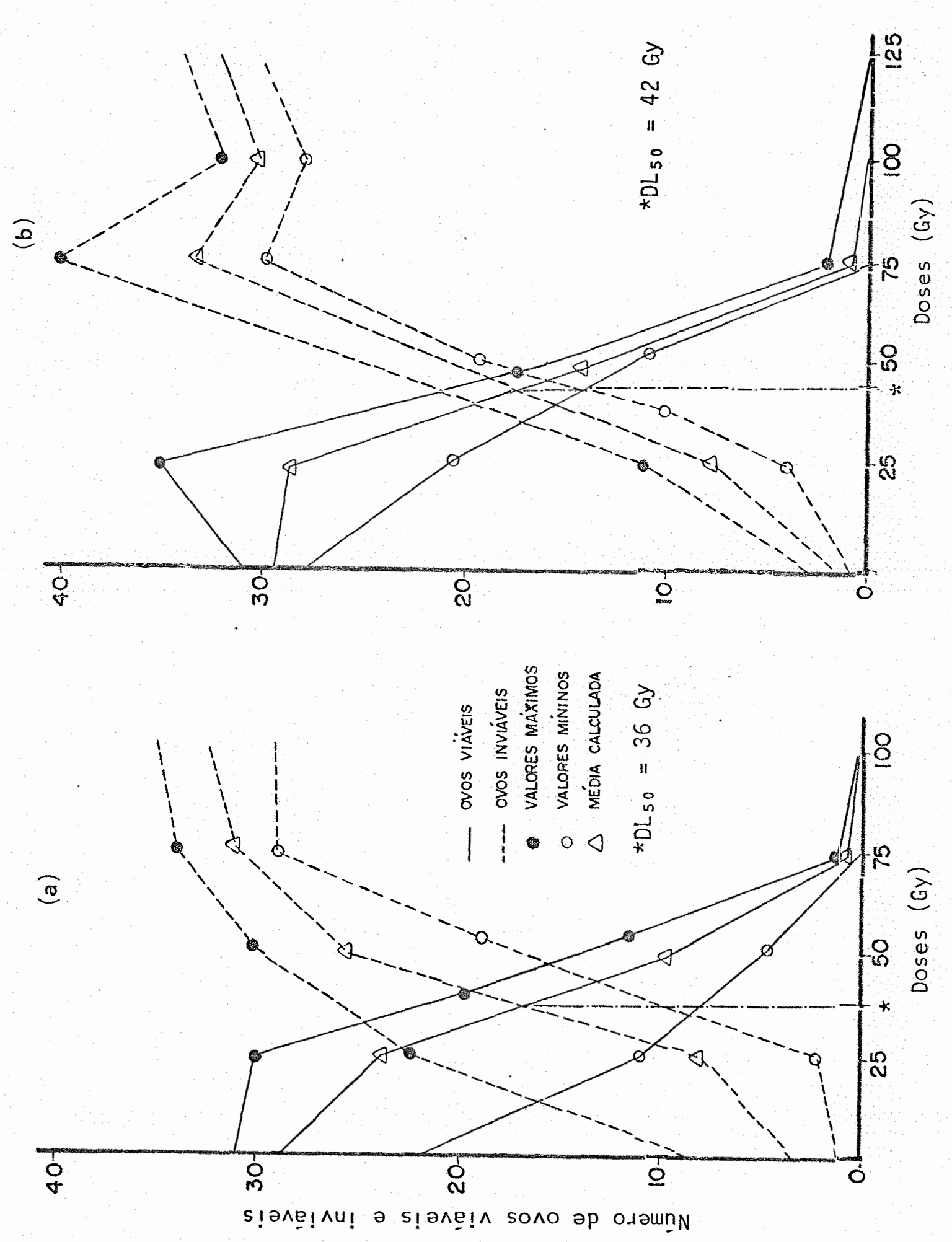

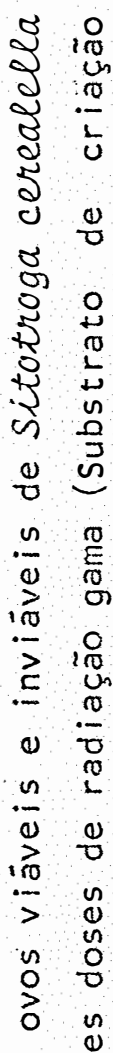
D 인 is 0

ㅇ 음

i)

in $\frac{0}{0}$

ए 20

$>1$

1) $\quad$ 눈

$\because \geq \frac{1}{0}$

$\overline{0} \overline{0}$

$-$

$\frac{0}{5}$ 

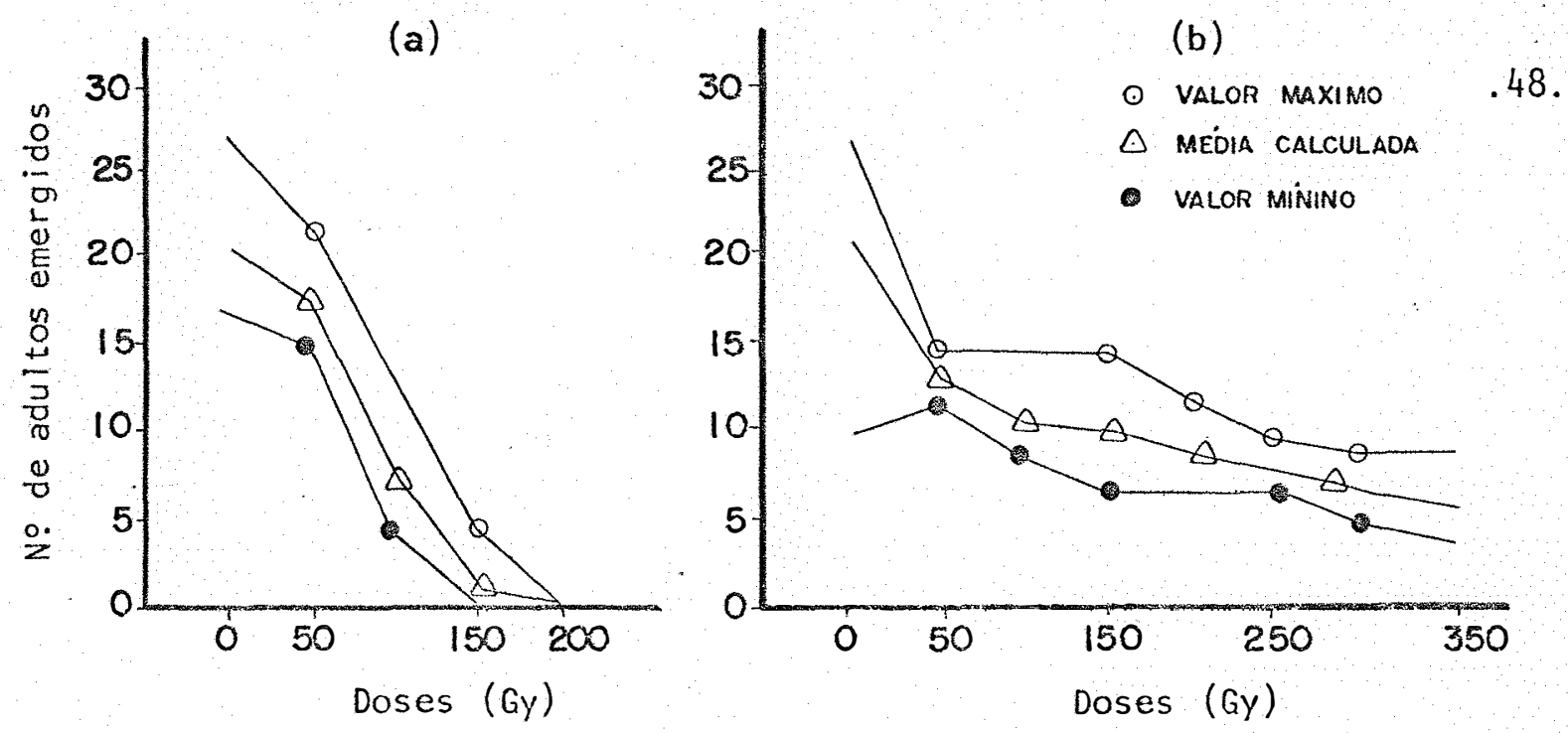

Figura 2 - Mëdias e variações numéricas de emergência de adultos de Sitotroga cerealella (oliv.) quando irradiados nas fases de lagartas e crisálidas (a) e (b) (Substrato de criação: arroz).
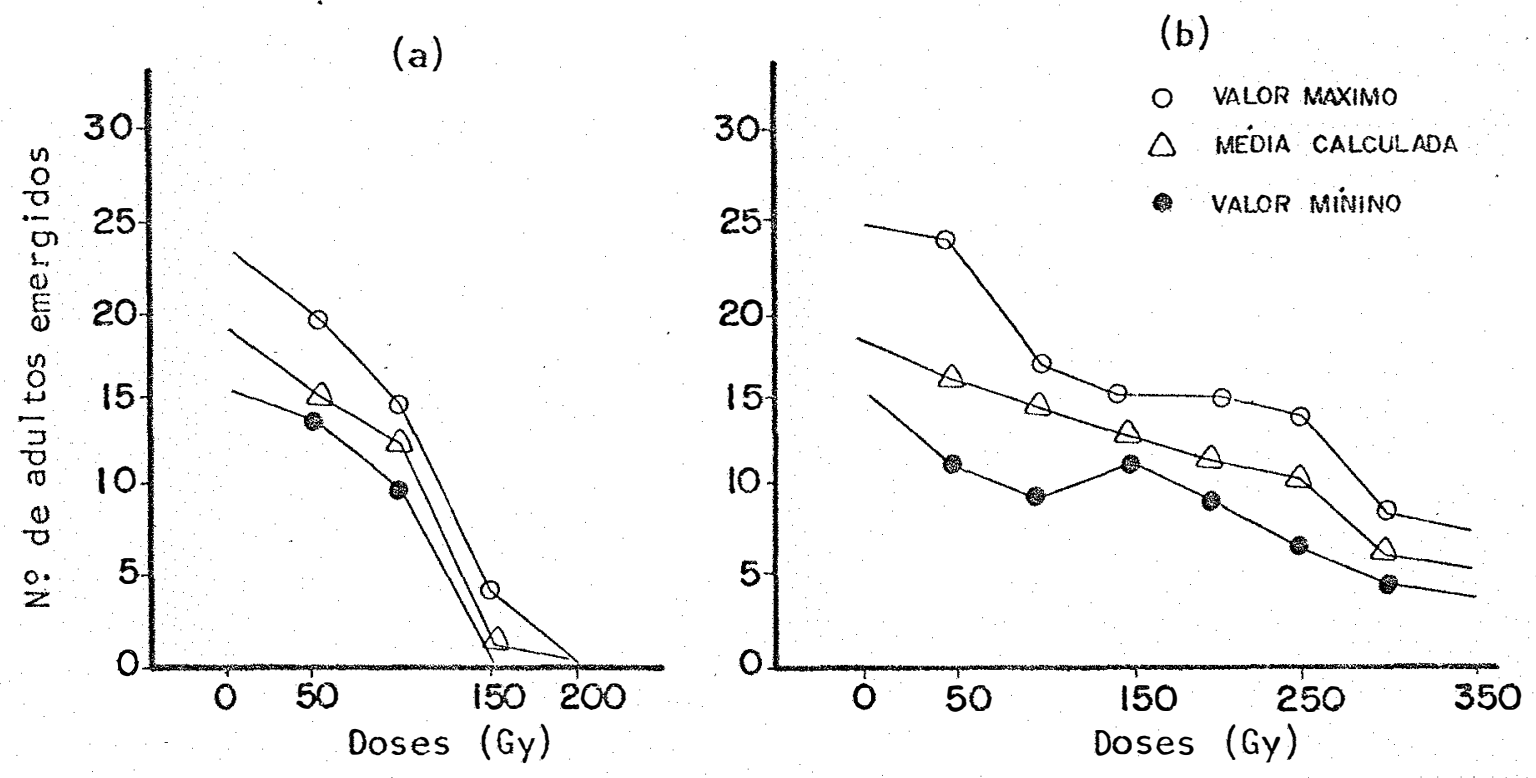

Figura 3 - Médias e variações numéricas de emergência de adultos de Sitotroga cerealella (01iv.) quando irradiados nas fases de lagartas e crisālidas (a) e (b) (Substrato de criação: milho). 


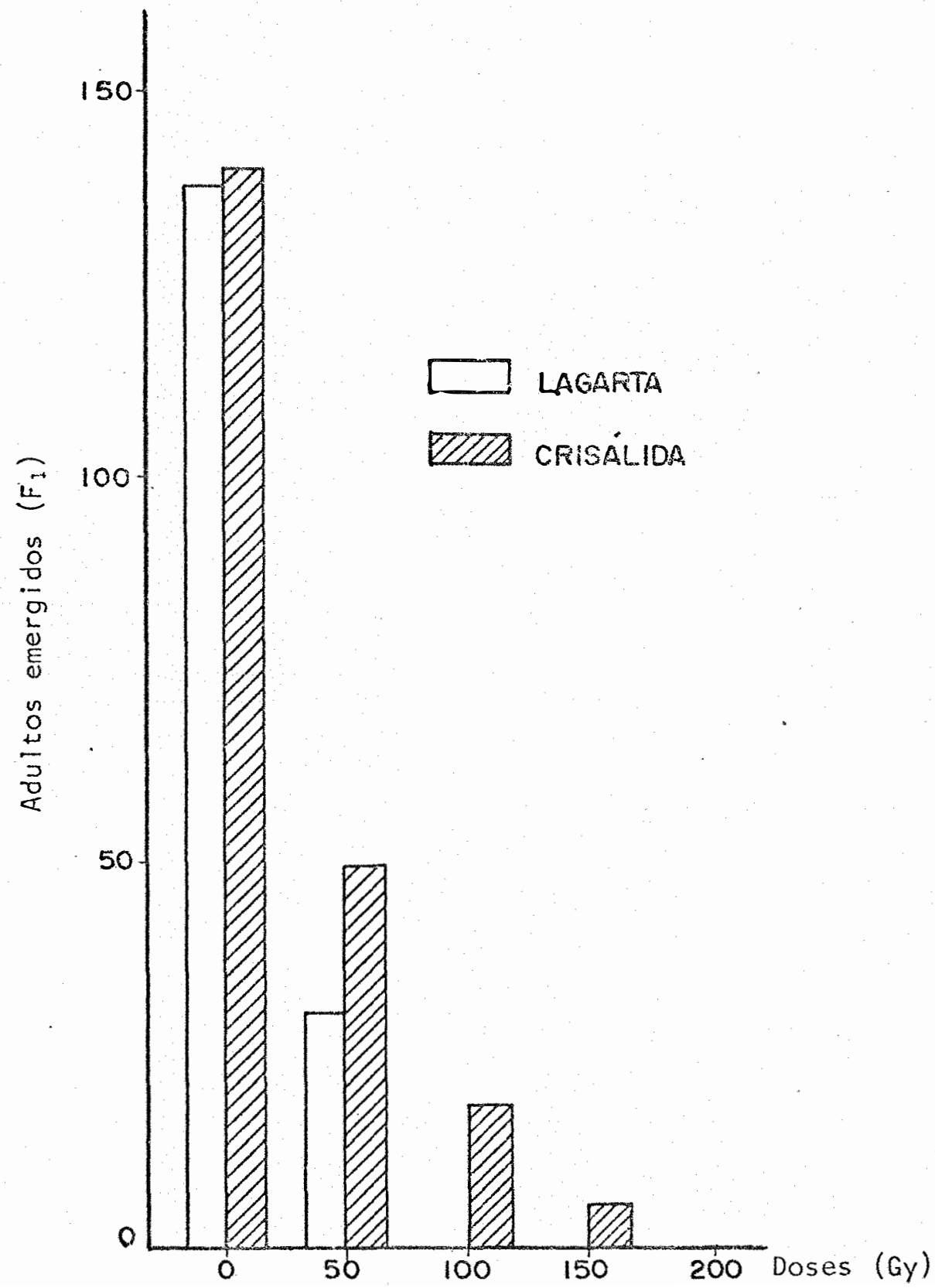

Figura 4 - Nümero de insetos da geração filial $\left(F_{1}\right)$ de Sitotroga cerealella (0liv.), provenientes de lagartas e crisālidas irradia das em arroz. 
.50 .

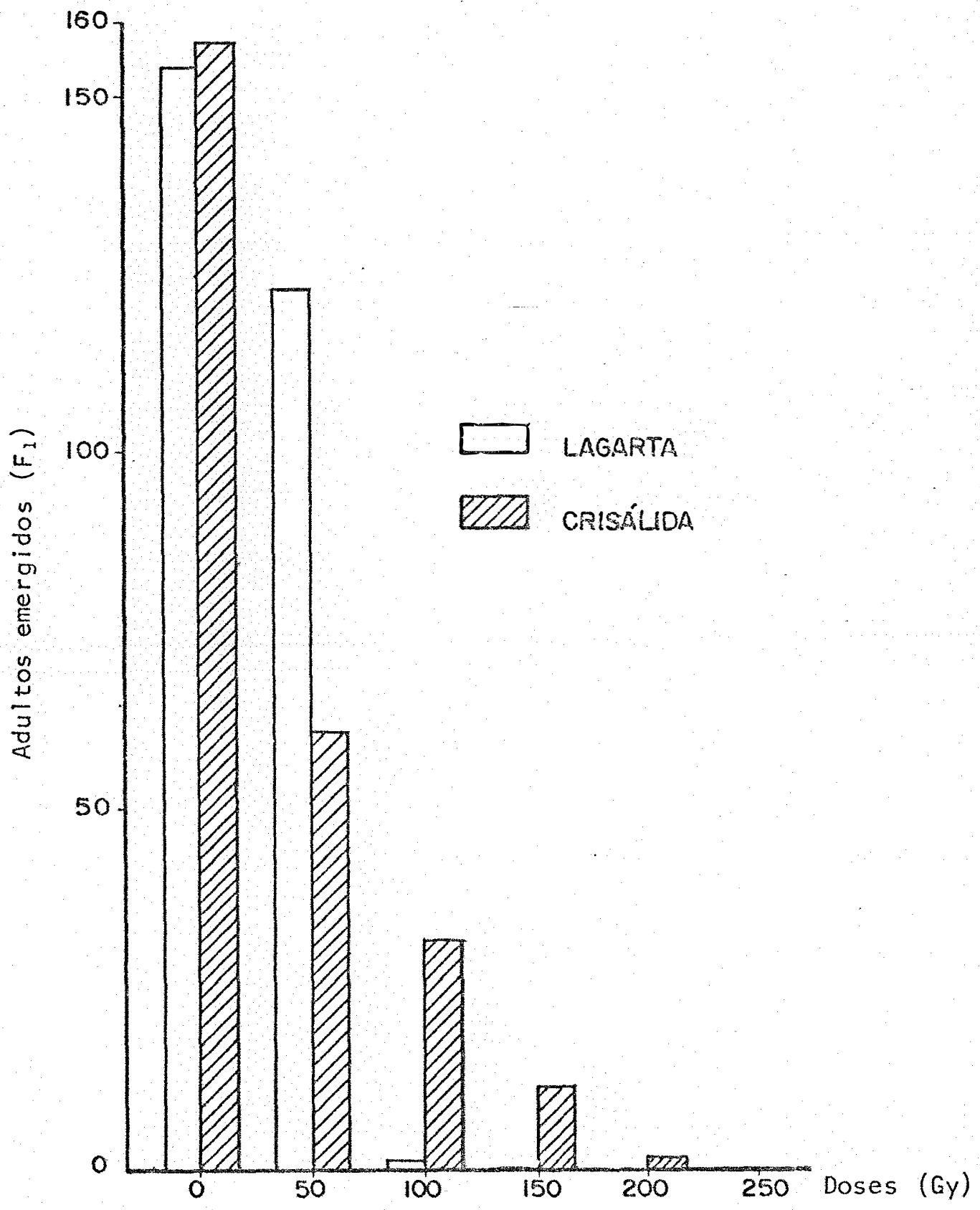

Figura 5 - Nümeros de insetos da geração filial $\left(F_{1}\right)$ de Sitotro ga cerealella (0liv.) provenientes de lagartas e cri sälidas irradiadas em milho. 


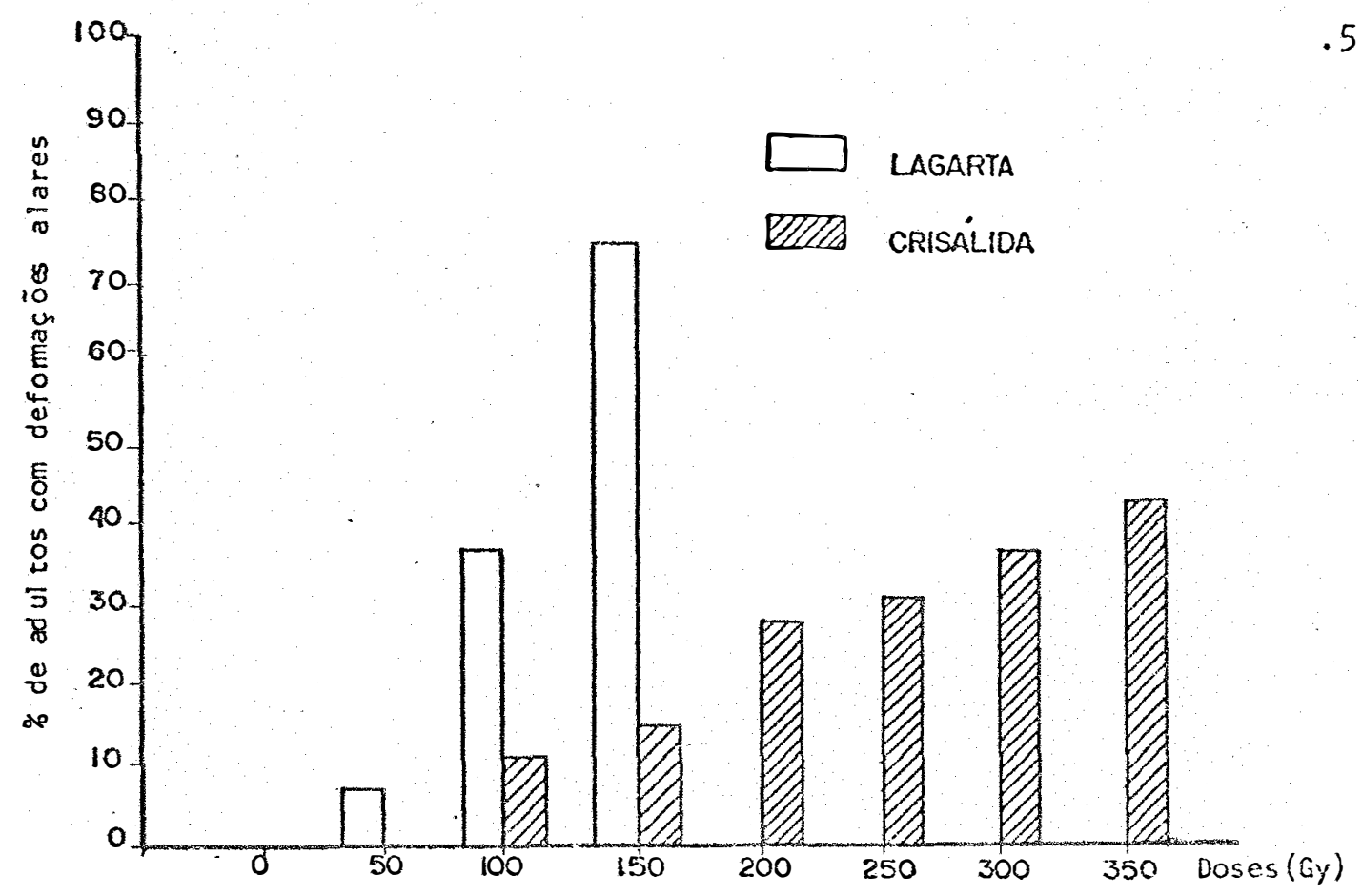

Figura 6 - Porcentagem de adultos com deformações alares de Sitotroga cerea lella (01iv.) cujas lagartas e crisálidas foram irradiadas em arroz.

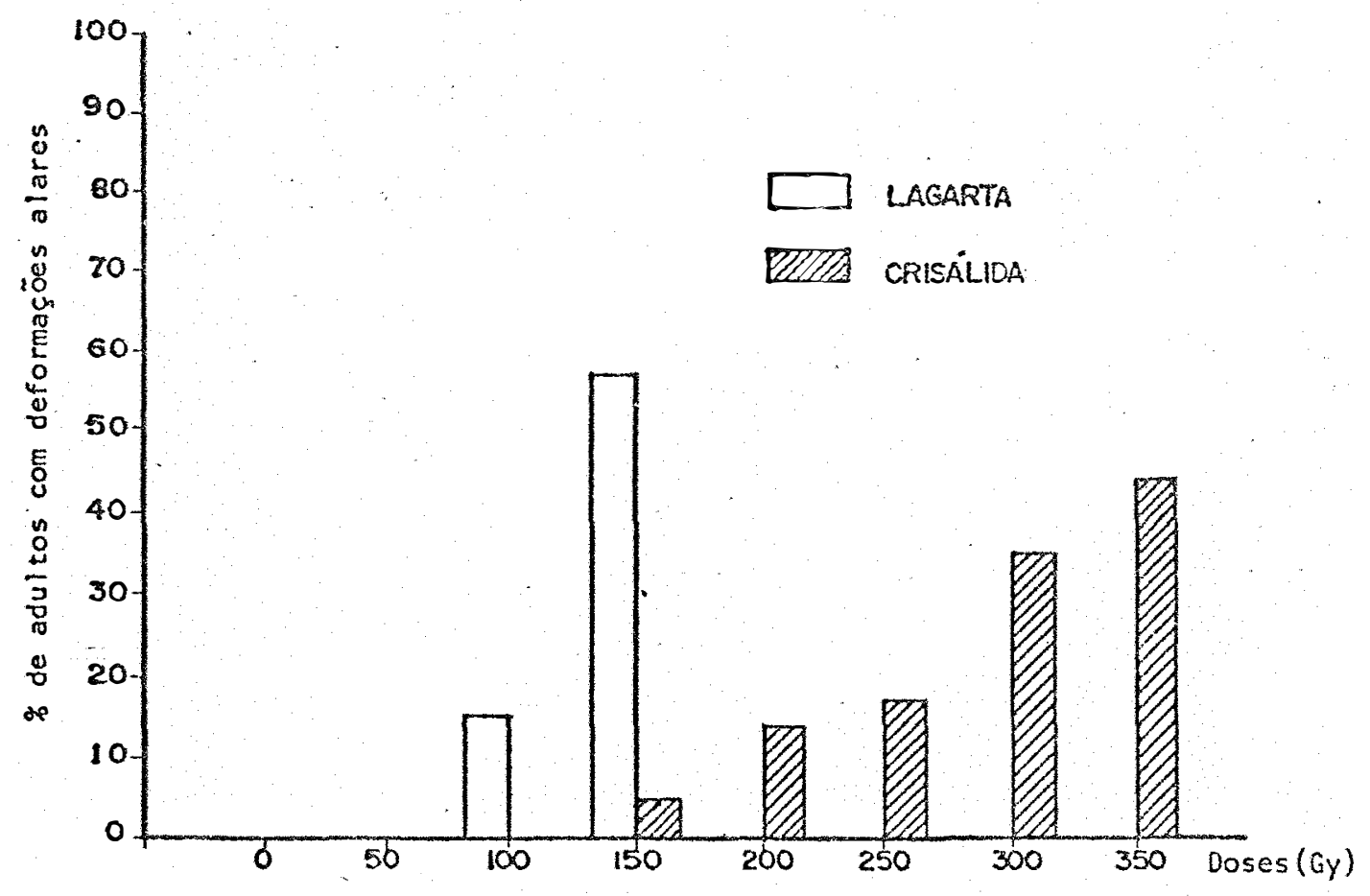

Figura 7 - Porcentagem de adultos com deformaçōes alares de Sitotroga cerea lella (0liv.) cujas lagartas e crisálidas foram irradiadas em milho. 


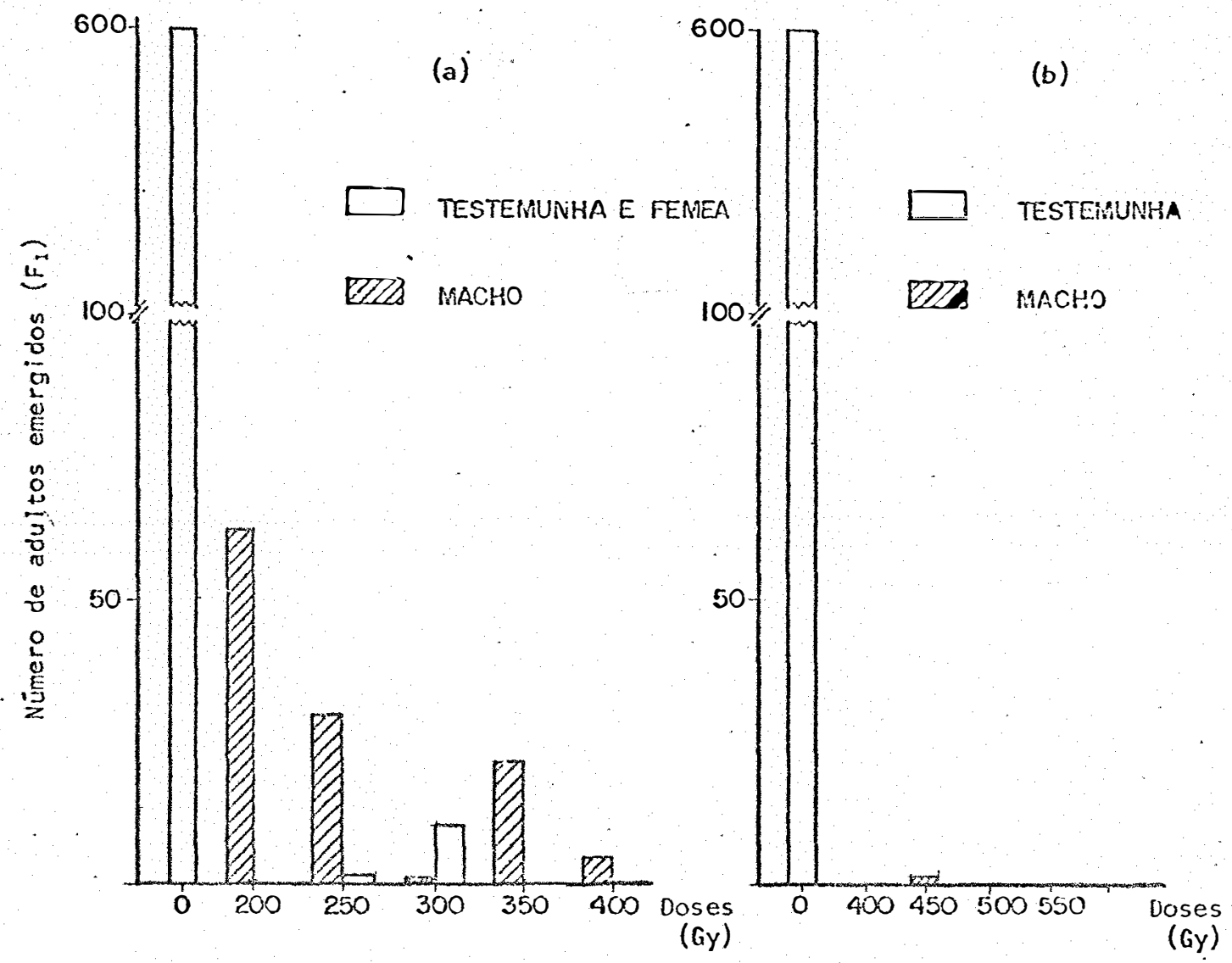

Figura 8 - Númeró de adultos da geração filial $\left(F_{1}\right)$ quando machos e fêmeas (a) e quando só machos (b) de Sitotroga cerealella (0liv.) foram irradiados e cruzados com adultos normais. 
.53 .

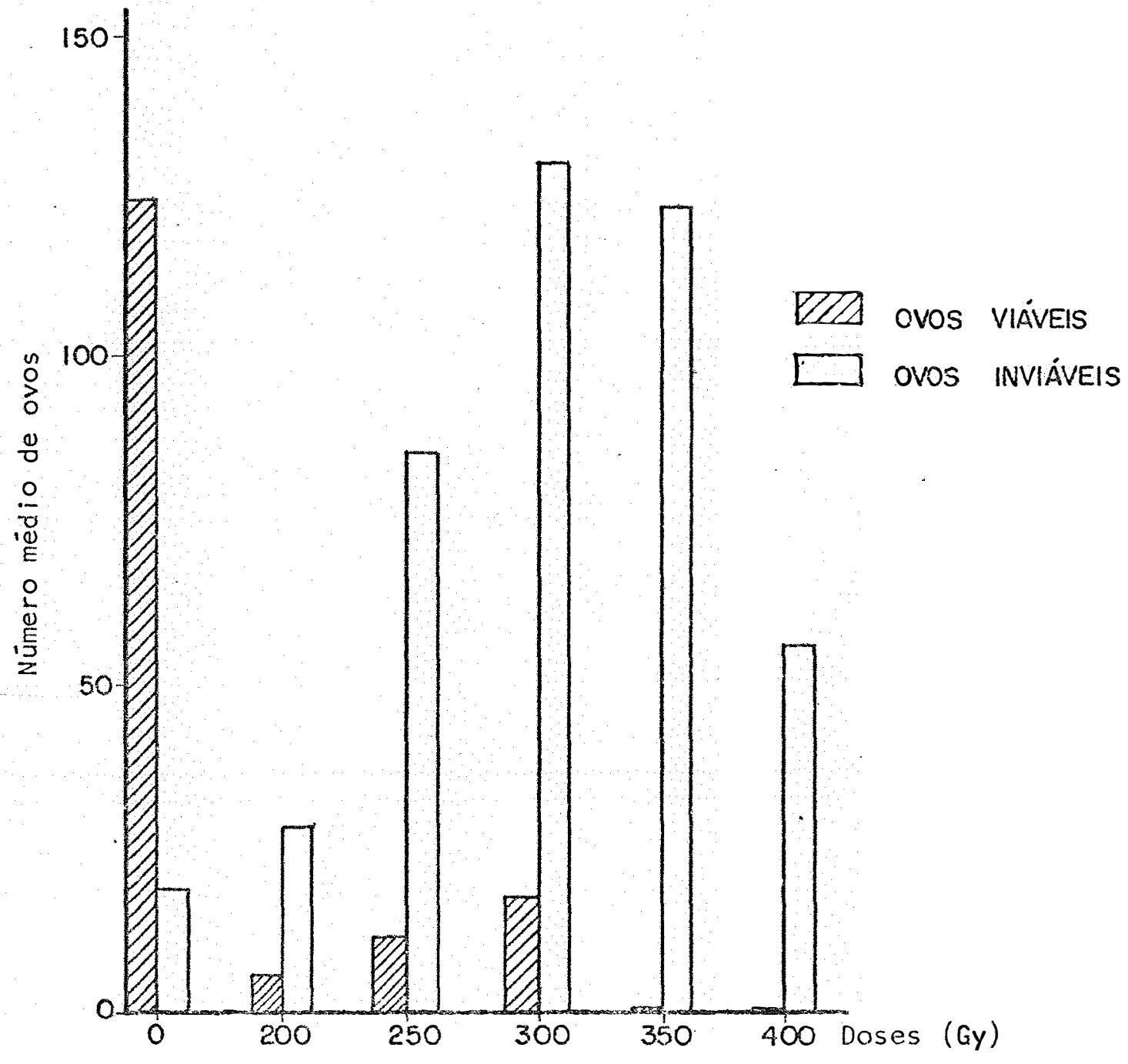

Figura 9 - Nümero médio de ovos viāveis e inviāveis quando fêmeas de Sitotroga cerealella (01iv.) foram ir radiadas e cruzadas com machos normais. 
.54 .

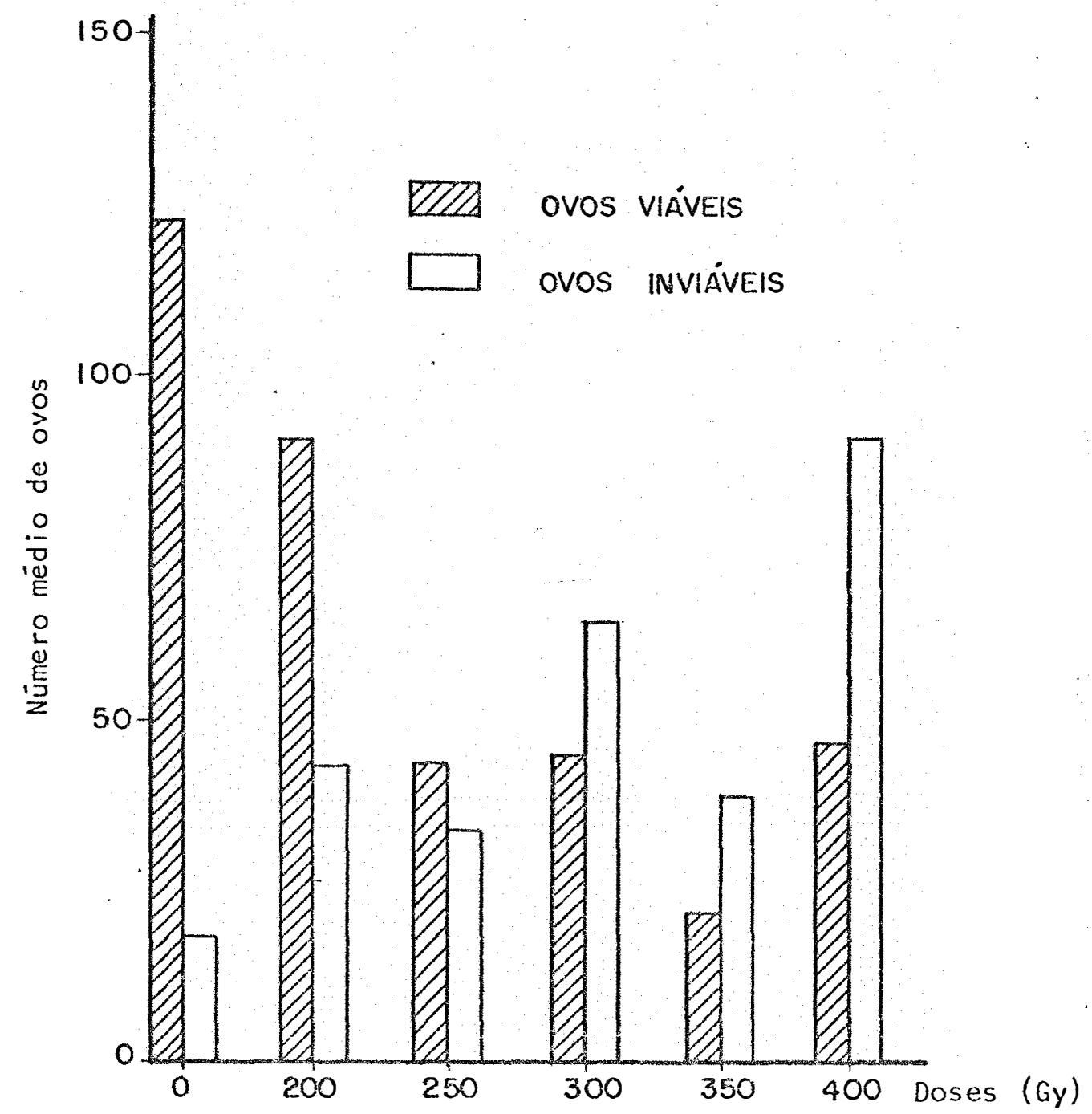

Figura 10 - Número médio de ovos viäveis e inviāveis quando machos de sitotroga cerealella (01iv.) foram irradiados e cruzados com fêmeas normais. 


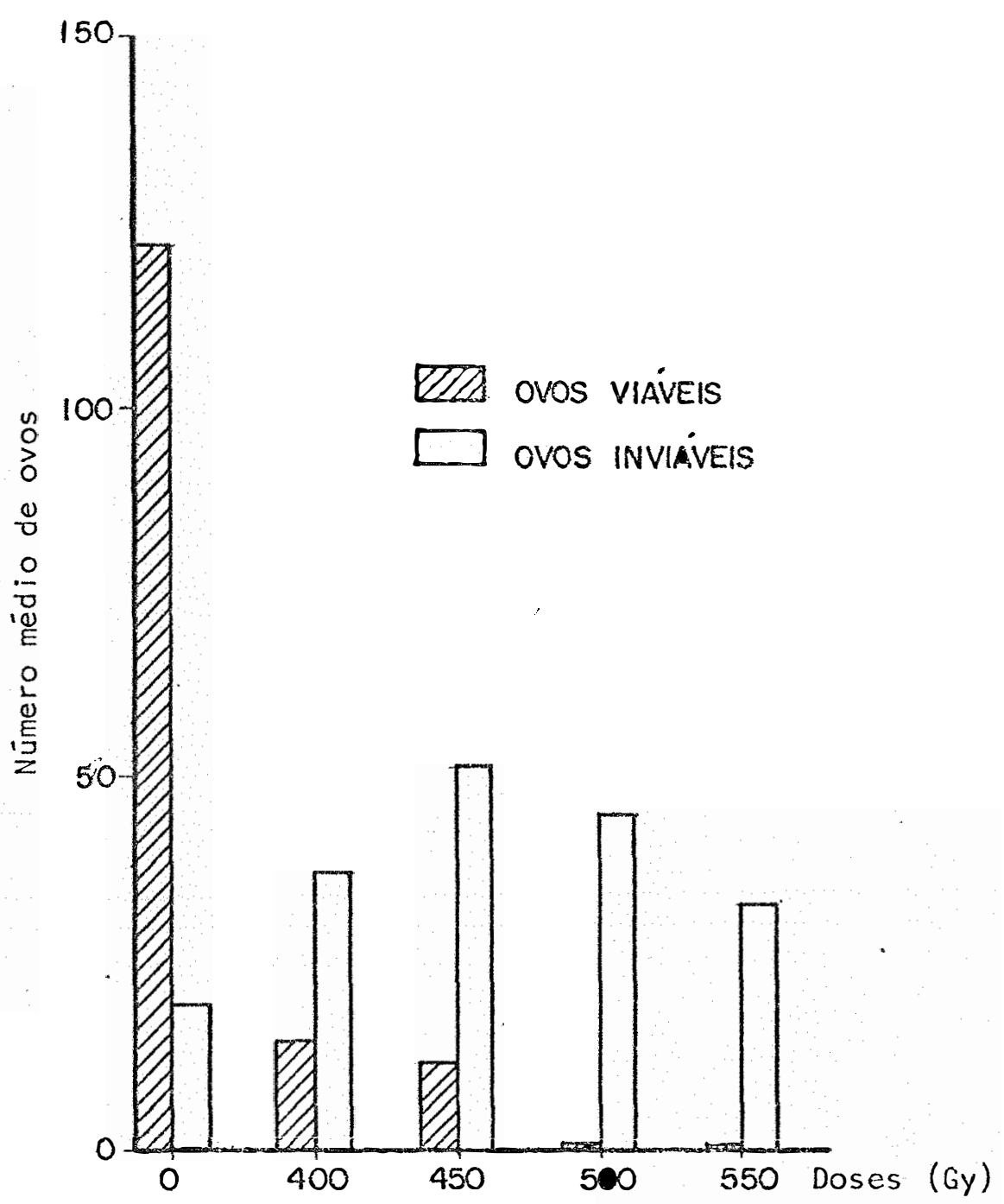

Figura 11 - Nümero mëdio de ovos viäveis e inviäveis quando só os machos de Sitotroga cerealella (01iv.) foram irradiados e cruza dos com fêmeas normais. 


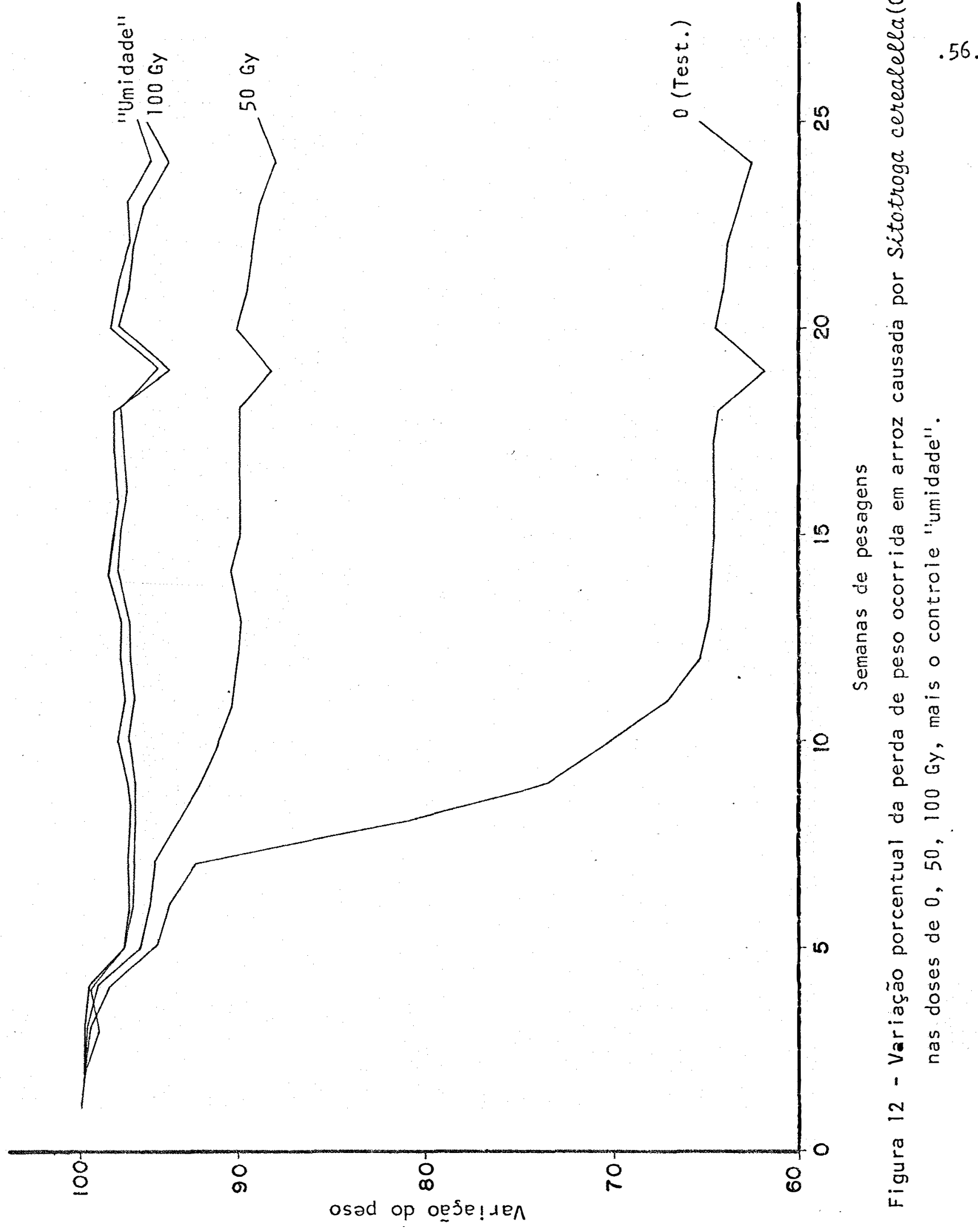




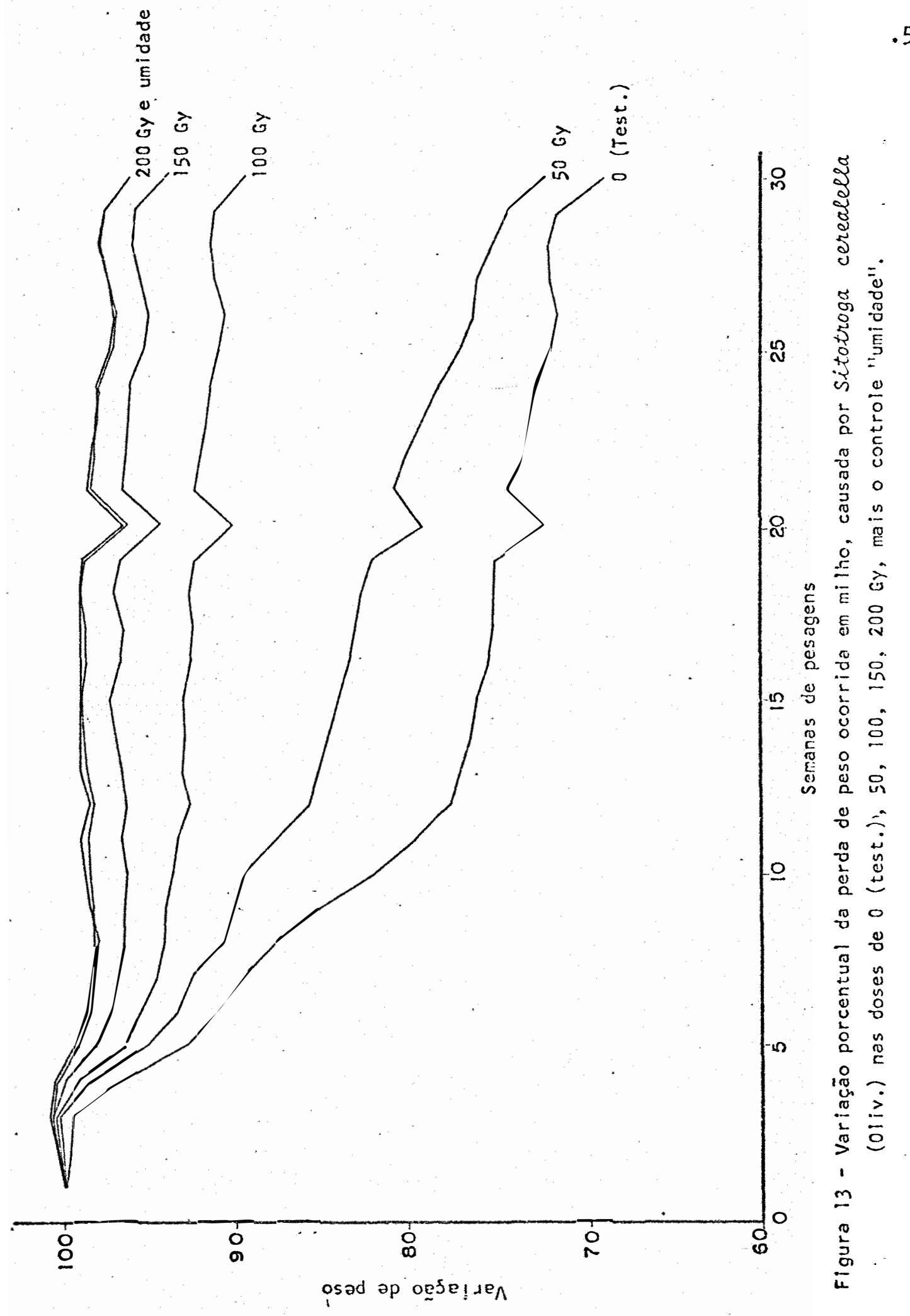




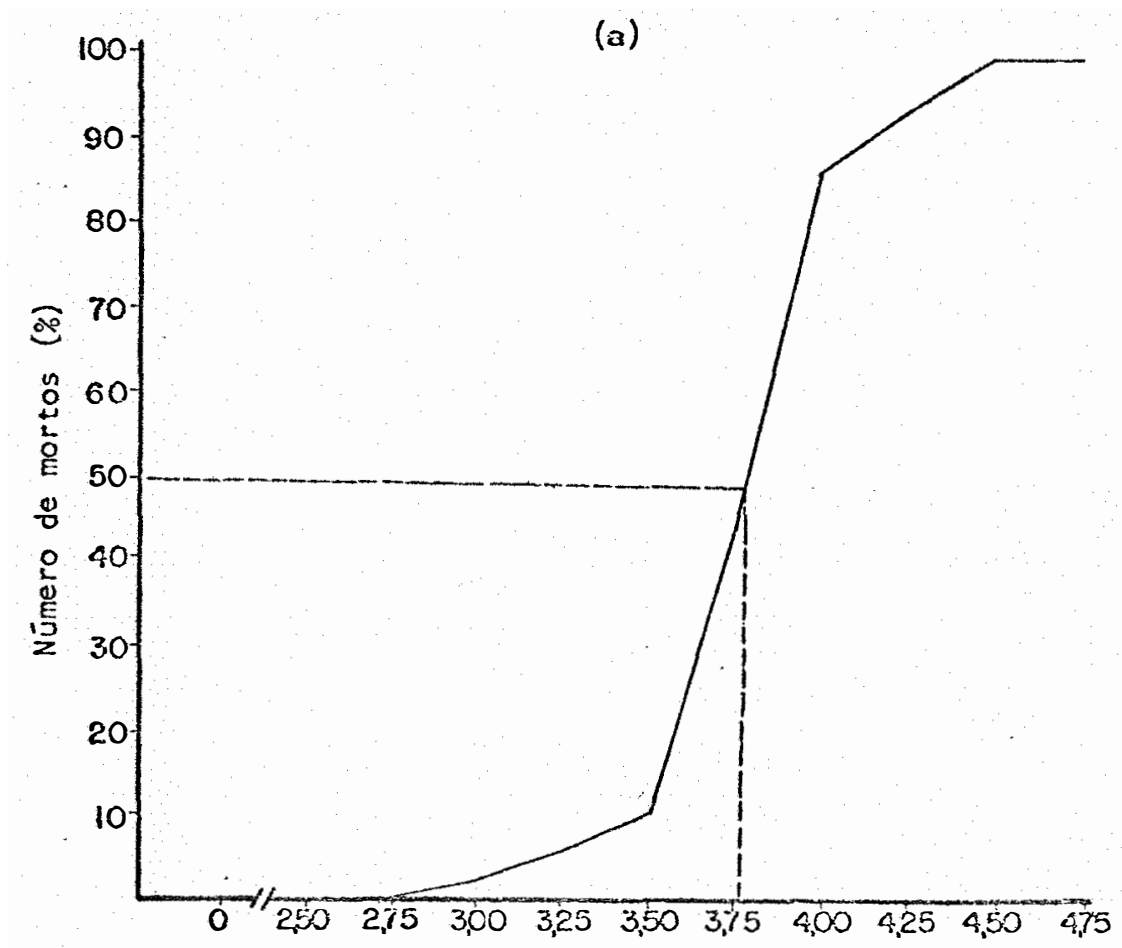

.58 .

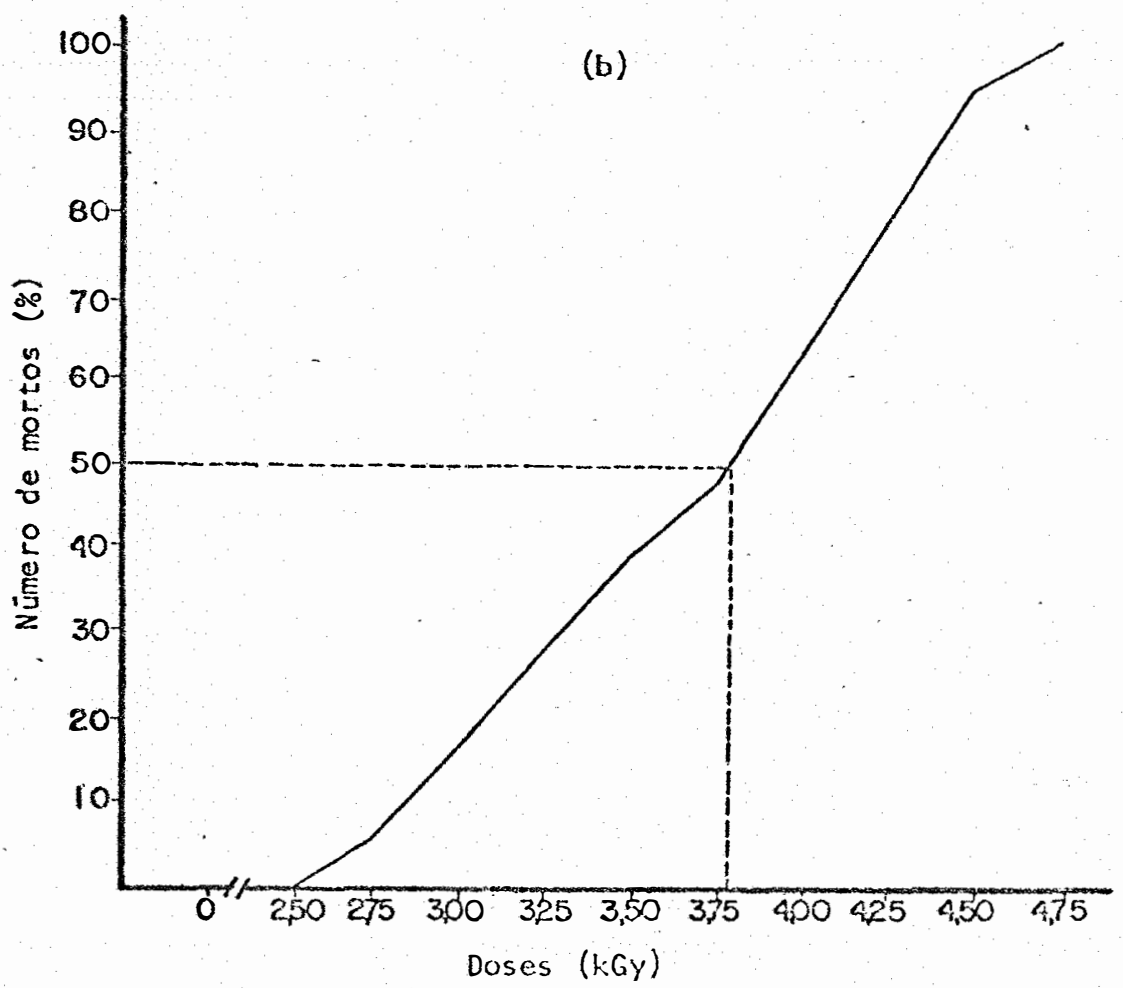

Figura 14 - Mortalidade em porcentagem de Sitotroga cerealella (01iv.) para machos (a) e fêmeas (b) irradiados com diferentes doses de radiação gama provenientes de arroz. 


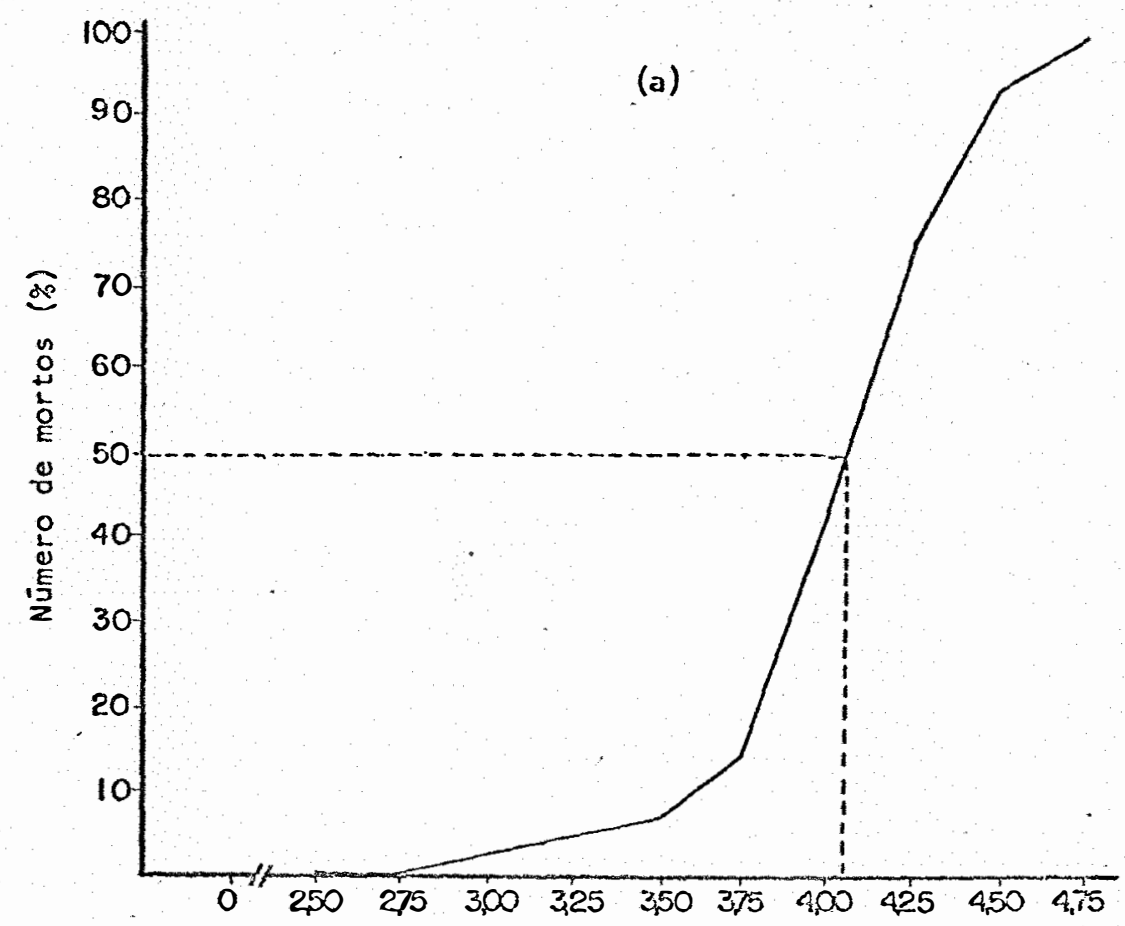

.59.

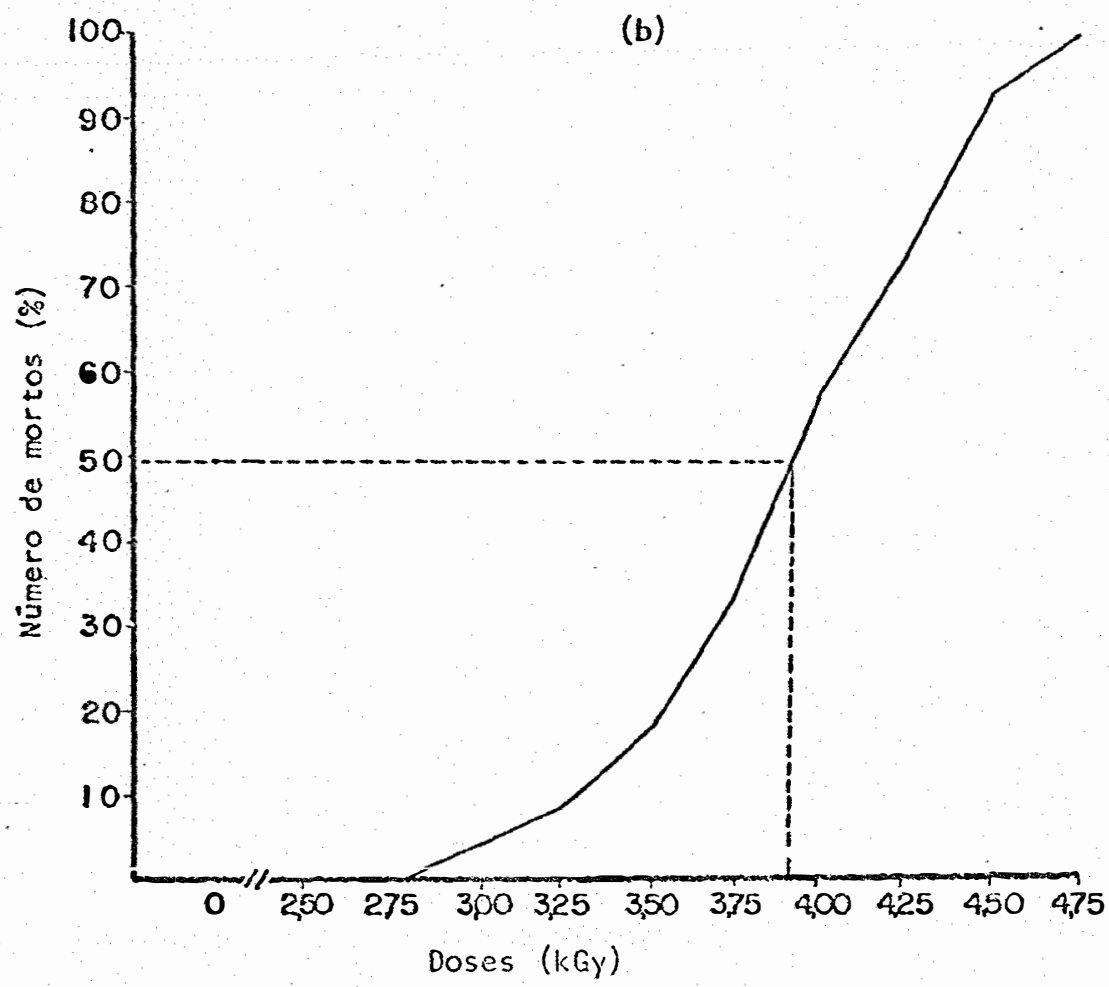

Figura 15 - Mortalidade em porcentagem de Sitotroga cerealella (oliv.) para machos (a) e fêmeas (b) irradiados com diferentes doses de radiação gama provenientes de milho. 
5. DISCUSSAO

De um modo geral, como pôde ser verificado pela Revisão de Literatura, os efeitos das radiações ionizantes são bastante variāveis, dependendo mormente dos resultados das pesquisas dos diferentes au tores, alguns estando de acordo e outros discordando com os resultados deste trabalho. Mas, neste caso, também não se deve esquecer que ca da pesquisador realizou suas investigações sob as mais diversas metodologias e condições climäticas.

Neste trabalho quando irradiaram-se ovos provenientes de adultos criados em arroz e milho (Tabeia 1), observa-se que as doses letais para matar a totalidade dos ovos $\left(\mathrm{DL}_{100}\right)$ foram de 100 Gy e 125 Gy. As doses de radiação para matar cincoenta por cento dos ovos ( $L_{50}$ ) foram obtidas graficamente na Figura 1, sendo de 36 Gy e 42 Gy, respectiva mente. Estes resultados estão de acordo com os de QURESHI (1966) e RODRIGUES et alii (1981). São um pouco menores que os valores obtidos por WIENDL et alii (1975). Com referência a origem dos ovos em termos de substratos, observa-se que ovos provenientes de insetos criados em arroz 
e posteriormente irradiados apresentaram uma maior susceptibilidade às radiações gama em relação aos do milho.

A irradiação de lagartas e crisálidas(Tabelas $2,3,4$ e 5) não apresentou diferenças significativas na emergência de adultos, sen do a dose de 350 Gy insuficiente para induzir a letalidade total nas cri sálidas. Para lagartas esta letalidade foi induzida com a dose de 200 Gy como observa-se nas Figuras 2 e 3 . Jä as doses esterilizantes para adultos irradiados nas fases de lagartas e crisálidas foram 100Gy e 200Gy, 150 Gy e 250 Gy em arroz e milho, respectivamente. Estes resultados são melhor visualizados nas Figuras 4 e 5 , estando de acordo com os de QURESHI (1966 e 1969). Analisando-se ainda as gerações filiais( $\left.F_{1}\right)$ obser vamos que para lagartas, provenientes tanto do arroz como do milho, a do se de 50 Gy de radiação gama não foi suficiente para induzir a esterilidade nos adultos, embora os insetos provenientes do substrato arroz mostraram-se mais susceptíveis às radiações.

Analisando-se ainda os efeitos das radiações gama na mor fologia dos insetos (Tabela 6) quando lagartas e crisălidas foram irra diadas observou-se que as doses de 50 Gy e 100 Gy e 100 Gy e 150 Gy observados nas Figuras 6 e 7, foram as que iniciaram a indução do apareci mento de deformações alares, em arroz e milho, respectivamente.

Adultos irradiados e cruzados com os normais (Tabelas 7, 8 , 9 e 10 ), observa-se que fêmeas irradiadas e cruzadas com machos normais apresentaram uma diminuição bastante significativa na emergência de adultos na geração filial $\left(F_{1}\right)$ (Figura 8 ), quando comparado ao trata- 
mento inverso. Quando irradiaram-se só machos e estes foram cruzados com fêmeas normais, os efeitos da radiação gama foram ainda mais pronunciados. As doses esterilizantes foram de 500 Gy e 350 Gy para machos e fêmeas, respectivamente, em substrato de criação milho.

Analisando-se as esperanças de vida $\left(e_{0}^{x}\right)$ (Tabela 11$)$ desses insetos adultos irradiados e cruzados com as norma is, pode-se observar que fêmeas irradiadas com 250 Gy e 300 Gy,cruzadas com machos normais, e machos irradiados com a dose de 550 Gy, cruzados com fêmeas normais, apresentaram uma maior e menor esperança de vida, respectivamente. Porém, anal isando-se a esperança de vida $\left(e_{0}^{x}\right)$ da população de todos os tratamentos e comparando a testemunha, não se observou diferença estatística significativa. Este resultado é da maior importância para uma possí vel aplicação da T.l.E. (Técnica do Indivíduo Estēril), uma vez que os in setos estéreis se apresentam com a mesma longevidade dos normais. A dose esterilizante por esse método para adultos de Sitotroga cerealella(0liv.) variou conforme o sexo, sendo que para machos a dose foi bem maior do que para fêmeas ou seja, 500 Gy e 350 Gy, respectivamente. Esses resultados apresentaram-se menores dos obtidos por WIENDL et alii (1975) e RODRIGUES et alii (1981) mas estão próximos dos observados por NICHOLAS e WIANT (1959). Ainda comparando-se o número médio de ovos viáveis e inviāveis quando fêmeas foram irradiadas e cruzadas com machos normais (Fi gura 9), observa-se um aumento na inviabilidade de ovos proporcional ao aumento das doses de radiações gama até 300 Gy. A partir desta, começou a diminuir, quando comparado com a testemunha. 0 inverso aconteceu quan 
do os machos foram irradiados e cruzados com fêmeas normais, como podemos observar na Figura 10. Já quando só os machos foram irradiados com doses mais elevadas e cruzados com fêmeas normais (Figura 11) a média de ovos inviáveis diminuiu a partir de 500 Gy.

Também determinou-se a dose esterilizante baseada na perda de peso dos grãos conforme pode-se ver nas Tabelas 12 e 13, visto que a espécie de inseto em estudo só causa prejuizo na fase de lagarta. Assim, quando o inseto se torna estéril devido a radiação gama, não há des cendentes que se alimentem e, conseqüentemente o substrato não perde peso. Uma visualização melhor do fenômeno, pode ser visto nas Figuras 12 e 13. Observa-se que as doses necessárias para induzir a esterilidade dos adultos foram de 100 Gy e 200 Gy em arroz e milho, respectivamente. Além disso podemos ainda observar que a dose de 50 Gy foi subesterilizante para os insetos do arroz. Para os do mi lho foram necessários, res pectivamente 100 Gy e 150 Gy. Entre a décima nona e vigésima semana de pesagem, verificamos uma queda brusca no peso de todos os tratamentos. Este fato ocorreu devido a problemas ocorridos na câmara climatizada, ha vendo perda de umidade, reestabelecida depois.

Quando comparamos os dois métodos de esterilização podemos observar que ao irradiar-se uma população de insetos adultos a dose esterilizante determinada é menor do que quando os insetos são irradiados individualmente. Isso é devido ao fato das fêmeas serem mais susceptiveis as radiações gama que os machos.

Irradiando-se adultos para determinar a dose letal imedia 
ta $\left(D_{1} 1_{100}\right)$, conforme Tabelas 14,15 e 16, podemos observar que as doses de radiação gama que começaram a induzir mortalidade foram as de 2750 e $3000 \mathrm{~Gy}$, sendo que para completo extermínio foram necessários doses de 4750 e 4500 Gy para machos e fêmeas provenientes de arroz e de 4750 Gy para ambos os sexos provenientes de milho. Pela anălise estatistica (Ta bela 18), observamos que, machos provenientes de mi lho são mais radioresistentes. Não houve diferença estatística entre fêmeas e nem entre sexos, quando analisados num mesmo substrato. Além da dose letal imediata determinou-se graficamente pelas figuras 14 e 15 as doses para matar a metade da população $\left(\mathrm{DL}_{50}\right)$ para machos e fêmeas provenientes de ambos os substratos de criação. Por este método verificou-se ser a $\mathrm{DL}_{50}$ igual a 3800 Gy para ambos os sexos em arroz. Foi de 4050 para machos e de 3900 para fêmeas, em milho.

Comparando-se a influência dos efeitos das radiações gama nas diferentes fases do ciclo evolutivo da traça do milho Sitotroga cerealella (01iv.) em ambos os substratos, podemos observar que estes foram sempre mais drāsticos nos insetos que se desenvolveram em arroz.

A diferença nos componentes nutritivos dos substratos é uma hipötese para explicar tal comportamento. 
6. CONCLUSOES

Nas condições que foram realizados os ensaios e conforme os resultados obtidos para sitotroga cerealella (01 iv.) conclui-se que:

- As $\mathrm{DL}_{50}$ e $\mathrm{DL}{ }_{100}$ de radiação gama para ovos de insetos provenientes de arroz foram 36 Gy e 100 Gy, respectivamente. Ovos provenientes de insetos criados em milho foram radioresistentes apresentando uma $\mathrm{DL}_{50}$ igual a 42 Gy e uma $D L{ }_{100}$ igual a 125 Gy.

- A radiação induziu a esterilidade dos insetos adultos, mesmo quando irradiados nas fases de lagarta e crisálida. Em arroz as doses foram $100 \mathrm{~Gy}$ e $200 \mathrm{~Gy}$, para lagartas e crisālidas, respectivamente. Em milho estas doses foram de 150 Gy e $250 \mathrm{~Gy}$, respectivamente para la gartas e crisālidas.

- As doses esterilizantes, para a fase adulta, foram de 350 Gy e 500 Gy, respectivamente para fêmeas e machos criados em milho. 
.66 .

- As doses letais imediatas para adultos foram de 4500 Gy para machos e de 4750 Gy para fêmeas criados em arroz. Para insetos criados em milho a dose letal foi igual para ambos os sexos de 4750 Gy. 


\section{LITERATURA CITADA}

AHMED, M.S.H.; Z: AL-HAKKAK e A. AL-SAQUR, 1970. Inherited sterility in the fig moth (Ephestia cautella, Walker). Symposium on the sterility principle for insect control or eradication. Athens, September. Intern. Atomic. Energy Agency-FAO, 15-18.

AHMED, M.Y.Y.; E.W. TILTON e J.H. BROWER, 1976. Competitiveness of irradiated adults of the Indian meal moth. Jour. Econ. Entomol., $69(3): 349-352$.

AMARAL, J.F., 1973. Contribuição ao estudo da avaliação dos prejuízos causados pela associação do gorgulho Sitophilus zeamais (Mots.) e traça Sitotroga cerealella ao milho armazenado em paiol de tabua da região de Botucatu. Botucatu, SP. UNESP, 143p. (Tese de Doutoramento).

AMARAL Fo, B.F.; J.A. FERREIRA E J.F. AMARAL, 1969. Levantamento e estudo das pragas do milho armazenado na região de Botucatu. Anais da Soc. Bras. de Entomol., p.95. (Nota Prévia). 
AMOAKO-ATTA, B. e R.B. MILLS, 1977. Gamma radiation effects on mating frequency and delayed mating of male Cadra cautella (Walker) (Lepidoptera : Pyralidae). Jour. Stor. Prod. Res., 13:139-143.

ARANDA, B.C., 1970. Aplicacion de 4 dosis diferentes de radiacion gamma sobre adultos de Sitotroga cerealella (01iv.). Symposium on the sterility principle for insect control or eradication. Athens, September Intern. Atomic Energy Agency-FAO, 37-38.

ARTHUR, V.; L.A. LOPES; F.M. WIENDL E J.M.M. WALDER, 1984a. Determinação da dose letal e esterilizante para traça Plodia interpunctella (Hbn., 1813) (Lep. Pyralidae). Cienc. e CuIt., 36(7):802 (Resumo).

ARTHUR, V.; C. CONSOLMAGNO e F.M. WIENDL, 1984b. Indução de esterilidade por radiações gama do Cobalto-60 em imagos da traça Plodia interpunctella (Hbn., 1813) (Lep. Pyralidae) provenientes de arroz. Cienc. e Cult., 36(7):802. (Resumo).

ARTHUR, V.; L.A. LOPES; F.M. WIENDL E J.M.M. WALDER, 1984c. Indução de esterilidade por radiação gama do Cobalto-60 em imagos da traça Plodia interpunctella (Hbn., 1813) (Lep., Pyralidae) em dieta artificial. IX Congres. da Soc. Bras. de Entomol., p.316. (Resumos).

ASHRAF, M.; J.H. BROWER e E.W. TILTON, 1971. Effects of gamma radiation on the larval midgut of the Indial-meal moth, Plodia interpunctella (Hbn.) (Lepidoptera : Phycitidae). Radiat. Res., 45(2):349-354. 
ASHRAFI, S.H. e R.M. ROPPEL, 1973. Radiation-induced alteration of testes of larvae of the Indial meal moth. Ann. Entomol. Soc. Amer., $66(6): 1324-1328$.

ASHRAFI, S.H.; E.W. TILTON E J.H. BROWER, 1972. Inheritance of radiation-induced sterility, in the Indian meal moth. Jour. Econ. Entomol., $65(5): 1266-1268$.

BAROUGHI-BONAG, H., 1965. Etude du développement post-embryonnaire de l'avaise chez Ephestia kuekniela Z: (Lepidoptera : Pyralidae). Food. Irrad., 6:14-15.

BROWER, J.H., 1972. "Scaleless" and "melanic" two undescribed mutations in Plodia interpunctella (Lepidoptera : Phycitidae). Jour. Kans. Entomol. Soc., 45(4):421-426.

BROWER, J.H., 1973. Gamma radiation sensitivity of malathion-resistant strains of the Indian meal moth. Jour. Econ. Entomol., $66(2): 461-462$.

BROWER, J.H., 1974. Lach of radioresistance in Plodia interpunctella (Lepidoptera : Phycitidae) exposed to subletal gamma irradiation for 30 generations. Radiat. Res., 57:73-79.

BROWER, J.N., 1975. Gamma irradiation of adult Plodia interpunctella: effects on mating, sterility, and number of progeny. Ann. Entomol. Soc. Amer., 68:1086-1090. 
BROWER, J.H., 1976a. Irradiation of pupae of the Indian meal moth to induce sterility or partial sterility in adults. Jour. Econ. Entomol., 69(2):277-281.

BROWER, J.H., 1976b. Recovery of fertility by irradiated males of the Indian meal moth. Jour. Econ. Entomol., 69(2):273-276.

BROWER, J.N., 1980. Irradiation of diapausing and non-diapausing larvae of Plodia interpunctella: effects on larvae and pupae mortality and adult fertility. Ann. Entomol. Soc. Amer., $73(4): 420-426$.

CARTWRIGHT, 0.L., 1939. Asevery of field infestation of insects attacking corn in ear in South Carolina. Jour. Econ. Entomol., $32(6): 780-782$.

CARVALHO, J.P. de, 1963. A entomofauna dos produtos armazenados: contribuição do método radiogrāfico para o estudo de Sitotroga cerealella (01 iv.) (Lepidoptera: gelechiidae). Lisboa, Junta de Inves. do Ultramar. $173 p$.

CHIPPENDALE, G.M., 1971. Growth and devolopment of Angoumois grain moth, Sitotroga cerealella (0liv.) in artificial diet. Jour. Insec. Physiol., 17:109-115. 
COGBURN, R.R.; J.H. BROWER e E.W. TILTON, 1971. Combination of gamma and infrared radiation for control of the Angoumois grain moth in wheat. Jour. Econ. Entomol., 64(4):923-925.

COGBURN, R.R.; E.W. TILTON e J.H. BROWER, 1973. Almond moth: Gamma radiation effects on the life stages. Jour. Econ. Entomol., $66(3): 745-751$

COGBURN, R.R.; E.W. TILTON e W.E. BURKHOLDER, 1966. Gross effects of gamma radiation on the Indian meal moth and the Angoumois grain moth. Jour. Econ. Entomol., 59(3):682-685.

CORSEUIL, E., 1960. Grãos armazenados: medidas de defesa que se impõem. Fert. Inset. Rą., 3(3):29-35.

CROMBIE, A.C., 1943. The development of the Angoumois grain moth Sitotroga cerealella (01 iv.). Nature Lond. (152):246.

ELLINGTON, G.W., 1930. A method of securing eggs of the Angoumois grain moth. Jour. Econ. Entomol., 23(1):237-238.

EVERLY, R.T.; P. SANOBERG e B. WEAVER, 1963. The effect of infestation of Angoumois grain moth on germination and vigor of corn." Proc. N. Cent. Brch. Am. Ass. Econ. Entomol., 18:76-79.

FA0, 1975. El estado mundial de la agricultura y la alimentación. Roma . 223p. 
FERRAZ, A.N., 1962. Combate às pragas na lavoura e no armazenamento do milho. Sel. Agric., 17(196):17-22.

FLINT, H.M. e E.L. KRESSIN, 1969. Transfer of sperm by irradiation Heliothis virescens (Lepidoptera-Noctuidae) and relationship to fecundity. Can. Entomol., 101:500-507.

FLOYD, E.H.; OLIVER, A.D.; POWELL, J.D., 1959. Damage to corn in Louisiana caused by stored grain insects. Jour. Econ. Entomol., $52(4): 612-5$.

FLOYD, E.H., 1971. Relationship between maize weevil infestation in corn at, harvest and progressive infestation during storage. Jour. Econ. Entomol., 64(2):408-411.

GALLO, D., 1960. Radioisōtopos no controle de pragas. O Sol., $1: 30-31$

GALLO, D., 1966. Pragas do milho. In: Cultura e Adubação do Milho. Potas., 333-356.

GALLO, D. e C.H.W. FLECHTMANN, 1967. Grãos armazenados. In: Pragas das plantas cultivadas. Centro Acad. Luiz de Queiroz. Dep. Ed. 95-97p.

GALLO, D.; 0. NAKANO; S.S. NETO; R.P.L. CARVALHO; G.C. de BATISTA; E.B. FILHO; J.R.P. PARRA; R.A. ZUCCHI e S.B. ALVES, 1978. Manual de Entomologia Agrícola. São Paulo, Ed. Agron. Ceres. 531 . 
GENEL, M.R. e D. BARNES, 1958. Los insectos y sus daños a los granos almacenados. Folh. Mocel., Sec. Agr. y Granad., (6):37.

GERBBERG, E.I. e S.L. GOLDHEIM, 1957. Weight loss in stored corn caused by insect feeding. Jour. Econ. Entomol., 50(4):391-393.

GORESLINE, H.E., 1965. Application des radiations ionizantes a las dēsinsectisation des grains. Food. Irrad., 6:11-13.

HOLT, G.G. e D.T. NORTH, 1970. Effects of gamma irradiation on the mechanism of sperm transfer in Trichoplusia nii. Jour. Insect. Physiol., 10:2211-2222.

IBGE, 1983. Anuärio Estatístico do Brasil, 44:1-988.

KHAPE, B.P. e R.B. MILLS, 1968. Development of Angoumois grain moths in kerness of wheat, sorghum and corn as affected by site of feeding. Jour. Econ. Entomol., 61(2):450-52.

LAMM, G.G., 1972. Proteção radiolögica em trabalhos com radiações ionizantes. Piracicaba, CENA. Bol. Did. n? 09. $51 \mathrm{p}$.

LEPAGE, H.S., 1939. Inimigos do milho armazenado. O Biol., $5(11): 243-249$.

LEPAGE, H.S. e L.I. GONÇALVES, 1939. Insetos prejudiciais ao milho armazenado. O Biol., 2(37):145-152 
LEPAGE, H.S., 1943. Defesa dos grãos alimenticios armazenados contra insetos nocivos. Bol. da Secr. da Agr. Ind. e Com. do Est. de São Paulo.' 47p.

LEPAGE, H.S., 1946. 0 expurgo e armazenagem dos grãos alimentícios. O Biol., $12(8): 201-206$.

MARANHAO, Z.C., 1957. Insetos nocivos aos cereais: prejuizos. Bras. Oes., $2(18): 2-4$.

MILLS, R.B., 1965. Early germ feeding and larvae development of the Angoumois grain moth. Jour. Econ. Entomol., 58(2):220-223.

MOOKE, S. III; H.B. PETTY; W.H. LUCKMAN E J.H. BYERES, 1966. LOS SES caused by the Angoumois grain moth in dent corn. Jour. Econ. Entomor., $5 \dot{4}(4): 880-82$.

NANATES, J.F.D. e CUNHA, M.L.Y., 1978. Influência da temperatura sobre a biologia de Sitotroga cerealella (01iv., 1819) (Lepidoptera-gelechiidae). 111 Congres. da Soc. Bras. de Entomol., p.34. (Resumo).

NICHOLAS, R.C. E D. WIANT, 1959. Radiation of important grain-infesting pests: order of death curves and survival values for the various metamorphic forms. Food: Technol., 13:58-62.

OUYER, M.T.; R.S. GARCIA e D.F. MARTIN, 1964. Determination of the optimum sterilizing dosage for pink boll worms treated as pupae with gamma radiation. Jour. Econ. Entomol., 57(3):387-390. 
PENDLEBURY, J.B.; D.J. JEFFERIES; E.J. BANHAN E J.0. BULL, 1962. SOMe effects of gamma radiation on the lesser grain borer (Rhizopertha dominica F.l, tropical werehouse moth (Cadra cautella WIk.), Indian meal moth (Plodia interpunctella Hübn.) and cigarete beet le (Lasioderma serricorne F.). Wantage Research Laboratory (A.E.R.E.). Wantage, Berks. March, 23p.

PIZZARELLO, D.J. e R.L. WITCOFSKI, 1972. Medical Biology. Lea e Febiger. Philadelphia, U.S.A. 111 p.

PUZZ1, D., 1973. Conservação de grãos armazenados. Armazēns e Silos. Ed. Agron. Cer. Ltda. São Paulo. $217 p$.

PROSHOLD, F.I. e J.A. BARTELL, 1970. Inherited sterility in progeny of irradiated male tobacco badworms: effects on reproduction developmental time and sex ratio. Jour. Ecorr. Entomol., $63(1): 280-285$.

QURESHI, A.Z., 1966. Effects of sub-lethal gamma radiation on the biology behavior of the Angoumo is grain moth, Sitotroga cerealella (01ivier). Univ. Kansas State, Manhatton Kansas. (Dissertation). $130 p$.

QURESHI, A.Z.; D.A. WILBUR e R.B. MILLS, 1969. Sub-lethal gamma radiation effects on pre-pupae, pupae and adults of Angoumo is grain moth. Jour. Econ. Entomol., 61(6):1699-1705. 
RAUN, E.S.; L.C. LEWIS; J.C. PICKER JR. A P.K. HOTCHKISS, 1967. Gamma irradiation of European corn borer larvae. Jour. Econ. Entomol., $60(6): 1724-1730$.

ROSSETO, C.J., 1966. Sugestões para o armazenamento dos grãos no Brasi1. Agron., 18(9-10):38-51.

RODRIGUES, Z.A.; A.M. REGO; M.L. OLIVEIRA E D. FERREIRA, 1981. Effects of gamma radiation Cobal to 60 on eggs and adults of Sitotroga cerealella (01ivier, 1819) (Lepidoptera-Gelechiidae) in the laboratory. Rod. Tech, and their Appl. to Ins. Pest., 29:5.

RUNNER, G.A., 1916. Effects of roentgen rays on the tobacco cigarette beetle and results of experiments with new roentgen tube. Jour. Agr. Res., 6:383-388.

SINGH, H. e J.N. LILES, 1972. Effect of gamma rays on the acute lethality and reproductive potential of lesser grain borer adults. Jour. Econ. Entomor., 65(3):656-659.

SMITH, C.N.; G.C. La BRECQUE e A.B. BORKOVEC, 1964. Insect chemosterilizants. Ann. Rev. Entomor., 9:269-284.

SNOW, J.H.; J.R. YOUNG; W.J. LEWIS E R.L. JONES, 1972. Sterilitacion of adult fall army-worms by gamma irradiation and its effect on competitiveness. Jour. Econ. Entomol, , 65(5):1431-1433. 
WATTERS, F.L. e K.F. Mac QUEEN, 1967. Effectiveness of gamma irradiation for control of five species of stored-product insects. Jour. Stor. Prod. Res., 3:223-234.

WIENDL, F.M. e E.B. FILHO, 1968. Influência da radiação gama na longevidade de Sitotroga cerealella (01iv.). I Congres. da Soc. Bras. de Entomol., p.22. (Resumo).

WIENDL, F.M.; O.A. BOVI e V. ARTHUR, 1975. Esterilização e efeitos letais da radiação gama em adultos e ovos de Sitotroga cerealella (01iv.). Bol. Cient., CENA, $28: 41$.

WIENDL, F.M.; J.M: PACHECO; J.M.M. WALDER; R.B. SGRILLO E R.E. DOMARCO, 1974. A method of determining the gamma radiation doses for the sterilization of stored insects. Sterility Principle for Control, 289-315. 